UNIVERSIDADE TECNOLÓGICA FEDERAL DO PARANÁ DEPARTAMENTO ACADÊMICO DE ELETROTÉCNICA CURSO DE ENGENHARIA DE CONTROLE E AUTOMAÇÃO

\author{
BRUNO DIAS CAMARGO \\ ELISON DE SOUZA MOREIRA \\ FELIPE DE SOUZA KALUME
}

INTEGRAÇÃO DE FONTES ALTERNATIVAS RENOVÁVEIS DE ENERGIA COM RESTABELECIMENTO OTIMIZADO PARA O AGRONEGÓCIO

TRABALHO DE CONCLUSÃO DE CURSO

CURITIBA 
BRUNO DIAS CAMARGO

ELISON DE SOUZA MOREIRA

FELIPE DE SOUZA KALUME

INTEGRAÇÃO DE FONTES ALTERNATIVAS RENOVÁVEIS DE ENERGIA COM RESTABELECIMENTO OTIMIZADO PARA O AGRONEGÓCIO

\section{RENEWABLE ALTERNATIVE SOURCES INTEGRATION WITH OPTIMIZED ENERGY RESTORATION ON AGRIBUSINESS}

Trabalho de conclusão de curso de graduação em Engenharia de Controle e Automação apresentado à disciplina de Trabalho de Conclusão de curso 2, do Departamento Acadêmico de Eletrotécnica (DAELT) da Universidade Tecnológica Federal do Paraná (UTFPR), como requisito parcial para obtenção do título de Engenheiro de Controle e Automação.

Orientador: Prof. Dr. Eloi Rufato Junior.

\section{CURITIBA}

\section{1}

Esta licença permite remixe, adaptação e criação a partir do trabalho, para fins não comerciais, desde que sejam atribuídos créditos ao(s) autor(es) e que licenciem as novas criações sob termos idênticos. Conteúdos elaborados por terceiros, citados e referenciados nesta obra não são cobertos pela licença. 


\title{
Integração de fontes alternativas renováveis de energia com restabelecimento otimizado para o agronegócio
}

Este Trabalho de Conclusão de Curso de Graduação foi julgado e aprovado como requisito parcial para a obtenção do Título de Engenheiro de Controle e Automação, do curso de Engenharia de Controle e Automação do Departamento Acadêmico de Eletrotécnica (DAELT) da Universidade Tecnológica Federal do Paraná (UTFPR).

Curitiba, 10 de maio de 2021.

\author{
Profa. Annemarlen Gehrke Castagna, Ma. \\ Coordenadora de Curso \\ Engenharia de Controle e Automação
}

Prof. Marcelo de Oliveira Rosa, Dr.

Responsável pelos Trabalhos de Conclusão de Curso

de Engenharia de Controle e Automação do DAELT

\section{ORIENTAÇÃO}

Prof. Eloi Rufato Junior, Dr.

Universidade Tecnológica Federal do Paraná

Orientador

\section{BANCA EXAMINADORA}

Prof. Eloi Rufato Junior, Dr.

Universidade Tecnológica Federal do Paraná

Profa. Nastasha Salame da Silva, Dra

Universidade Tecnológica Federal do Paraná

Prof. Paulo Cícero Fritzen, Dr.

Universidade Tecnológica Federal do Paraná 


\section{RESUMO}

CAMARGO, Bruno; MOREIRA, Elison; KALUME, Felipe. INTEGRAÇÃO DE FONTES ALTERNATIVAS RENOVÁVEIS DE ENERGIA COM RESTÁBELECIMENTO OTIMIZADO PARA O AGRONEGÓCIO. 2021. 115 f. Trabalho de conclusão de curso (Graduação - Curso de Engenharia de Controle e Automação), Universidade Tecnológica Federal do Paraná, Curitiba, 2021.

O presente trabalho refere-se à apresentação das alternativas de matrizes e soluções energéticas para o agronegócio no estado do Paraná, bem como as tecnologias que participam dos processos de captação, gerenciamento e distribuição de energia. O Brasil é um dos maiores produtores agropecuários do mundo e ainda não possui ampla implementação de tecnologias para a integração e reconfiguração de fontes independentes de energia voltadas para o agronegócio e propriedades rurais, o que a longo prazo reduziria custos para as concessionárias de energia elétrica e usuário e aumentariam a qualidade do fornecimento de energia. A metodologia de pesquisa utilizada é descritiva, utilizando-se de casos já existentes ao redor do mundo, as relacionando com o agronegócio do Paraná, e as tecnologias disponíveis e acessíveis do mercado, bem como seus respectivos usos e funcionamentos e a também a criação de um estudo de caso utilizando o Paraná como cenário e 3 propriedades simuladas. O projeto criado como estudo de caso utiliza as melhores opções de fontes alternativas para a geração de energia no agronegócio e utiliza tecnologias que já foram utilizadas em projetos pilotos da COPEL para controle e restabelecimento da energia. O fluxo de potência e os cenários de reconfiguração do fluxo de energia das propriedades do estudo de caso são discutidos e também é apresentada análise da viabilidade técnico econômica do projeto. Foram empregados dados da Companhia Paranaense de Energia Elétrica (COPEL), Agência Nacional de Energia Elétrica (ANEEL) e Secretaria de Agricultura e Abastecimento (SEAB) para verificação da relação entre Agronegócio e Energia Elétrica. As alternativas apresentadas ao longo do trabalho mostram a capacidade da autonomia das propriedades se utilizando dos seus próprios recursos disponíveis e a viabilidade dessa implementação. A junção dos potenciais energéticos e as redes inteligentes mostram um cenário promissor no fornecimento de energia elétrica de qualidade, redução de custos para todos os envolvidos e de sustentabilidade ambiental, o que apresenta um grande estímulo ao investimento na implementação de microrredes e geração distribuída no estado do Paraná.

Palavras-chave: Redes Inteligentes. Reconfiguração Automática. Fontes Renováveis. Agronegócio. 


\begin{abstract}
CAMARGO, Bruno; MOREIRA, Elison; KALUME, Felipe. RENEWABLE ALTERNATIVE SOURCES INTEGRATION WITH OPTIMIZED ENERGY RESTORATION ON AGRIBUSINESS. 2021. 115 f. Trabalho de conclusão de curso (Graduação - Curso de Engenharia de Controle e Automação), Universidade Tecnológica Federal do Paraná, Curitiba, 2021.

This work refers to alternatives of different sources and energetic solutions for agribusiness in the state of Paraná, as well as the technologies that participate in the processes of development, management and distribution of energy. Brazil is one of the largest agricultural producers in the world and still does not have a wide implementation of technologies for the integration and reconfiguration of independent energy sources aimed at agribusiness and rural properties, which in the long run would reduce costs for the electricity concessionaires and user and increase the quality of the power supply. The research methodology used is descriptive, using cases that already exist around the world, relating them to the agribusiness of Paraná, and the available and accessible technologies of the market, as well as their respective uses and functions and also the creation of a case study using Paraná as a scenario and 3 simulated properties. The project created as a case study uses the best options of alternative sources for energy generation in agribusiness and uses technologies that have already been used in COPEL's pilot projects to control and restore energy. The power flow and the property power flow reconfiguration scenarios of the case study properties are discussed and an analysis of the technical and economic feasibility of the project is also presented. Data from Companhia Paranaense de Energia Elétrica (COPEL), National Electricity Agency (ANEEL) and Secretaria de Agricultura e Abastecimento (SEAB) were used to verify the relationship between Agribusiness and Electric Energy. The alternatives presented throughout the work show the capacity of the properties' autonomy using their own available resources and the feasibility of this implementation. The combination of energy potentials and smart grids shows a promising scenario in the supply of quality electricity, cost reduction for all involved and environmental sustainability, which presents a great incentive to invest in the implementation of micro networks and distributed generation in the state of Paraná.
\end{abstract}

Keywords: Smart Grids. Automatic reconfiguration. Renewable sources. Agribusiness. 


\section{LISTA DE SIGLAS}

ACCESS - Assisting Communities to Connect to Electric Sustainable Sources ANEEL - Agência Nacional de Energia Elétrica

BEN - Balanço Energético Nacional

COPEL - Companhia Paranaense de Energia Elétrica

DEC - Duração Equivalente de Interrupção por Unidade Consumidora

EPE - Empresa de Pesquisa Energética

FEC - Frequência Equivalente de Interrupção por Unidade Consumidora

FIC - Frequência de Interrupção Individual por Unidade Consumidora

IN - Corrente nominal

IPARDES - Instituto Paranaense de Desenvolvimento Econômico e Social

LACTEC - Instituto de Tecnologia para o Desenvolvimento

MPPT - Maximum power point tracking

NTC - Norma Técnica Copel

REN - Resolução Normativa

SCADA - Supervisory Control and Data Acquisition

SEAB - Secretaria de Agricultura e Abastecimento

TE - Tarifa de Energia

TIR - Taxa Interna de Retorno

TUSD - Tarifa de Uso do Sistema

YFA - Yukon Feeder 


\section{LISTA DE FIGURAS}

Figura 1 - Arranjo de uma microcentral hidrelétrica.......................................................20

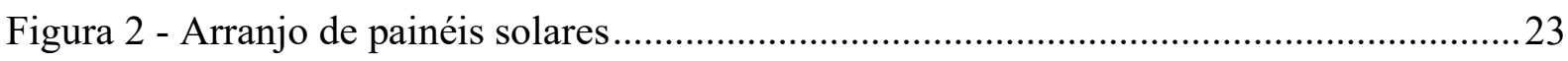

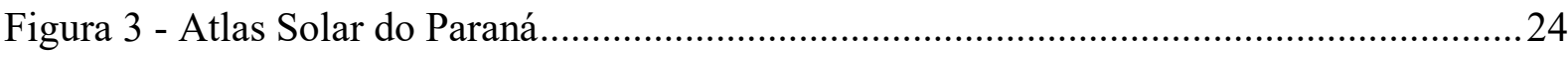

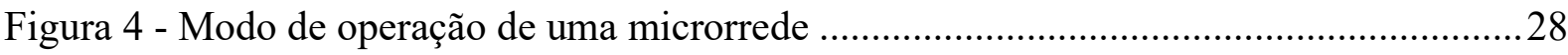

Figura 5 - Automação de rede Projeto Fazenda Rio Grande ....................................................42

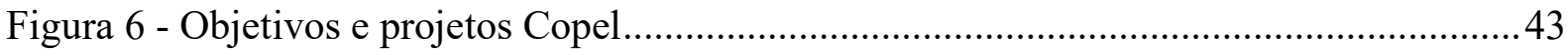

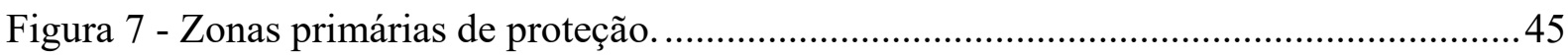

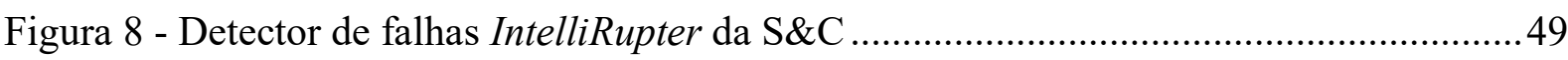

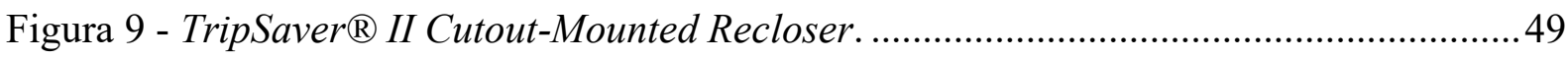

Figura 10 - Sensor Inteligente GridAdvisor Série II........................................................50

Figura 11 - Modelos de religador automático OSM .................................................................51

Figura 12 - Cabine de Controle e Comunicação.........................................................................51

Figura 13 - Tela Geral do simulador de consumo Copel......................................................63

Figura 14 - Tela para adição de equipamento simulador Copel. ............................................64

Figura 15 - Especificações Elétricas Painel Fotovoltaico Balfar Solar. ..................................65

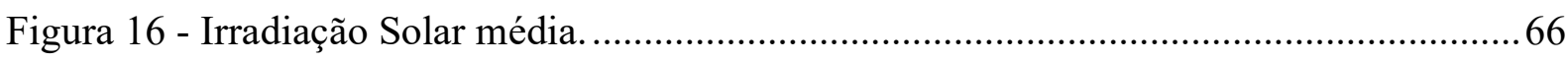

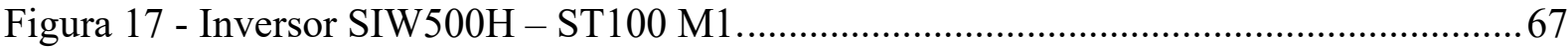

Figura 18 - Especificações Técnicas inversor SIW500H - ST100 M1 _................................67

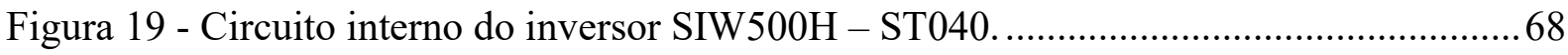

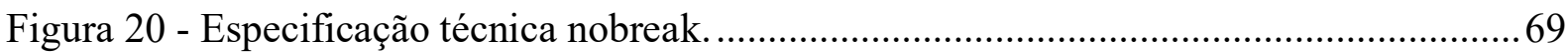

Figura 21 - Especificação técnica nobreak - baterias.......................................................... 70

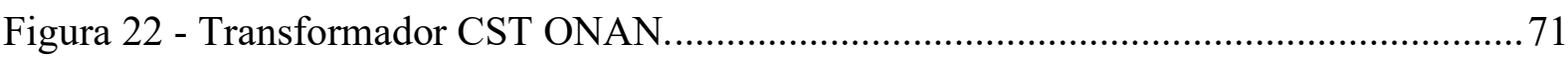

Figura 23 - Projeto de propriedade com Geração Fotovoltaica.............................................. 73

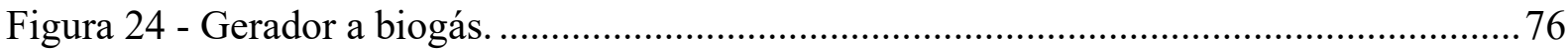

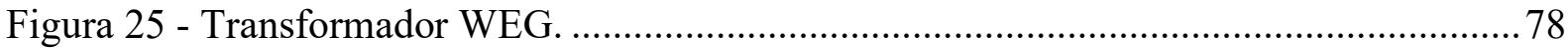

Figura 26 - Projeto de propriedade com geração a biomassa. .................................................. 80

Figura 27 - Gráfico guia para seleção de turbinas...............................................................83

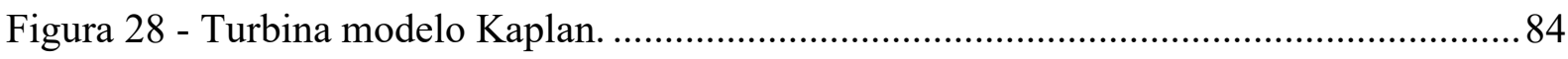

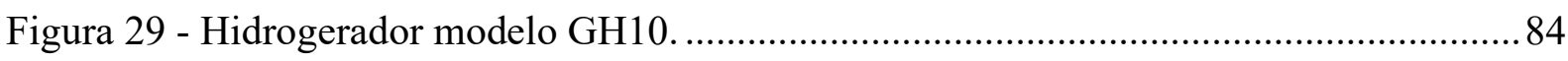

Figura 30 - Projeto de propriedade com geração hidrelétrica. ...............................................86

Figura 31 - Projeto completo com interligação das três propriedades. ...................................... 87

Figura 32 - Fluxo de potência para o cenário padrão............................................................... 89 
Figura 33 - Fluxo de potência para modo ilha......................................................................90

Figura 34 - Fluxo de potência para perda de geração da propriedade 01(Solar).....................91

Figura 35 - Fluxo de potência para perda de geração da propriedade 02(Biomassa)...............92

Figura 36 - Fluxo de potência para perda de geração da propriedade 03(PCH). ....................93

Figura 37 - Sistema de Compensação de Energia Elétrica.....................................................95

Figura 38 - Fluxo de Energia Médio Mensal - Propriedade 1................................................96

Figura 39 - Fluxo de Energia Médio Mensal - Propriedade 2 .................................................97

Figura 40 - Fluxo de Energia Médio Mensal - Propriedade 3 .................................................98

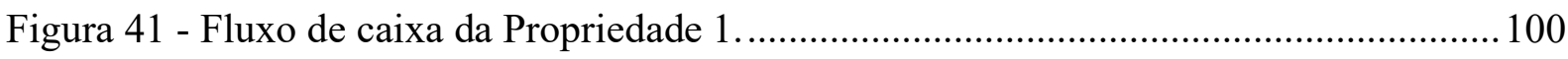

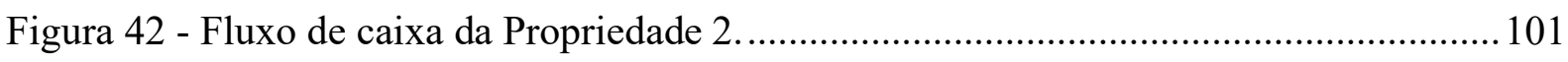

Figura 43 - Fluxo de caixa da Propriedade 3 .................................................................. 101 


\section{LISTA DE TABELAS}

Tabela 1 - Prós e Contras para diferentes soluções para fornecimento de energia ..................29

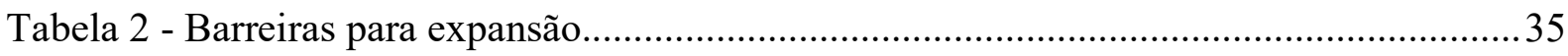

Tabela 3 - Tabela de cargas de consumo residências propriedade 1 .....................................62

Tabela 4 - Tabela de cargas de consumo dos galpões, sistema de bombeamento água e

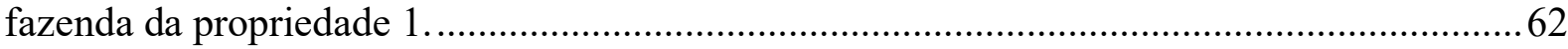

Tabela 5 - Tabela de cargas consumo residência propriedade 2 ..........................................75

Tabela 6 - Tabela de cargas consumo galpão e bombeamento água propriedade 2 ................75

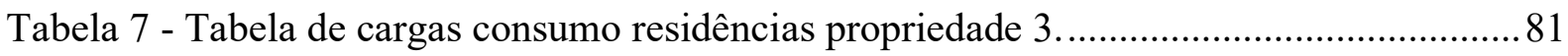

Tabela 8 - Tabela de cargas consumo lavoura e bombeamento água propriedade $3 \ldots \ldots \ldots \ldots \ldots . . . .82$

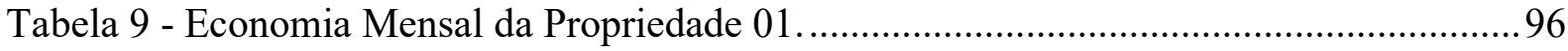

Tabela 10 - Economia Mensal das Propriedade 02. ................................................................97

Tabela 11 - Economia Mensal das Propriedade 03. ...............................................................98

Tabela 12 - Custo da instalação e geração de energia..............................................................99

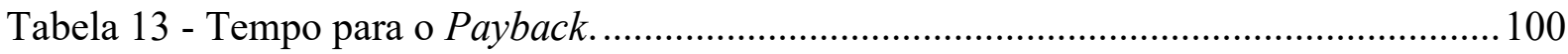

Tabela 14 - Custo operacional de diferentes arquiuteturas................................................ 102

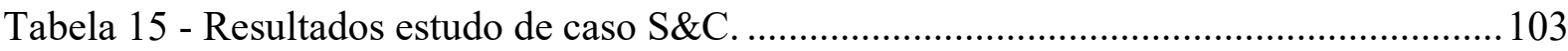




\section{SUMÁRIO}

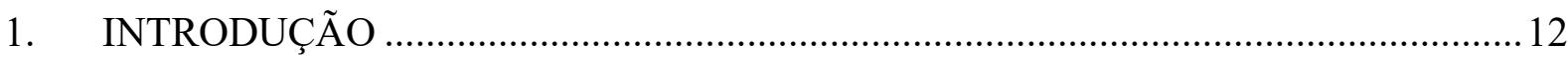

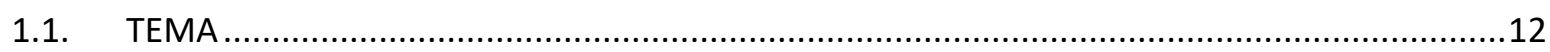

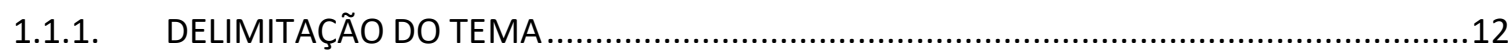

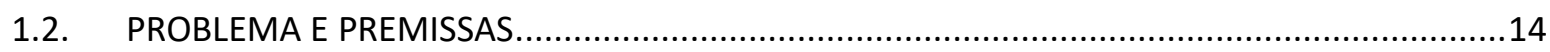

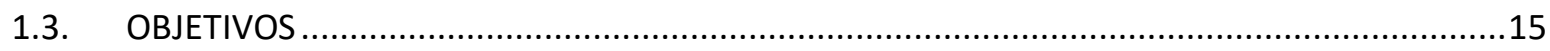

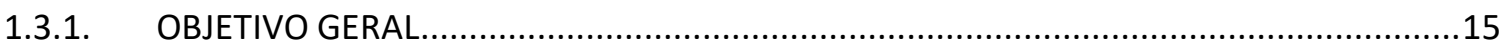

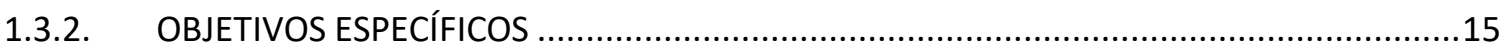

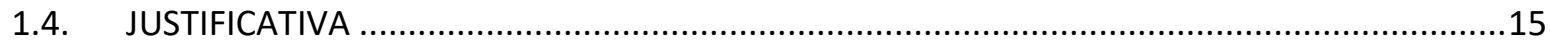

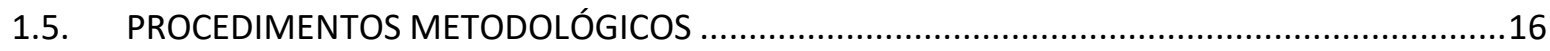

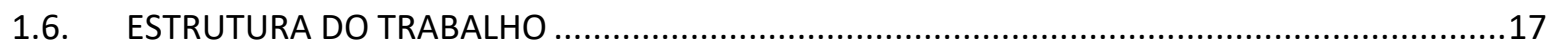

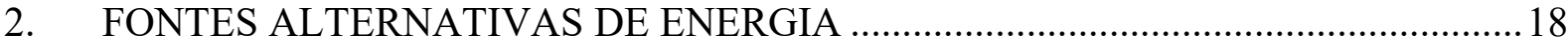

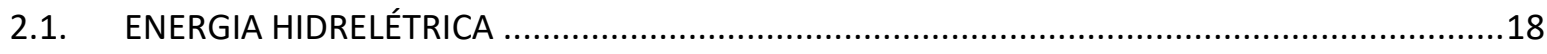

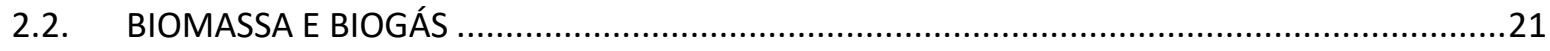

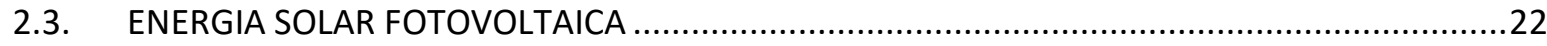

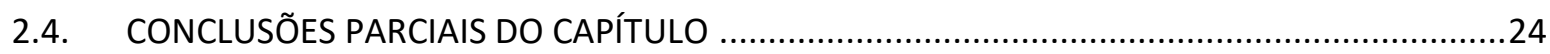

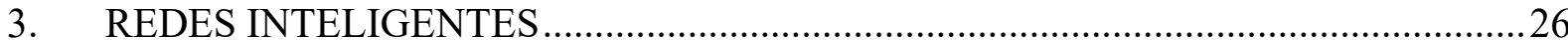

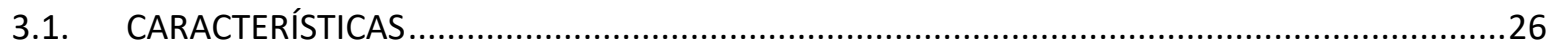

3.1.1. MOTIVO PARA SE TER UMA REDE INTELIGENTE .....................................................26

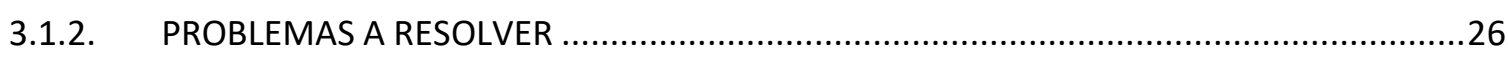

3.1.3. ANÁLISE DE UTILIDADE: TENDÊNCIAS E DESAFIOS COMUNS .......................................27

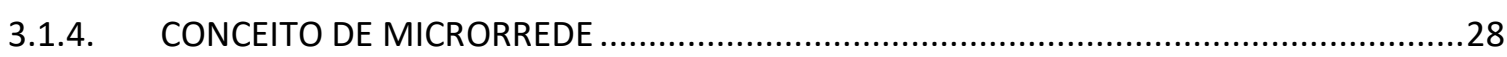

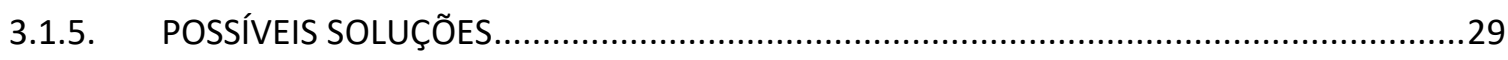

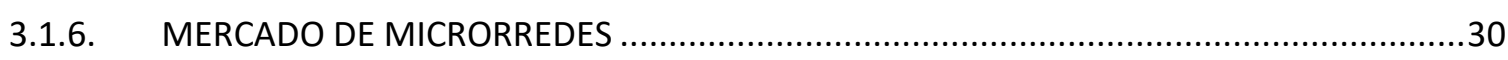

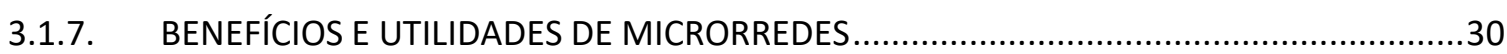

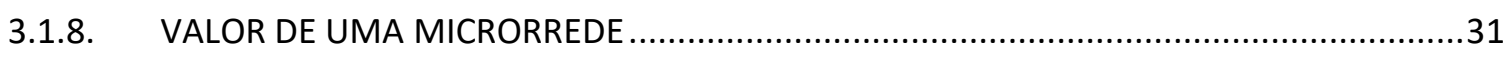

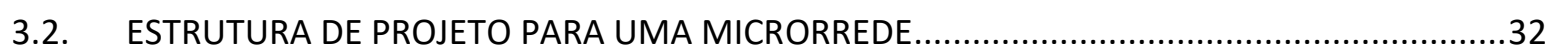

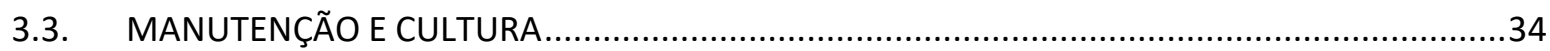

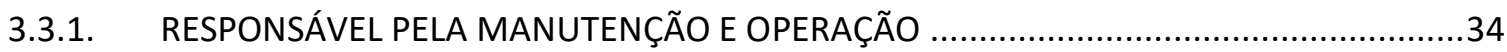

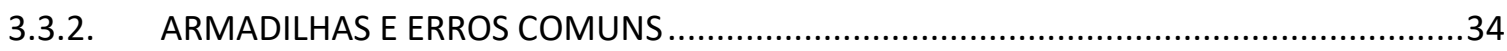

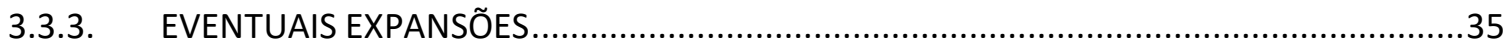

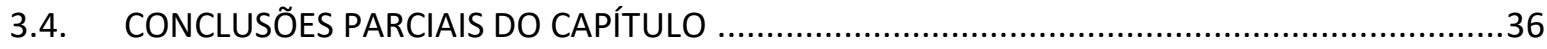

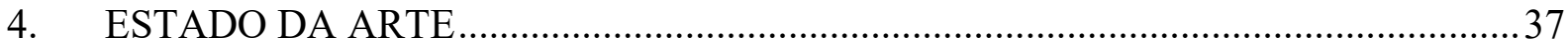


4.1. CENÁRIO ATUAL DE MICRORREDES E PERSPECTIVAS FUTURAS ….......................................

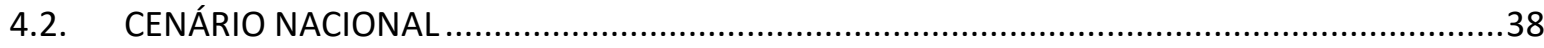

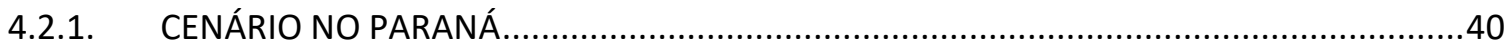

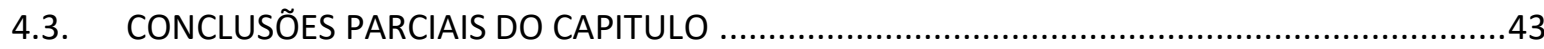

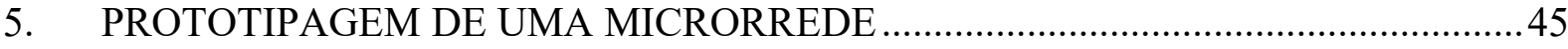

5.1. DISPOSITIVOS DE PROTEÇÃO

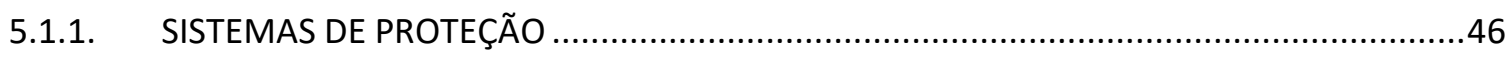

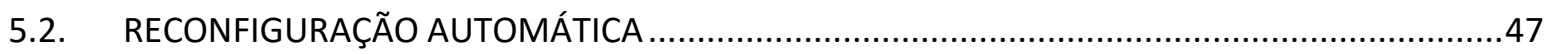

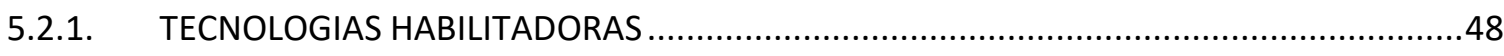

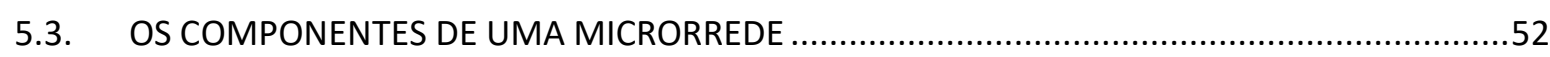

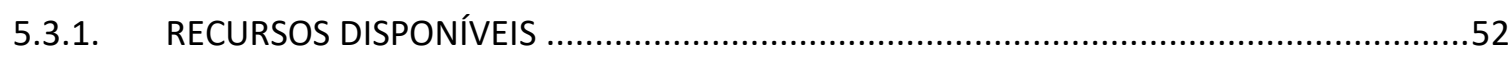

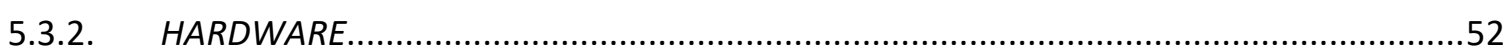

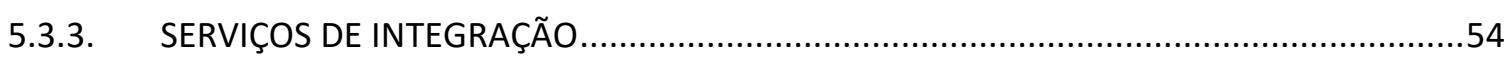

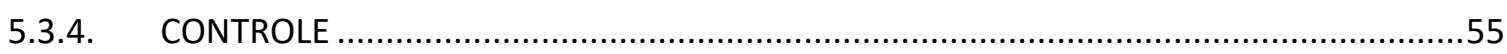

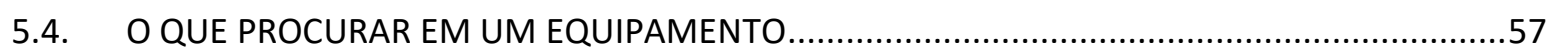

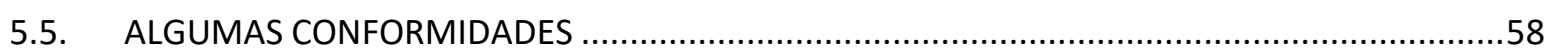

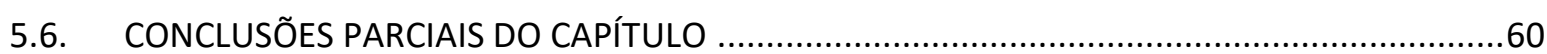

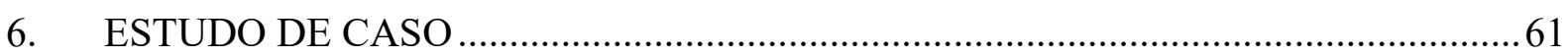

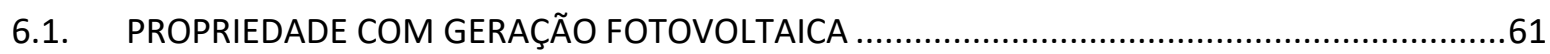

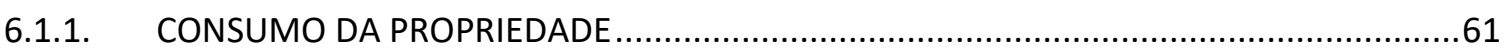

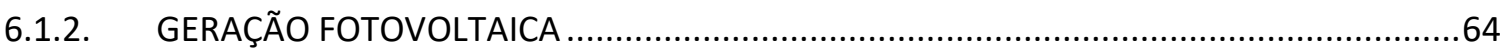

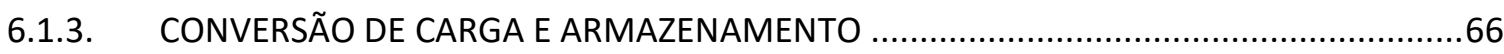

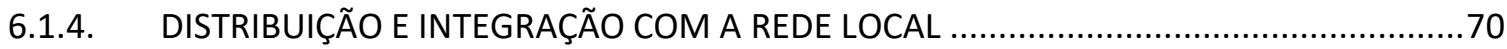

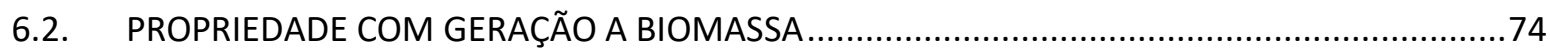

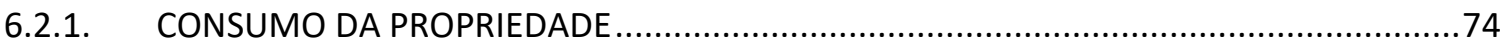

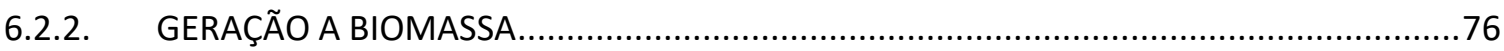

6.2.3. DISTRIBUIÇÃO E INTEGRAÇÃO COM A REDE LOCAL …...............................................78

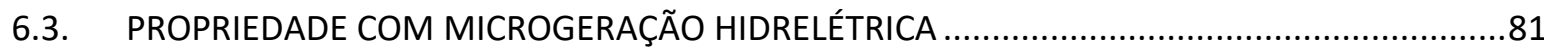

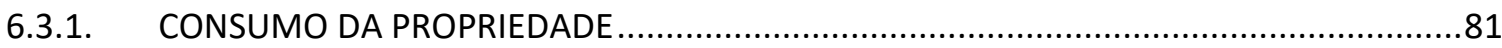

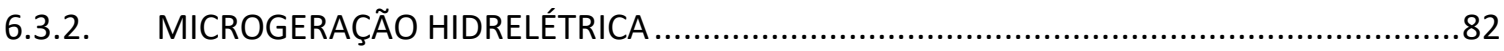

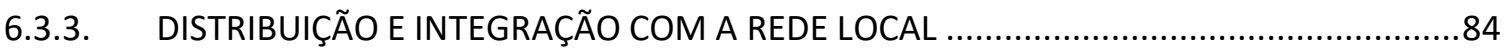

6.4. INTEGRAÇÃO DAS FONTES E GERENCIAMENTO DA MICRORREDE ….................................86

6.4.1. FLUXO DE POTÊNCIA PARA CENÁRIOS DE RECONFIGURAÇÃO DA REDE ......................8

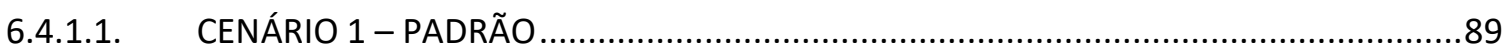

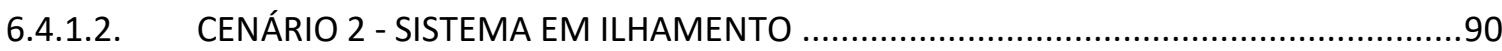




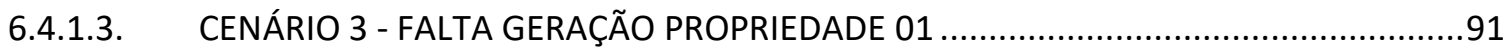

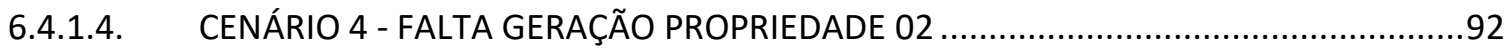

6.4.1.5. CENÁRIO 5 - FALTA GERAÇÃO PROPRIEDADE 03 .................................................93

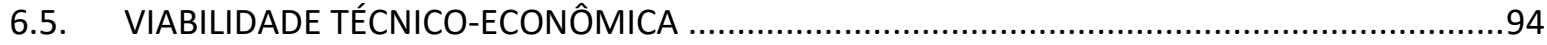

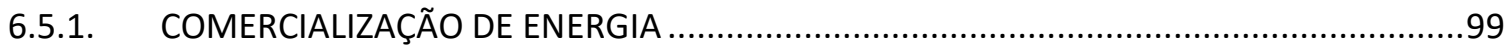

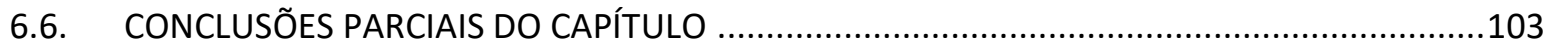

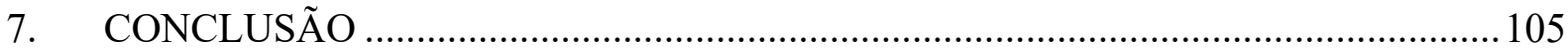

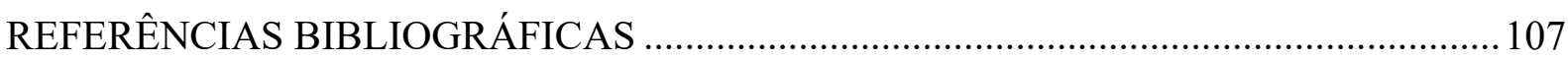

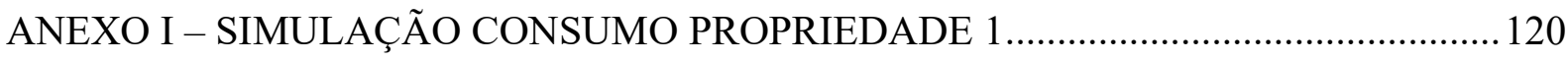

ANEXO II - SIMULAÇÃO CONSUMO PROPRIEDADE 2 ........................................ 121

ANEXO III - SIMULAÇÃO CONSUMO PROPRIEDADE 3 …...................................... 122

ANEXO IV - CONFIGURAÇÃO EQUIPAMENTOS NO SOFTWARE ETAP .................. 123 


\section{INTRODUÇÃO}

\subsection{TEMA}

A reconfiguração automática é uma das tecnologias mais atrativas e relevantes para concessionárias de energia elétrica, justamente por trazer independência para a rede em alguns casos de perda de fornecimento e maior aproveitamento dos recursos já utilizados, resultando na diminuição da necessidade de construção de novas infraestruturas e/ou substituição de equipamentos já existentes nas redes de distribuição, transporte e armazenamento, colocando todo o investimento somente na nova tecnologia a ser estudada e implementada.

Quando o sistema está operando, a essência recai no aumento de sua eficiência e na diminuição de custos operacionais fazendo o sistema operar no estado de mínimas perdas que consiste basicamente na melhor distribuição do fluxo de potência, tendo impacto direto na vida útil dos equipamentos e no perfil de tensão dos circuitos de alimentação.

Existem várias tecnologias relacionadas a redes inteligentes, mas geralmente só são eficientes apenas para os problemas específicos aos quais foram desenvolvidos e dentro deste contexto é importante o melhor entendimento das ferramentas disponíveis que podem ser implementadas. Neste caso, no setor agropecuário, que foi responsável pelo consumo de 4,7\% da eletricidade no Brasil (29,8 TWh) em 2018 (Balanço Energético Nacional - BEN, 2019). O objetivo deste estudo é discorrer sobre a criação de pequenas zonas descentralizadas de geração independente de energia alternativa renovável que funcionem como ilhas, e com o potencial de sustentar-se autonomamente em relação ao fornecimento primário de energia, formando microrredes e, de acordo com o BEN de 2019 (dados referentes ao ano de 2018), as energias renováveis correspondem a 45,3\% da Oferta Interna de Energia e 83,3\% da matriz elétrica nacional.

\subsubsection{DELIMITAÇÃO DO TEMA}

As propriedades agrícolas apresentam alto potencial energético natural renovável, e ao mesmo tempo baixo aproveitamento deste recurso. Segundo Mourad, Ambrogui e Guerra (2004) o Brasil gera expressiva biomassa nos processos resultantes da colheita e processamento de produtos agropecuários. No mundo a contribuição da biomassa para o suprimento de energia é de 10 a 14\%, enquanto no Brasil 8,5\% da matriz elétrica brasileira é 
composta por biomassa, de acordo com a Empresa de Pesquisa Energética (EPE, 2018). Em complemento, é possível a escolha da utilização de outras fontes de energia, como a fotovoltaica (0,5\% da Matriz Elétrica Brasileira em 2018), cuja geração elétrica cresceu em 316,1\% do ano de 2017 para o ano de 2018 e a eólica (7,6\% da Matriz Elétrica Brasileira em 2018) que teve sua geração aumentada em quase quatro vezes em menos de cinco anos (de 12.210GWh em 2012 para 48.475GWh em 2018), segundo os dados do BEN, fornecidos pela EPE. Tendo isso em vista, é interessante incentivar e amadurecer a ideia da geração independente de energia, estimulando a geração de energias renováveis para pequenos e médios produtores em propriedades rurais, utilizando-se de seus próprios meios excedentes e contando com o incentivo do governo estadual.

Essa produção autônoma é tão somente uma alternativa, pois seu funcionamento se dá de maneira complementar ao fornecimento da concessionária de energia, fazendo assim necessário o uso de uma ferramenta de integração das fontes de energias renováveis alternativas às já fornecidas por padrão. $\mathrm{O}$ método a ser utilizado nesse contexto são as redes inteligentes, também conhecidas como Smart Grids, que, segundo Farhangi (2010), ocorrem como sendo a convergência de tecnologia de informação e comunicação com a engenharia de sistemas de potência, tendo em vista, essencialmente, prover uma total visibilidade e amplo controle sobre ativos e serviços, autocorreção e resiliência contra anomalias do sistema e ser capaz de se auto configurar e se adaptar às transações de energia em todo o conjunto. Mais especificamente, neste trabalho serão utilizadas microrredes que, como explicado por Liserre, Sauter e Hung (2010, p. 22) consistem em diversos produtores, sistemas de armazenamento e cargas conectadas umas às outras as quais operam em uma ilha controlada que pode ou não vir a interagir com a rede elétrica principal e com outras ilhas.

Camacho (2011) cita alguns benefícios das redes inteligentes, como a facilitação da conexão e operação de geradores de variados tamanhos e tecnologias, permitir a participação dos consumidores na otimização do sistema e conceder maiores informações e opções para escolha do fornecimento de energia com níveis de confiabilidade, qualidade e segurança mantidos ou melhorados, a redução do impacto ambiental desse sistema elétrico e a integração no mercado.

Segundo Farhangi (2010) os resultados esperados com a implantação das redes inteligentes são: controle digital, comunicação de duas vias, geração distribuída, automonitoramento, adaptabilidade, monitoramento remoto, maior controle pelo consumidor, armazenamento de energia, maior resposta à demanda, interoperabilidade, segurança de infraestrutura, entre outros. 
De acordo com o Balanço Energético Nacional de 2019 (EPE, 2019), a Micro e a Minigeração Distribuídas tiveram aumento de 131\% de 2017 para 2018, sendo que em 2018 foram gerados $828 \mathrm{GWh}$, sendo 65,3\% solar, 19,1\% hidráulico, 1,7\% eólico, 1,8\% gás natural e $13,9 \%$ as outras fontes renováveis.

\subsection{PROBLEMA E PREMISSAS}

A carga de energia no campo normalmente encontra-se em lugares remotos, longe da concessionária de energia, trazendo dificuldades no restabelecimento da carga quando há queda no sistema. A duração dessa demora muitas vezes prejudica a produção das propriedades afetadas e este problema pode se agravar dependendo da duração da falta de energia.

Fernandes (2014) identifica as zonas rurais como áreas de recorrente falta de energia, pois estas são mais vulneráveis a chuvas, ventos e descargas elétricas, assim como são mais suscetíveis a falhas devido a arborização, ocasionalmente proporcionando acidentes com a queda de galhos de árvores na rede de distribuição elétrica. Os produtores rurais são, então, caracterizados como reféns da recorrente falta de energia, muitos não conseguem manter a qualidade dos produtos, podendo ter desde perda parcial a aniquilamento da produção.

A baixa taxa de produção energética autônoma no campo é outro problema evidente, mesmo em propriedades com diversos recursos para a produção de energia, como produção de biomassa em propriedades agrícolas, e até mesmo potencial fotovoltaico em campos com alta incidência de radiação solar.

Marques (2012) evidencia a fonte alternativa de energia proveniente da biomassa como solução para sustentabilidade e aproveitamento de resíduos animais e orgânicos em pequenas propriedades agroindustriais, bem como o aproveitamento do biogás proveniente da biomassa gerada por dejetos animais. 


\subsection{OBJETIVOS}

\subsubsection{OBJETIVO GERAL}

Pesquisar e desenvolver um estudo sobre a implementação de um sistema de reconfiguração automática em redes inteligentes para interligação de fontes alternativas de energia, com o propósito de distribuição, armazenamento e transporte da energia elétrica no agronegócio.

\subsubsection{OBJETIVOS ESPECÍFICOS}

Para atingir o objetivo geral, será necessário:

- Estudar e definir as melhores opções de fontes alternativas para a geração de energia nos agronegócios;

- Pesquisar sobre sistemas integrados de geração distribuída de energia;

- Pesquisar sobre sistemas de restabelecimento automatizado;

- Realizar estudo de caso da integração das fontes renováveis;

- Analisar o fluxo de potência;

- Realizar análise técnico econômica de modelo real.

\subsection{JUSTIFICATIVA}

Apesar do Brasil ser um dos maiores produtores agropecuários do mundo, ainda não possui ampla implementação de tecnologias para a integração e reconfiguração de fontes independentes de energia voltadas para o agronegócio e propriedades rurais. Este projeto traz um estudo de viabilidade técnica e econômica dessas tecnologias em média e baixa tensão dentro deste contexto de produtores que têm capacidade de produção.

Um ponto importante a ser levantado é a questão da sustentabilidade, que vem ganhando forças nos últimos anos e é algo que países desenvolvidos buscam conciliar junto ao desenvolvimento tecnológico e a diminuição do preço em relação a geração de energias renováveis.

Para Pereira (1997 apud MARTINS, 2004) a utilização de energia fotovoltaica pode gerar benefícios para o país, viabilizando o desenvolvimento de regiões remotas onde o custo 
oriundo da rede convencional de distribuição é alto. Há possível retorno financeiro após o investimento.

Vale destacar os países que de acordo com Liserre, Sauter e Hung (2010, p. 20), lideram na capacidade de geração de energias renováveis, como a Alemanha com mais de 85\% da capacidade total da Europa, seguido da Espanha. Dados estes que mostram de maneira expressiva como países com alto grau de investimento tecnológico preocupam-se com fontes alternativas renováveis de energia.

Além do conforto e confiabilidade proporcionado por uma fonte de energia própria, o restabelecimento automatizado e a integração visam distribuição, transporte e armazenamento energético entre as propriedades próximas, reduzindo custos com a concessionária de energia e evitando quedas repentinas e duradouras da carga elétrica.

Pazzini (2002) levanta a questão da privatização das empresas provedoras de energia elétrica no Brasil, as quais enfatizam componentes como lucro e competição, gerando maiores custos a população, que é marcada por desigualdades sociais e econômicas, tendo em sua grande parte a falta de direitos básicos, entre eles, a eletricidade. Por isso é necessário a universalização do serviço de distribuição de energia, particularmente para que garanta-se o atendimento eficiente da zona rural.

\subsection{PROCEDIMENTOS METODOLÓGICOS}

O trabalho realizado, envolve inicialmente um levantamento bibliográfico, a partir de materiais já elaborados, como livros e artigos, referente aos assuntos de fontes alternativas de energia e redes inteligentes, mantendo o foco para as zonas rurais.

Para a etapa de estudo de caso e viabilidade foi realizada a análise de uma possível propriedade onde tem-se interesse de implementar o modelo e realizado o levantamento dos dados sobre potencial energético, características da rede elétrica do local e possíveis vizinhos para integração, assim como análise dos custos para implementação do projeto.

Para a construção do protótipo foram analisados os modelos já existentes no mercado, utilizados pelas concessionárias de energia, como, por exemplo, o Intellirupter da S\&C e o Self Healing da Cooper, e a partir disso foi confeccionado o modelo para utilização na integração das fontes alternativas de energia da comunidade agrícola em estudo e reconfiguração automática da rede. 


\subsection{ESTRUTURA DO TRABALHO}

O projeto é dividido em basicamente três partes, a primeira envolvendo a fundamentação teórica, na segunda realiza-se o estudo de caso para a viabilidade da implementação das fontes alternativas e do sistema de integração, e na terceira é realizada a confecção do protótipo.

A primeira parte engloba os quatro primeiros capítulos. $\mathrm{O}$ capítulo 1 trata sobre a metodologia utilizada no projeto, delimitação do tema, levantamento de problemas e técnicas a serem utilizadas.

O capítulo 2 inicia a fundamentação teórica com o estudo sobre as fontes alternativas de energia disponíveis para implementação no agronegócio. No capítulo 3 é abordado o tema de redes inteligentes assim como os seus aspectos e características tanto de hardware como de software.

Após o embasamento teórico dos capítulos anteriores, no capítulo 4 é realizada uma conexão entre os assuntos levantados, introduz-se o tema de integração das fontes alternativas e é retratada a ferramenta a ser utilizada nessa integração, a qual proporciona o restabelecimento automatizado.

Finalizando a fundamentação teórica, inicia-se a segunda parte do projeto, a qual é apresentada no capítulo 5, no qual é feito o levantamento dos dados sobre potencial energético da propriedade que se deseja instalar o modelo, características da rede elétrica do local e possíveis vizinhos para integração, assim como o levantamento dos custos da implementação do projeto para garantir a viabilidade do mesmo.

A terceira parte, abordada no capítulo 6, traz a estrutura do protótipo, o protocolo de integração da rede e o gerenciamento da energia gerada. $O$ trabalho é finalizado na sequência com as conclusões e seguido das referências bibliográficas. 


\section{FONTES ALTERNATIVAS DE ENERGIA}

Segundo Tiepolo (2014), historicamente o Estado do Paraná tem sido um dos maiores produtores de energia elétrica do país, quase em toda a sua totalidade através de hidrelétricas. Entretanto, o aproveitamento desta fonte no estado, assim como no Brasil, está em declínio devido ao esgotamento do potencial hídrico e, também, devido à pressão da sociedade quanto aos impactos ambientais, sociais e econômicos. A geração de energia eólica, biomassa e fotovoltaica tem sido pesquisada no estado para superar essas limitações.

A micro e minigeração é uma tendência que vem tomando espaço no setor elétrico no país. A regulamentação criada em 2012, e sua aprimoração em 2015 realizada pela ANEEL (Agência Nacional de Energia Elétrica), tornou mais acessível a geração distribuída para um número maior de consumidores, possibilitando a conexão de geradores de até $5 \mathrm{MW}$, oriundos de fontes renováveis e cogeração qualificada, na rede de distribuição (Ministério de Minas e Energia/Empresa de Pesquisa Energética, 2018). Esta regulamentação trouxe uma alta procura de sistemas de geração autônoma, o que ocasionou em uma diminuição da fatura do proprietário e um investimento em seu capital.

O Ministério de Minas e Energia (2018) afirma que, até o ano de 2027 haverá 1,35 milhões de usuários do sistema de micro e mini geração distribuída, exigindo um investimento de cerca de 60 bilhões de reais ao longo do período. Este sistema de geração distribuída irá contribuir com cerca de 2400 MWméd, atendendo 2,4\% da carga total nacional do período.

\subsection{ENERGIA HIDRELÉTRICA}

A geração de energia hidrelétrica consiste inicialmente no aproveitamento da energia potencial fornecida pela água, a partir da vazão de rios e lagos ou ainda reservatórios, para produção de energia mecânica que será convertida, por meio de geradores, em energia elétrica (REIS, 2011). Segundo a ANEEL, em 2002, a energia hidrelétrica era apresentada como a principal fonte geradora de energia elétrica mundial, representando cerca de $20 \%$ de toda geração. No Brasil, esta forma de energia representou $66,6 \%$ da matriz elétrica nacional em 2018 (BEN, 2019).

De acordo com o Ministério do Meio Ambiente (ANEEL 2002), a bacia hidrográfica do Paraná possui a maior capacidade instalada de energia elétrica do país, em 2006 cerca de $60 \%$ da potência nacional. (apud. Ministério do Meio Ambiente, 2006). Porém, nesta região, 
a maior parte do seu potencial hídrico já vem sendo utilizado, mais de $50 \%$ de todas as bacias com potencial de geração já possuem instalações de aproveitamento, deste modo, as alternativas preferenciais para suprir o crescimento da demanda dos próximos anos se voltam para micro centrais hidrelétricas e outras fontes renováveis de pequeno porte disponíveis na região.

As usinas hidrelétricas são classificadas a partir de suas características de utilização da água para geração de energia e sua potência gerada. Dentro deste contexto do uso das vazões naturais, as usinas podem ser classificadas como centrais de fio d'água, centrais de acumulação e centrais com armazenamento por bombeamento ou reversão (REIS, 2011).

As centrais de fio d'água utilizam, em geral, as vazões naturais do curso d'água onde estão instaladas. Algumas destas usinas possuem reservatórios de acumulação, onde armazenam energia potencial em períodos fora de pico para ser utilizada em horários de pico (REIS, 2011).

Centrais de acumulação possuem grandes reservatórios que armazenam energia potencial proveniente das águas no período de cheia para ser utilizada no período de estiagem (REIS, 2011).

Centrais de bombeamento ou reversão utilizam de energia extra gerada por outras usinas em períodos de baixa demanda, para bombear água para um reservatório, armazenando energia para ser utilizada em períodos de alta demanda (REIS, 2011).

Como já dito, a classificação de usinas hidrelétricas é realizada também sobre a potência fornecida. Essa classificação se dá na seguinte forma (REIS, 2011):
A. Micro centrais
$\mathrm{P} \leq 100 \mathrm{~kW}$
B. Mini centrais
$100<\mathrm{P} \leq 1000 \mathrm{~kW}$
C. Pequenas centrais
$1<\mathrm{P} \leq 30 \mathrm{MW}$
D. Médias centrais
$10<\mathrm{P} \leq 100 \mathrm{MW}$
E. Grandes centrais
$\mathrm{P} \geq 100 \mathrm{MW}$

Apesar de causar menos impactos ambientais, a geração de energia elétrica com sistemas a fio d'água varia no tempo, devido à vazão não constante dos rios, e assim necessitam de estudos pluviométricos e topográficos mais aprofundados. Os sistemas com reservatórios potenciais, frequentemente ocupam grandes espaços, porém, fornecem vazão constante enquanto estão com os níveis necessários para a geração elétrica (NOGUEIRA, 2004). 
Para a utilização de reservatórios ou tanques (presentes em muitas propriedades rurais), como acumuladores de água para geração, as instalações devem receber algumas mudanças e adições dos pontos de captação de água. Uma microcentral hidrelétrica, de modo geral, possui a seguinte estrutura (NOGUEIRA, 2004):

- Barragem vertedoura - utilizada para armazenar a energia potencial das águas, é construída de diversas formas, variando com as características físicas do terreno, sendo as mais comuns construídas de terra, alvenaria de pedra argamassa e de concreto;

- Tomada de água - trecho que capta a água da barragem para a geração de energia elétrica;

- Canal de adução - caminho que conduz a água até a turbina geradora, com desnível suficiente para manter a energia potencial para geração. O canal pode ser aberto, revestido por alvenaria, ou podem ser utilizadas tubulações até a casa de máquinas;

- Câmara de carga - dispositivo que realiza a transição entre o canal de adução de baixa pressão, e o conduto forçado, de alta pressão;

- Conduto forçado - trecho que garante maior queda e energia potencial necessária para a geração. No geral são adotadas tubulações de materiais extremamente resistentes, como ferro ou aço;

- Casa de máquinas - onde as turbinas e equipamentos geradores são abrigados;

- Canal de fuga - trecho que devolve a água utilizada pelas turbinas ao curso do rio.

O arranjo do conjunto mencionado pode ser visto na Figura 1.

Figura 1 - Arranjo de uma microcentral hidrelétrica.

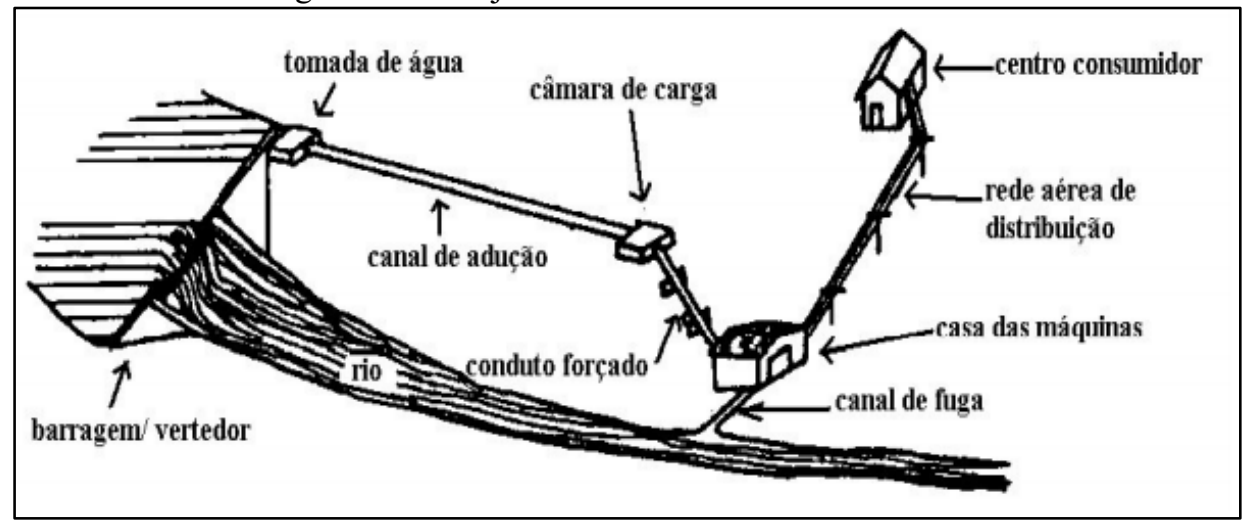

Fonte: Balarin (1998) apud Nogueira (2004). 
A potência máxima, em $\mathrm{kW}$, fornecida pode ser calculada com a equação (1) (NOGUEIRA, 2004).

$$
P=\gamma * g * Q * H * \eta / 1000
$$

Onde $\gamma$ é a massa específica da água $\left(\sim 1000 \mathrm{~kg} / \mathrm{m}^{3}\right)$, g é a constante de aceleração gravitacional $\left(\sim 9,8 \mathrm{~m} / \mathrm{s}^{2}\right)$, Q é a vazão disponível do curso d'água, em $\mathrm{m}^{3} / \mathrm{s}, \mathrm{H}$ é a queda líquida, em m e $\eta$ é o rendimento do conjunto turbina-gerador.

\subsection{BIOMASSA E BIOGÁS}

O conceito compreende todas as matérias orgânicas utilizadas como fontes de energia. Resíduos agrícolas, madeira e plantas - como a cana de açúcar, o eucalipto e a beterraba - são exemplos de biomassa. Outra forma de aproveitamento da biomassa é o biogás, sendo este uma fonte barata e abundante de energia, podendo ser obtido através de resíduos agrícolas, ou até excrementos animais e humanos. A formação do biogás acontece durante a decomposição da matéria viva, onde são lançados na atmosfera gases e calor.

O biogás pode ser utilizado no funcionamento de motores, geradores, moto picadeiras, resfriadores de leite, aquecedores de água, geladeira, fogão, lampião e lançachamas, podendo ainda substituir o gás liquefeito de petróleo na cozinha. Dentro das propriedades agrícolas, o biogás pode ser produzido em aparelhos simples chamados biodigestores e os resíduos que sobram podem ser utilizados como fertilizantes.

Junto à energia hidrelétrica, a energia de biomassa é responsável pelo suprimento da maior parte de energia consumida no Brasil. O que traz uma situação privilegiada ao Brasil, no que se refere a suas fontes primárias de oferta energética. Dados da COPEL (Companhia Paranaense De Energia Elétrica), 30\% das necessidades de energia no país são supridas por biomassa, usando lenha para queima direta em padarias e cerâmicas, carvão vegetal para redução de ferro gusa em fornos siderúrgicos e combustíveis alternativos em fábricas de cimento e queima de carvão mineral, álcool etílico ou álcool metílico no Sul. Esses dados trazem uma perspectiva da capacidade brasileira e a sua maturidade tecnológica em relação à biomassa.

Segundo Souza et al (2002), o potencial técnico estimado de produção de energia elétrica apenas de Resíduos Vegetais é de 108.619.490 GJ/ano, equivalente a 30,16 TWh/ano, sendo que não foram considerados neste estudo outros tipos de resíduos. 
Nesse contexto se torna vantajoso para o Paraná investir no aproveitamento de biomassa e/ou biogás para a produção de energia elétrica, pois possui uma grande área de produção agrícola, dados da SEAB (Secretaria de Agricultura e Abastecimento) mostram que comparado ao resto do Brasil, o Paraná produziu, no ano de 2016, 17,77\% da aveia (em grão), $17,69 \%$ da batata-inglesa, $30,99 \%$ do centeio, 53,68\% da cevada, $22,78 \%$ do feijão, $20,95 \%$ do Fumo, 17,67\% da Mandioca, 20,97\% do milho, 17,57\% da soja, 51,02\% do Trigo entre outros produtos, além da pecuária. Esses dados dão uma noção do potencial de geração de energia com biomassa e biogás a partir desses insumos.

\subsection{ENERGIA SOLAR FOTOVOLTAICA}

Uma fonte alternativa importante de ser mencionada é a de energia solar fotovoltaica, pois esta é de fácil acesso, totalmente limpa, renovável e de baixo custo de manutenção. "A radiação solar constitui-se numa inesgotável fonte energética, havendo um enorme potencial de sua utilização por meio de sistemas de captação e conversão em outra forma de energia" (PINHO, GALDINO, 2014, p.67).

O desenvolvimento dessa fonte está muito relacionado ao aperfeiçoamento dos materiais utilizados para a fabricação das células, os quais podem ocasionar diferentes níveis de eficiência na geração de energia, ou seja, "a capacidade de converter luz solar em eletricidade" (REIS, 2018).

Para a captação da energia solar, as células são interligadas formando módulos ou painéis solares como mostrado na Figura 2. Estes módulos podem variar de tamanho, eficiência e potência, de acordo com o fabricante.

Blasques (2005) cita alguns detalhes importantes para a eficiência dos painéis fotovoltaicos: o formato das células, sendo o ideal aquele em que estas consigam ocupar a maior área possível do módulo; análise das características elétricas dos módulos e devem ser considerados fatores como irradiância e temperatura da célula.

Reis (2018) relaciona a eficiência de um painel fotovoltaico com a capacidade do mesmo de converter energia a baixo custo e com grande fornecimento, listando as principais marcas disponíveis no mercado de acordo com a sua eficiência (em porcentagem), sendo elas, SunPower com 22,2\%, Panasonic com 21,6\%, LG com 21,1\%, Hanwha Q Cells com 19,5\% e Solaria com $19,4 \%$.

Os painéis solares transformam a energia solar em energia elétrica, fornecendo tensão em corrente contínua. Além da geração, é necessário realizar a conversão e a 
disponibilização da energia, para isso é utilizado o inversor, o qual é o componente responsável pela conversão da energia gerada pelo sistema fotovoltaico de corrente contínua para corrente alternada, gerando a tensão elétrica na frequência da rede local, com maior teor de harmônicos e onda da forma senoidal. Os inversores de última geração são equipados com circuitos microprocessados com o intuito de otimizar a geração de energia elétrica com rápida atuação sobre a energia gerada pelos módulos solares (RÜTHER, 2004 apud GROTH, 2013).

Para a otimização e melhor aproveitamento da potência dos painéis solares, estes são associados em série ou em paralelo, de modo a atingir uma faixa de tensão mais elevada para a conversão da energia. Como pode ser visto na Figura 2, um grupo de painéis conectados em série são comumente denominados strings, que serão responsáveis pelo nível de tensão do conjunto conectado aos inversores, e a associação das strings em paralelo são denominados de arrays, que possibilita a soma das correntes de cada string associada, elevando a potência conectada aos inversores (Kasim, 2020).

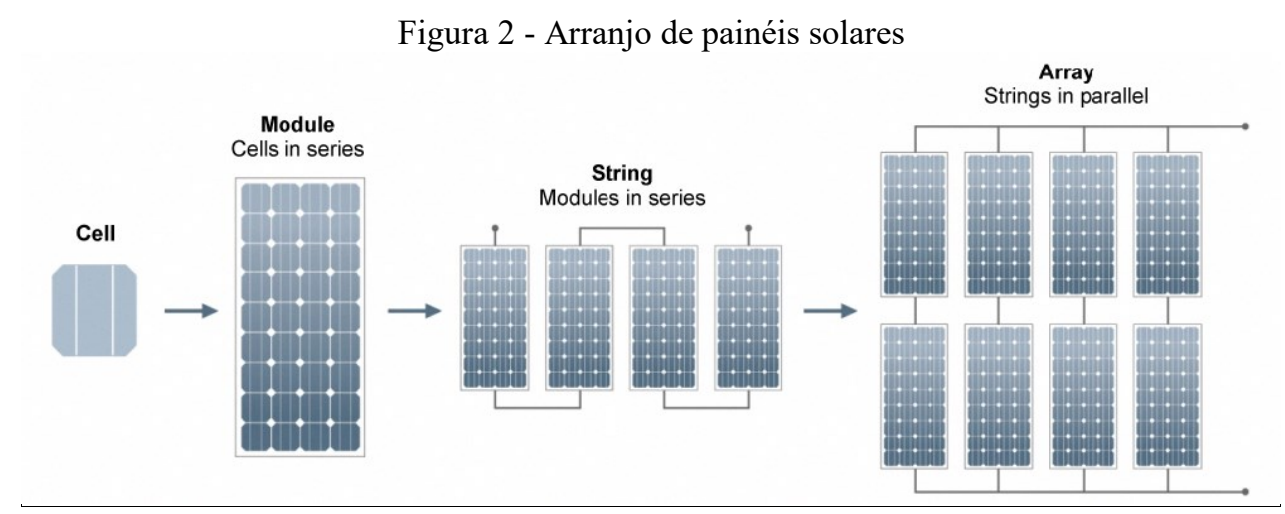

Fonte: Kasim e Al-Saleem (2020).

Segundo Groth (2013), para complementar, são utilizados alguns componentes que proporcionam o funcionamento correto e seguro de um sistema fotovoltaico, entre eles estão: disjuntores e fusíveis (proteção contra corrente de sobrecarga e curto-circuito); Diodos de bypass e de bloqueio (evita que uma célula com baixo rendimento interfira no desempenho das outras); aterramento e proteção contra descarga atmosférica; baterias (armazenam energia produzida, suportando o período de baixa geração); e, também, sistemas de monitoramento e identificação de falhas.

De acordo a COPEL (2016), seu primeiro estudo para aproveitamento da energia solar foi feito em 1994, em 1996 foi feita a instalação de uma central fotovoltaica para carregamento de baterias para iluminação de 35 casas, em 1997 foi realizado o projeto de Conservação de Energia na Ilha do Mel, depois em outras 12 comunidades e assim foi se 
expandindo a tecnologia para diversas regiões do Paraná. Foram empregados esforços no sentido de divulgar esta tecnologia dentro e fora da Copel, através de seminários, feiras, cursos e folhetos, mostrando a ideia da empresa de utilizar novas tecnologias para o incremento de sua eficiência aliada à preservação do meio ambiente.

No Paraná, como é mostrado no Atlas de Energia Solar, apresentado na Figura 3, há uma maior incidência solar na região noroeste, o que explica o crescimento da geração de energia fotovoltaica nas microrregiões de Maringá, Paranavaí, Cianorte, Campo Mourão e Umuarama. Outros dois motivos podem explicar o aumento da demanda: o crescimento na oferta de financiamentos para sistemas fotovoltaicos e a diminuição no preço dos equipamentos (AGROLINK, 2019).

Figura 3 - Atlas Solar do Paraná

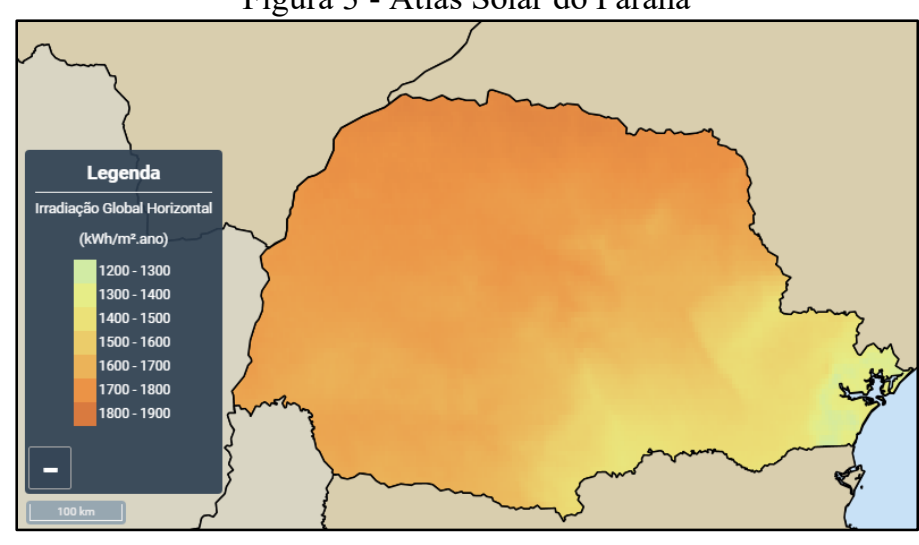

Fonte: Tiepolo (2017).

\subsection{CONCLUSÕES PARCIAIS DO CAPÍTULO}

Estudos realizados pela ANEEL (2002) e pelo Ministério de Minas e Energia/Empresa de Pesquisa Energética (2018) apontam uma descentralização efetiva no setor de geração elétrica nos próximos anos. A grande redução de custos de geração distribuída, aliada ao posicionamento das centrais perto dos consumidores finais, traz um contínuo benefício para o investidor, tornando atrativa e eficiente tanto para o produtor rural como para o setor elétrico do país.

A energia fotovoltaica vem sendo a fonte renovável com maior perspectiva de crescimento para os próximos anos, pela sua disseminação na sociedade e custo decrescente. Porém, com o autoconsumo e geração compartilhada, outras fontes renováveis como biomassa, hidrelétrica e eólica também tomam espaço no planejamento de geração 
descentralizada futura (Ministério de Minas e Energia/Empresa de Pesquisa Energética, 2018).

Outro fator a ser considerado é a facilidade de instalação destes tipos de fontes mencionados e redes de microgeração em locais de difícil acesso, evitando transtornos em caso de rompimento da transmissão, reduzindo custos e perdas na linha. 


\section{REDES INTELIGENTES}

Neste capítulo são utilizadas referências bibliográficas e técnicas do fabricante de equipamentos e sistemas elétricos utilizados para microrredes.

\subsection{CARACTERÍSTICAS}

\subsubsection{MOTIVO PARA SE TER UMA REDE INTELIGENTE}

Microrredes estão se tornando soluções predominantes por uma boa razão, a de que são uma abordagem moderna para resolver vários desafios relacionados à energia. Porém, a sua natureza única pode atrapalhar os mais experientes engenheiros e equipes de grandes concessionárias.

Segundo Huayllas (2015), uma microrrede pode ser composta por uma ou mais fontes associadas a uma carga, podendo operar de forma independente ou ligada à rede de distribuição principal. Para o consumidor, uma microrrede tem o objetivo de reforçar a confiabilidade, aumentar a eficiência e melhorar a qualidade da tensão. A estrutura de uma microrrede pode variar de acordo com a carga e com as fontes de energia disponíveis.

\subsubsection{PROBLEMAS A RESOLVER}

Os problemas que a construção de uma microrrede visa resolver estão relacionados a interrupções na rede de distribuição que geram custos adicionais, implementação de novas tecnologias e preocupações sociais emergentes que estão causando ruptura na indústria e à infraestrutura existente que não é projetada para mudanças rápidas.

Em relação às interrupções na rede de distribuição, são levados em consideração: a satisfação do cliente, o qual, nessa era digital, espera estar conectado à rede em todos os momentos, ou seja, até mesmo interrupções de curta duração são cada vez mais inaceitáveis; o tempo destrutivo, sendo este um desafio imprevisível, desastres naturais podem causar grandes danos e pra isso existem tecnologias que podem fortalecer a rede e melhorar a resiliência; e desafios geográficos, nos quais estão relacionadas topologias, como florestas e montanhas, que podem dificultar ou tornar caro o fornecimento de energia confiável (S\&C, 2018). 
Um evento que ocorreu em 2009 no Brasil é destacado por Huayllas (2015), quando ocorreu um blecaute, sem causas definidas, na usina de Itaipu e afetou várias cidades das regiões Sudeste, Sul, Centro-Oeste e Nordeste, além de aproximadamente 90\% do território paraguaio. Essa interrupção de fornecimento de energia atingiu vários setores, como indústrias, hospitais, instituições acadêmicas, iluminação pública e sistemas de comunicação. Além deste, também ocorreram eventos similares em 2003 na Europa, quando o sistema elétrico Italiano e parte da Suíça ficaram sem energia; em 2005 na Indonésia e; em 2012 na Índia, onde mais de 600 milhões de pessoas ficaram sem eletricidade por dois dias.

$\mathrm{Na}$ questão de novas tecnologias e preocupações sociais, estão em destaque: a deserção das redes tradicionais, podendo ser observado que atualmente muitos clientes optam por gerar sua própria energia para reduzir o custo e controlar a confiabilidade, usando a rede elétrica somente como energia reserva; a redução na emissão de carbono, pela qual há uma pressão crescente com objetivo de diminuir a emissão de gases nocivos e utilizar energia oriunda de fontes renováveis; estratégias de modernização da rede, mudando de uma geração centralizada para uma descentralizada; e novas tecnologias de geração de energia, que promovem impactos nos planos antigos de geração de energia, os quais não consideram o fato de que usinas de carvão e usinas nucleares estão sendo rapidamente substituídas por fontes de energia renovável e geração por gás natural (S\&C, 2018).

Segundo a S\&C (2018), quando se enfatiza a infraestrutura existente, são considerados: a mudança dos padrões de uso de energia pelo cliente, que deixou de ser somente o uso na residência e tarefas simples e passou a participar da rede de novas formas, tais como o uso de carros elétricos e a geração distribuída; a geração mais perto das cargas, que deixou de ser centralizada com o fluxo em direção às extremidades da rede e passou a possuir um fluxo bidirecional com fontes de energia localizadas em diversas partes da rede; e o envelhecimento da infraestrutura da rede de distribuição, a qual possui muitas partes em que se está com a capacidade sobrecarregada e exige atualizações ou até substituição, fazendo com que as concessionárias procurem maneiras de prolongar a vida dos equipamentos e adiar os custos de reposição.

\subsubsection{ANÁLISE DE UTILIDADE: TENDÊNCIAS E DESAFIOS COMUNS}

A UtilityDIVE (2016 apud S\&C, 2018) traz números, relacionados a região da América do Norte, que mostram a tendência atual no mercado de energia. É mostrado que 97\% das concessionárias acreditam que o seu modelo de negócios precisa mudar, 74\% das 
concessionárias relatam ver crescimento de carga mínima ou estagnada em seu território, 32\% das concessionárias dizem que o seu maior desafio relacionado ao fornecimento de energia em constante mudança é a integração confiável de recursos renováveis variáveis e distribuídos, $16 \%$ das concessionárias relatam que a deserção de carga está entre os três principais desafios, $37 \%$ das concessionárias dizem que a integração entre fontes renováveis está entre os três principais desafios e $38 \%$ das concessionárias dizem que o envelhecimento da infraestrutura está entre os três principais desafios.

\subsubsection{CONCEITO DE MICRORREDE}

A S\&C (2018) conceitua a microrrede como um grupo de cargas interconectadas e recursos de energia distribuídos dentro de limites elétricos definidos, que atuam como uma única entidade controlável em relação à rede. Uma microrrede pode se conectar e desconectar da rede para permitir que ela opere em uma rede conectada ou em modo de ilha, o que é mostrado esquematicamente na Figura 4.

Figura 4 - Modo de operação de uma microrrede

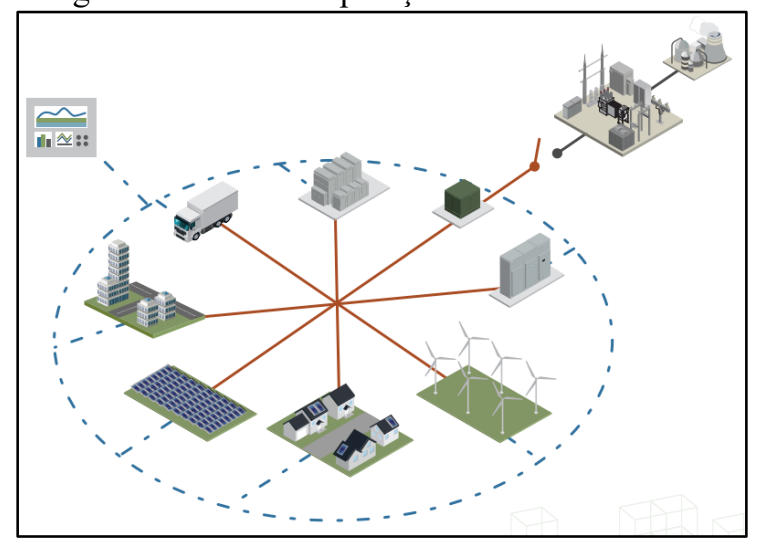

Fonte: S\&C (2018)

Huayllas (2015) define o modo de operação conectado à rede como uma forma de oferecer suportes reativos a rede, controlando a tensão local e injetando potência ativa na mesma. O modo de ilha é dividido em dois modelos, o planejado, o qual resulta na geração de pequenos transitórios de tensão e, apesar de alguns possíveis problemas de desequilíbrio entre carga e geração, é um modo atrativo para os consumidores no ponto de vista econômico, e o forçado, que ocorre devido à presença de falhas na rede de distribuição pela presença de perturbações. 


\subsubsection{POSSÍVEIS SOLUÇÕES}

$\mathrm{Na}$ Tabela 1 são apresentadas algumas soluções que podem ser tomadas relacionadas ao fornecimento de energia, todas elas acompanhadas com os seus pontos positivos e negativos.

Tabela 1 - Prós e Contras para diferentes soluções para fornecimento de energia

\begin{tabular}{|c|c|c|}
\hline SOLUÇÃO & PRÓS & CONTRAS \\
\hline NÃO FAZER NADA & Sem nenhum custo hoje & $\begin{array}{l}\text { Torna-se caro a longo prazo } \\
\text { pois problemas crescem e ainda } \\
\text { causam interrupções }\end{array}$ \\
\hline $\begin{array}{l}\text { REPROJETAR A } \\
\text { INFRAESTRUTURA } \\
\text { EXISTENTE }\end{array}$ & $\begin{array}{l}\text { Obter exatamente o que você } \\
\text { quer e o que você precisa }\end{array}$ & $\begin{array}{l}\text { Extremamente caro e } \\
\text { demorado, pode gerar } \\
\text { interrupções com frequência } \\
\text { para os clientes locais durante a } \\
\text { construção }\end{array}$ \\
\hline $\begin{array}{l}\text { GRANDES } \\
\text { CAPACITORES E } \\
\text { VOLANTES }\end{array}$ & $\begin{array}{l}\text { Amortece ou equilibra picos } \\
\text { de carga }\end{array}$ & $\begin{array}{l}\text { Caro e fornece apenas alguns } \\
\text { segundos de energia de back- } \\
\text { up }\end{array}$ \\
\hline USINAS DE PICO & $\begin{array}{l}\text { Pequenas, precisam ligar } \\
\text { somente quando a carga } \\
\text { excede a geração primária } \\
\text { ou quando um nível de } \\
\text { importação seja atingido }\end{array}$ & $\begin{array}{l}\text { Caro, não pode ser } \\
\text { dimensionado ao longo do } \\
\text { tempo para atender as } \\
\text { necessidades de mudança, além } \\
\text { de contribuir com emissão de } \\
\text { carbono }\end{array}$ \\
\hline MICRORREDES & $\begin{array}{l}\text { Solução escalável, } \\
\text { comprovada em campo que } \\
\text { podem ser dimensionadas } \\
\text { para diversas necessidades e } \\
\text { incorporar fontes renováveis, } \\
\text { garante a confiabilidade da } \\
\text { energia, reage } \\
\text { automaticamente quando há } \\
\text { um problema de distribuição } \\
\text { e pode oferecer várias } \\
\text { vantagens econômicas. }\end{array}$ & $\begin{array}{l}\text { Caro, sistemas complexos } \\
\text { podem exigir mais tempo para } \\
\text { projetar e instalar do que outras } \\
\text { soluções }\end{array}$ \\
\hline
\end{tabular}




\subsubsection{MERCADO DE MICRORREDES}

Em pesquisa realizada, levando em consideração o pensamento das concessionárias relacionado a microgrids, a UtilityDIVE (2016 apud S\&C, 2018) apresenta números, relacionados a região da América do Norte. É mostrado que 19\% das concessionárias estão buscando oferecer microrredes como um serviço aos clientes, $12 \%$ das concessionárias estão investindo mais em microrrede do que em outras tecnologias, 34\% das concessionárias acreditam que devem investir mais em microrredes, 91\% das concessionárias esperam que tanto a geração distribuída quanto a energia solar em escala pública aumentem suas futuras combinações de combustível e $60 \%$ das concessionárias acreditam que a parceria com fornecedores terceirizados é a melhor maneira de construir um modelo de negócio envolvendo geração de energia distribuída.

\subsubsection{BENEFÍCIOS E UTILIDADES DE MICRORREDES}

É citado pela S\&C (2018) alguns benefícios e utilidades relacionados a microrredes, são esses:

- Integração Renovável: Incorpora as fontes renováveis e suaviza a geração variável;

- Black Start: Potência de iniciação e sincronização da frequência das fontes, com a capacidade de iniciar o sistema sem estar conectado à rede;

- Ilhamento: Operação de forma independente da rede;

- Venda de energia: Possibilita a venda de energia na taxa de varejo contra o preço de atacado;

- Picos de energia: Reduz o alto nível de consumo de energia;

- Suporte de tensão: Mantém a tensão consistente através da variação de potência reativa;

- Reserva: Fornece energia para cobrir em casos de perda de geração primária;

- Qualidade: Proteger cargas de eventos momentâneos, como interrupções de energia e quedas e aumentos de tensão;

- Mudança de tempo de energia: Guarda quando o custo de energia é baixo e usa quando os custos são elevados;

- Capacidade Local: Fornece energia em áreas restritas da rede de distribuição;

- Confiabilidade: Cargas de apoio quando a rede perde energia; 
- Fluxo de potência ótimo: Corrige continuamente a geração de carga;

- Regulação de frequência: Frequência de rede balanceada fornecendo carga ou geração;

- Diferimento de distribuição: Adiar investimentos em ativos de distribuição;

- Resposta de frequência: Equilibra a frequência rapidamente após uma mudança repentina de consumo ou geração de energia;

- Otimização econômica: Realiza o despacho ideal de fontes de geração nos modos conectados à rede e de ilhamento.

\subsubsection{VALOR DE UMA MICRORREDE}

Dar um valor para uma microrrede é um desafio pois não há uma fórmula simples capaz de capturar todas as microrredes. Cada local possui problemas únicos que microrredes podem ajudar a resolver. Microrredes podem ser concebidas de diferentes maneiras para entregar um conjunto exclusivo de serviços.

Para a S\&C (2018), deve-se começar tomando uma decisão holística a partir das três perspectivas a seguir:

- Comparação entre as alternativas: A construção da microrrede não é simplesmente por isso ser tendência na indústria. Provavelmente, existem problemas que precisam dessa abordagem mais cedo ou mais tarde. Como podem ser consideradas outras soluções, o custo de uma microrrede não pode ser comparado a um investimento nulo;

- Imagem a longo prazo: Uma razão de uma microrrede e os elementos dentro dela possuírem um alto custo é que são construídos para operar durante várias décadas e se adaptarem a mudanças futuras. Os custos atuais são analisados com maior precisão se vistos de maneira espalhada durante a vida útil do projeto, em torno de 20 anos;

- Soma de fluxo de valor: Como o valor de uma microrrede é proveniente de várias fontes, todos os fluxos de valor devem ser entendidos, quantificados e acrescentados para cada projeto individual. Alguns desses fluxos podem ser determinados através de cálculos simples, mas a avaliação do valor de evitar eventos catastróficos de baixa probabilidade é menos direta. 


\subsection{ESTRUTURA DE PROJETO PARA UMA MICRORREDE}

Para o estabelecimento de uma microrrede são necessários alguns procedimentos. $\mathrm{O}$ planejamento e levantamento de dados energéticos da propriedade são fundamentais. Segundo a S\&C (2018) a execução de um projeto de implementação de uma microrrede segue 7 passos essenciais:

- $\quad$ Avaliação de viabilidade: Cada microrrede possui característica de geração e operação diferente, desta maneira o estudo do impacto financeiro é necessário para cada projeto. Componentes do sistema como hardwares e softwares mudam de uma planta para outra, desta forma além da análise financeira para o futuro investimento, se faz necessário o estudo de mercado e o retorno do capital investido em longo prazo;

- $\quad$ Projeto do sistema: Totalmente atrelada a avaliação de viabilidade, esta etapa de projeto visa a escolha das tecnologias que serão implementadas, tipos, tamanhos, localização e métodos de integração entre os sistemas;

- $\quad$ Planejamento financeiro: Nesta etapa define-se as formas de investimento, os benefícios, o retorno para quem implementou o projeto, o capital necessário para a operação do sistema e se haverá investimento de terceiros, o que surge como uma boa alternativa quando não há a quantia necessária para a projeção desejada;

- $\quad$ Projeto de engenharia: Para a conclusão com êxito de um projeto deste porte se faz necessário um certo nível de experiência com microrredes e familiaridade com sistemas de distribuição, possibilitando uma interconexão dos sistemas eficaz e segura;

- Construção: A instalação do sistema exige uma prévia experiência com trabalho em ambientes eletrificados, a noção de como e quando agir é extremamente importante para segurança tanto do sistema quanto dos indivíduos envolvidos na obra. $\mathrm{Na}$ aquisição dos equipamentos é importante orçamentar os custos operacionais, ciclo de vida e custo de implantação;

- Comissionamento do Sistema: Nesta etapa se realiza os testes de funcionamento da rede, verificação de geração e inspeção do local. A parte de treinamento de pessoas responsáveis pela operação da rede após a finalização do projeto também é realizada aqui;

- Operação e otimização: Além da manutenção regular, para manter uma microrrede operando com desempenho de alto nível requer a construção de controladores especificamente para micro redes. A utilização destes equipamentos pode maximizar a 
eficiência do sistema, utilizando previsões de tempo, análise de mercado e venda de energia e dados de desempenho do sistema.

Dentro deste contexto, a estrutura das microrredes se dividem em 5 grandes grupos:

- Ativos Existentes: Compreende todas as cargas existentes, fontes geradoras e distribuição de serviço público. A definiç̧ão de como a rede irá operar juntamente com estes três elementos citados, irão determinar a tecnologia a ser adotada para atingir os resultados esperados;

- Hardware: Aqui situa-se todos os tipos de tecnologias empregadas para a operação da microrrede. Estas tecnologias, como já citado, serão escolhidas a partir dos critérios de operação desejados. Autores como Gungor et al. (2011) evidenciam a importância da comunicação para os sistemas de geração distribuída e disponibilizam estudo sobre as tecnologias disponíveis;

- Serviços de integração: Segundo Fang et al. (2012), o sistema de infraestrutura inteligente integra informação e comunicação. Neste sentido nota-se que uma microrrede não funciona sem uma integração estável e eficiente, sendo essencial para garantir que hardware, software e controles reajam de forma rápida e inteligente a oscilações do sistema;

- Controles: O cérebro por trás da operação da rede, os controladores são responsáveis pela coordenação dos componentes do sistema. Os controladores operam em três níveis, em nível de ciclo onde se detecta e comunica-se eventos de forma instantânea na microrrede, em nível de segundos onde ocorre a tomada de decisão a partir dos dados coletados e por fim em nível de horas, onde é permitido o operador da microrrede realizar mudanças nos critérios de operação;

- Serviços de implantação: São o conjunto de serviços e ações desde a implementação da rede até sua operação em longo prazo. Após a construção do sistema é necessário tomar medidas para garantir a operação contínua de toda a rede, providenciando e preparando mão de obra para manutenção regular, reduzindo possíveis problemas que aparecem no decorrer dos anos.

Em muitas propriedades, os projetos iniciais partem de fontes geradoras já instaladas no local, influenciando na escolha de equipamentos do sistema. A interligação destas fontes que já estavam em operação, pode acarretar em necessidade de hardwares sobressalentes, como relés, medidores e outros equipamentos de comunicação para a subestação do local, ou ainda modificações no sistema de integração. 
Novas formas de energia não podem simplesmente serem conectadas a um sistema microrrede já instalado, para sua conexão é necessário a implementação de equipamentos de interconexão, nesta nova fonte, compatíveis com os já existentes.

Com um sistema conectado, é necessária uma atenção extra com a segurança da rede contra ataques cibernéticos. A invasão da rede ou a infecção da mesma por malwares pode causar danos irreparáveis, deste modo é recomendado a terceirização do serviço para uma empresa especialista no assunto.

Em muitos dos casos as microrredes podem ser atendidas usando apenas recursos de energia distribuídos. Embora o armazenamento de energia forneça infinidade de benefícios e flexibilidade para uma microrrede, nem sempre é necessário. Sendo assim, ela pode funcionar sem a necessidade de armazenamento de energia.

\subsection{MANUTENÇÃO E CULTURA}

\subsubsection{RESPONSÁVEL PELA MANUTENÇÃo E OPERAÇÃo}

Após a instalação de uma microrrede é necessária uma noção das operações relacionadas ao dia-a-dia e necessidades a longo prazo. As pessoas responsáveis pela manutenção e operação da rede devem ser pessoas com treinamento e capacitadas, então é importante saber quem fica responsável pelo monitoramento e solução de problemas. As soluções mais comuns são fornecidas por três principais opções, que são: o próprio consumidor, alguma empresa especializada em serviços de monitoramento e a empresa que forneceu a integração (S\&C, 2018).

\subsubsection{ARMADILHAS E ERROS COMUNS}

De acordo com a S\&C (2018), empresa especializada no seccionamento, proteção e controle de sistemas de energia elétrica é importante estar atento a alguns pontos que geralmente acarretam no mal funcionamento desses sistemas, que são:

- Não monitorar o sistema: Mesmo com a construção perfeita de um sistema, ele pode parar de funcionar se não for inspecionado regularmente. Questões simples como baterias e limpeza devem ser feitas de maneiras periódicas pois sua negligência pode levar a falha do sistema; 
- Não designar responsáveis: Se a manutenção depende do dono da propriedade ou de terceiros, saber quem se responsabiliza por qual tarefa evita cair em falhas;

- Ignorar pequenos sinais: Mesmo que a microrrede tenha sistemas de redundância, ignorar pequenos sinais pode rapidamente se tornar em grandes problemas dentro de todo o sistema;

- Não ter planos de manutenção: Lidar com vários tipos de componentes de diversos fornecedores requer flexibilidade e cuidado com demandas individuais, que inclui atualização de softwares e correção de bugs, especialmente pelo aprimoramento contínuo de sistemas de segurança;

- $\quad$ Negligenciar peças de reposição: Alguns equipamentos são muito caros e sua manutenção não é trivial. Por isso é importante se manter um estoque de peças para facilitar eventuais reposições;

- Treinamento de funcionários: A rotatividade de funcionários é algo natural, mas é necessário se criar um treinamento simples e compreensivo para o entendimento da rede a fim de que o conhecimento da rede não desapareça junto aos ex-funcionários.

\subsubsection{EVENTUAIS EXPANSÕES}

Para se fazer eventuais expansões é necessário passar por três principais barreiras: espaço, carga e controle, mostradas na Tabela 2.

Tabela 2 - Barreiras para expansão.

\begin{tabular}{|c|c|c|}
\hline BARREIRAS & NÃO VIÁVEL & VIÁVEL \\
\hline ESPAÇO & $\begin{array}{l}\text { Não há espaço físico ou o custo é } \\
\text { muito elevado. }\end{array}$ & $\begin{array}{l}\text { Há espaço físico adequado, o espaço } \\
\text { para expansão foi planejado ou a } \\
\text { infraestrutura existente pode ser } \\
\text { utilizada. }\end{array}$ \\
\hline CARGA & $\begin{array}{l}\text { Carga adicional pode debilitar o } \\
\text { funcionamento e sobrecarregar o } \\
\text { sistema. }\end{array}$ & $\begin{array}{l}\text { O sistema pode suportar carga } \\
\text { adicional. }\end{array}$ \\
\hline CONTROLE & $\begin{array}{l}\text { Dependendo da nova expansão o } \\
\text { sistema como um todo deverá ser } \\
\text { recodificado e reconfigurado, pois } \\
\text { basicamente, está sendo } \\
\text { implementada uma nova rede. }\end{array}$ & $\begin{array}{l}\text { Estão sendo adicionados novos } \\
\text { equipamentos em situações ou } \\
\text { cenários próximos aos já existentes, } \\
\text { então a implementação é fácil e } \\
\text { parecida com a existente. }\end{array}$ \\
\hline
\end{tabular}




\subsection{CONCLUSÕES PARCIAIS DO CAPÍTULO}

Assim sendo, ficam evidenciados os principais conceitos e características de uma microrrede, pontos que são extremamente importantes para se decidir se a implementação da rede é de fato a melhor solução para cada realidade em questão. Além disso, foram apontados prós e contras das diversas ferramentas, assim como seus respectivos benefícios e utilidades possíveis da microrrede.

Caso haja a necessidade real da construção e implementação de uma microrrede, foi demonstrado o seu passo a passo, que abrange desde o levantamento de dados para a avaliação de sua viabilidade, até a operação e cuidados da rede em funcionamento, não esquecendo também das tecnologias e processos que compõe e ficam nos caminhos intermediários entre esses dois passos. 


\section{ESTADO DA ARTE}

\subsection{CENÁRIO ATUAL DE MICRORREDES E PERSPECTIVAS FUTURAS}

De acordo com a Smart Energy $G B$ (2017), organização sem fins lucrativos que faz o monitoramento e estudo de medidores inteligentes na Grã Bretanha, a implementação da distribuição inteligente de energia elétrica nas áreas rurais, visa a redução geral no consumo de energia, melhorar estabilidade, segurança do fornecimento local de energia, aumentar o uso de geração renovável, estimular o uso de energia produzida localmente e reduzir o custo para o consumidor e a pobreza de combustíveis.

A maioria dos projetos destinados à zona rural focam na resolução de desafios específicos de fornecimento de energia, problemas estes muitas vezes relacionados com a infraestrutura da rede. Muitos desses problemas são resolvidos com o uso de microrredes, gerando autonomia.

Os projetos utilizados como exemplo foram retirados de um jornal periódico intitulado "A smart energy future for rural areas (2017)" que retrata as perspectivas e usos da energia inteligente nos projetos: ACCESS na Escócia, Energy Local no País de Gales, Eigg Eletric na Escócia, NINES na Escócia e Heat Smart Orkney na Escócia e Welcome to our Woods no País de Gales.

O ACCESS é implementado nas ilhas de Mull e Iona, na Escócia, que implementa tecnologias inteligentes para balancear a geração local renovável e a demanda de energia elétrica das casas e edifícios comerciais das ilhas. Por restrições na rede local e falta de acesso aos dutos de gás, as casas em comunidades rurais estão pagando mais para aquecer suas casas. O projeto ACCESS visa, através do uso de energias renováveis que existem em abundância nas ilhas, criar soluções por meio de um distrito virtual de aquecimento, para substituir os métodos convencionais e, às vezes, inacessíveis. Esse projeto visa facilitar e possibilitar o uso de energias renováveis produzidas localmente, focando maior autonomia e confiabilidade da produção local.

A Smart Energy GB (2017) apresenta o projeto piloto Cyd-ynni: Ynni Lleol (2012) (Co-energia: energia local), em Bethesda no País de Gales, focando no aproveitamento da energia hidrelétrica local e a conscientização sobre o uso da energia através do uso de métodos avançados de monitoramento, fornecendo uma energia mais barata aos moradores locais. Todas as casas participantes do projeto têm um medidor avançado instalado que mede a energia utilizada a cada meia hora. Esse uso inteligente dos dados acarreta em um uso mais 
consciente da energia, provendo informações sobre os melhores horários para o uso da energia e relatórios mensais sobre o consumo de cada residência. Os projetos voltados para a área rural apresentados aqui são consistentes nos objetivos de adequar o uso de energia aos melhores horários, incentivar e facilitar a produção através de fontes renováveis, e para isso se utilizam de tecnologias inteligentes e redes.

O Eigg Eletric (2008), da ilha de Eigg na Escócia, é, de acordo com a Smart Energy $G B$ (2017), uma companhia gerenciada e mantida pela comunidade, que fornece eletricidade para os moradores da ilha através da integração de geração de energia a partir de fontes renováveis como água, sol e vento. Como a ilha não é conectada ao fornecimento de energia do continente, o projeto foi concebido com o intuito de prover uma fonte confiável de energia para os residentes, sendo iniciado no ano de 2008. Como o sistema é totalmente autônomo, ele requer monitoramento e um gerenciamento cuidadoso, a fim de garantir energia igual a todos os moradores.

Os projetos apresentados demonstram o impacto do uso de redes inteligentes e tecnologias de monitoramento e gerenciamento inteligente de energia nas comunidades rurais, e apesar de serem projetos emergentes e em desenvolvimento, seu impacto para a as comunidades locais fica claro.

As tecnologias para redes inteligentes têm um importante papel em dar suporte para mudanças comportamentais, reduzindo o consumo e aumentando a eficiência e a segurança das fontes de energia locais, além de possibilitar o uso de energias renováveis como recurso para benefício da população local. A Smart Energy GB (2017) apresenta que nos locais mais remotos, o papel da tecnologia inteligente é de manter um balanço delicado na questão de demanda e oferta de energia, ao passo que em outros locais o papel é de possibilitar a entrada de fontes renováveis para substituir a necessidade do uso de combustíveis fosseis. Os exemplos de utilização de novas tecnologias para o uso inteligente de energia são muitos e variados, o que só demonstra seu potencial e importância.

\subsection{CENÁRIO NACIONAL}

A matriz energética brasileira tem alterado com o crescimento das fontes alternativas, como solar, eólica e biomassa. Pela topografia nacional, há um grande favorecimento para geração de energia a partir de recursos hídricos, porém com o avanço tecnológico tem aumentado rapidamente o uso de energia solar fotovoltaica (LEÃO, 2009, apud GOINSK, 2019). 
O sistema elétrico nacional possui sistemas de automação e supervisão na área de geração e transmissão das companhias de energia. Porém, nas redes de distribuição (tensão menor que 34,5 kV) a realidade é outra. Mikos (2014, apud ABOBOREIRA; CRUZ, 2016) enfatiza que devido a complexidade e o número elevado de consumidores, a implantação da automação nesse sistema é mais complexa e a gestão ainda é realizada da forma convencional.

As concessionárias de energia vêm investindo na automação das redes de distribuição, com o desenvolvimento de sistemas integrados para maximizar a eficiência da operação. Nesse contexto de melhora, está envolvida a ideia de redes inteligentes, com o objetivo de aumentar o nível de automação, tornando melhor e mais confiável o fornecimento de energia (LEÃO, 2019).

Rivera (2013, apud ABOBOREIRA; CRUZ, 2016) traz como principais motivadores para a implantação de redes inteligentes no Brasil a eficiência comercial e energética, a melhora da confiabilidade do sistema elétrico, a segurança operacional e a sustentabilidade econômica e ambiental.

Um dos grandes desafios para a implantação das Redes Inteligentes no país está relacionado com o custo de implantação do sistema em larga escala, com a instalação dos sistemas de sensoriamento, telecomunicação e processamento, três pilares que são a base do Smart Grid (BOCCUZZI, 2011 apud ABOBOREIRA e CRUZ, 2016, p.117).

Somente o custo inicial com a substituição dos medidores seria de aproximadamente $\mathrm{R} \$ 25$ bilhões, visto que cada medidor inteligente custa cerca de $\mathrm{R} \$ 355$ somado a uma taxa média de instalação de R\$ 20,00 (LAMIN, 2013, apud ABOBOREIRA e CRUZ, 2016, p.117).

Além disso, há as características técnicas especiais atribuídas aos medidores, a sua baixa escala de produção e a vida útil dos medidores eletrônicos, que comparada ao do eletromecânico, projetado para funcionar por 25 anos, é menor, de aproximadamente 13 anos, segundo dados divulgados no $8^{\circ}$ Congresso Brasileiro de Metrologia, em Bento Gonçalves/RS (SARAIVA, 2015 apud ABOBOREIRA; CRUZ, 2016).

Apesar do custo e do processo lento para implantação de uma rede inteligente, esta é vista como o futuro da distribuição de energia, devido a isso são realizados estudos através de projetos pilotos que estão em desenvolvimento no Brasil, estes apoiados por concessionárias de distribuição de energia. A seguir, uma lista com alguns destes projetos, dividido por estados, com a informação da concessionária que o apoia e as cidades que estão localizados.

- Minas Gerais:

○ Cidades do Futuro (Cemig) - Sete Lagoas 
- Rio de Janeiro:

○ Cidade Inteligente Búzios (Ampla / Endesa Brasil) - Búzios;

- Smart Grid Light (Light) - Área metropolitana do Rio de Janeiro;

- Amazonas:

○ Parintins (Eletrobras Amazonas Energia) - Parintins;

- São Paulo:

- Smart Grid (AES Eletropaulo) - Barueri, Vargem Grande e Caucaia do Alto;

○ InovCity (EDP Bandeirante) - Aparecida;

- Ceará:

○ Cidade Inteligente Aquiraz (Coelce / Endesa) - Aquiraz;

- Pernambuco:

- Arquipélago de Fernando de Noronha (CELPE) - Ilha de Fernando de Noronha;

- Paraná:

- Paraná Smart Grid (Copel) - Curitiba (Fazenda Rio Grande)

\subsubsection{CENÁRIO NO PARANÁ}

O estado do Paraná é um grande aliado da geração de energia elétrica Brasileira. Dados de 2018 apontavam uma capacidade de aproximadamente 18,23 GW de geração, o estado fica em terceiro lugar no ranking nacional de geração de energia, abrangendo 10,2\% de todo o montante (OGAWA, 2018). Apesar dos 18,23 GW produzidos, cerca de $17 \mathrm{GW}$ são provenientes de $32 \mathrm{PCHs}$ e 20 usinas hidrelétricas instaladas no estado, restando um número pobre de aproximadamente 1,23 GW de geração a partir de fontes renováveis alternativas, como solar, eólica e termelétrica (OGAWA, 2018).

Para o mesmo ano de 2018, dados do IPARDES apontam um consumo para o ano, em consumidores cadastrados como rurais, de aproximadamente 2,56 mil GWh (GOVERNO DO PARANÁ, 2019). No mesmo conjunto de dados, foi apontado um número de 359.194 consumidores rurais, o que aponta uma média de consumo anual de aproximadamente 7,12 MWh por consumidor rural. Neste período, segundo Tele (2018), a distribuidora estadual de energia (COPEL), dispunha a taxa de $\mathrm{R} \$ 0,65039 \mathrm{o} \mathrm{kWh}$, para consumidores enquadrados nos dados anteriores, assim, foram gastos em média anual $\mathrm{R} \$ 4.600,00$ por propriedade rural com 
energia elétrica, montante que poderia ser investidos em outras áreas, ou ainda, em instalações de fontes distribuídas de energia.

A Companhia Paranaense de Energia - Copel - é a responsável pelas normativas e regulamentos referentes à geração distribuída e ligação de fontes de energia à rede de distribuição. Além da geração, distribuição, fiscalização e da regulamentação da energia elétrica no estado do Paraná, a Copel investe em pesquisa e desenvolvimento de novas tecnologias para o setor de distribuição e automação da rede no estado. Em parceria com a Universidade Federal de Santa Maria (UFSM), e a empresa paranaense NHS Sistemas de energias, a Copel está desenvolvendo uma solução para a otimização do uso de energia de clientes que produzem em casa sua própria energia, a proposta utiliza o Inversor Solar On Grid Híbrido combinado a uma solução de software específica (SMART ENERGY, 2020). O projeto em desenvolvimento promete entregar uma ferramenta que dá ao produtor a possibilidade de utilizar a energia gerada, armazenar ou utilizar a energia de baterias ou ainda utilizar a energia da rede de distribuição, tudo isto com comunicação direta com a rede da concessionária, que auxiliaria na tomada de decisão de quando realizar as operações.

Outro projeto piloto desenvolvido pela Copel, em parceria com Lactec, tem o foco de gerar créditos aos produtores que fornecem potência à rede de distribuição local. Para isto foi desenvolvido um sistema de controle externo que monitora o fluxo de potência de forma remota, tornando possível a adição de créditos à conta de produtores distribuídos que poderão ser utilizados em momentos de maior demanda, o que já é prática em outros países de forma mais otimizada (SMART ENERGY, 2020).

O governo do estado também investiu $\mathrm{R} \$ 820$ Milhões no programa Rede Elétrica Inteligente, que irá modernizar a distribuição da energia elétrica no estado do Paraná. Abrangendo 151 municípios, o projeto visa a instalação de medidores digitais as unidades consumidoras, que passarão a comunicar diretamente com o Centro Integrado de Operações da Distribuição da Copel, possibilitando a leitura de consumo a distância, favorecendo na redução de furtos de energia e reduzindo as intempéries e outros fatores externos do sistema (GOVERNO DO PARANÁ, 2020).

O resultado dos projetos de pesquisa realizados pela Companhia paranaense de energia pode ser observado em execuções de projetos de Smart Grid paranaenses, como o projeto piloto da cidade Fazenda Rio Grande, região metropolitana de Curitiba. 
Figura 5 - Automação de rede Projeto Fazenda Rio Grande

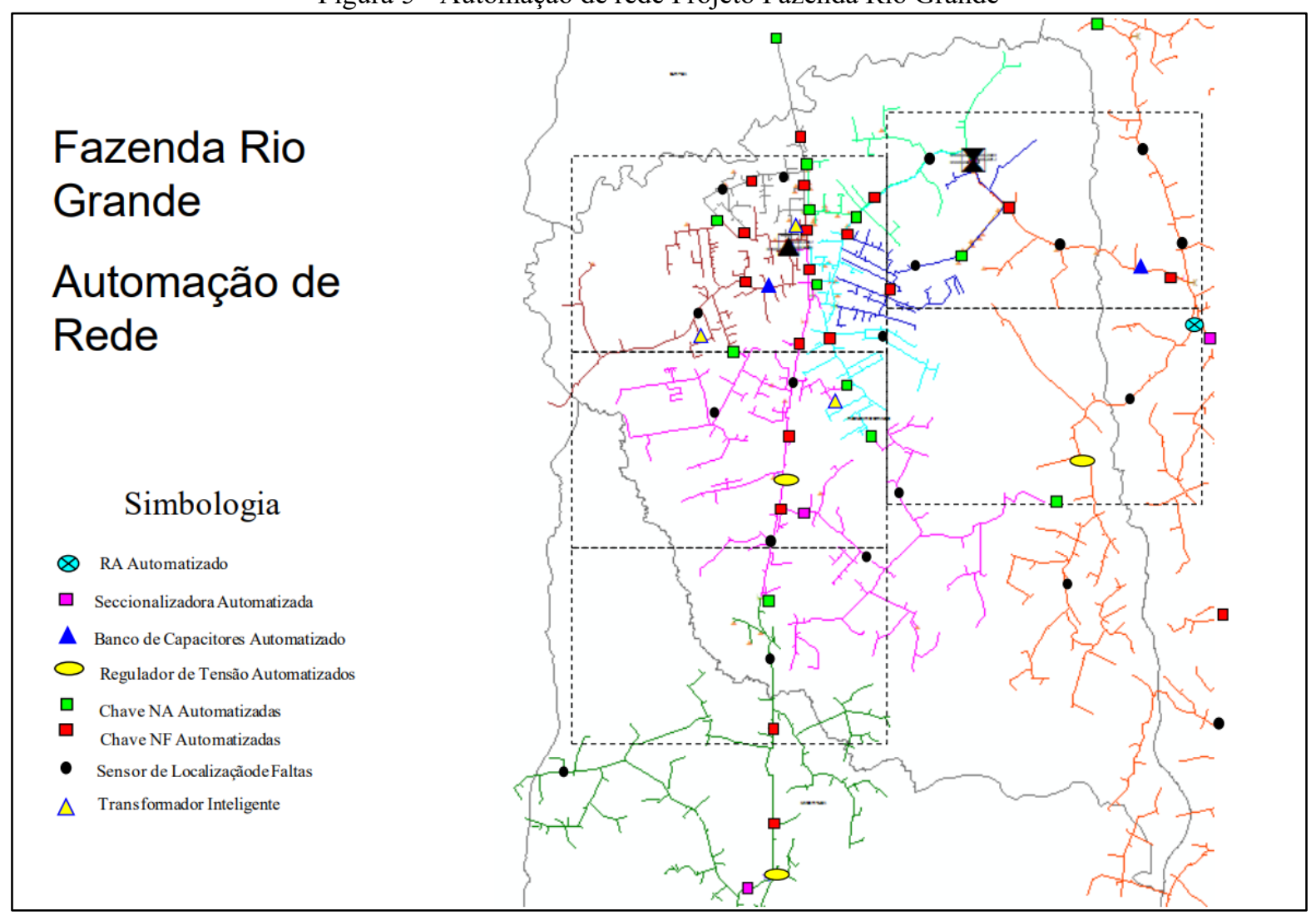

Fonte: COPEL (2014)

Como é mostrado na Figura 5, e descrito em sua legenda, o projeto conta com seccionadoras, chaves NA, chaves NF, reguladores de tensão, banco de capacitores, religadores automáticos, todos automatizados, além de sensores de localização de faltas e transformadores inteligentes. O projeto de Fazenda Rio Grande visa a implantação de sistemas Self Healing, que possibilita a rede responder automaticamente a distúrbios causados por falhas e eventos extraordinários (COPEL, 2014).

Outras medidas vêm sendo adotadas e objetivos sendo traçados pela Copel, conforme ilustrado na Figura 6, apresentada na 14 Semana de engenharia do Instituto Paranaense de engenharia, que nos torna possível a visualização do planejamento para novos projetos e desenvolvimentos da empresa distribuídos por todo o estado do Paraná (COPEL, 2014). 
Figura 6 - Objetivos e projetos Copel

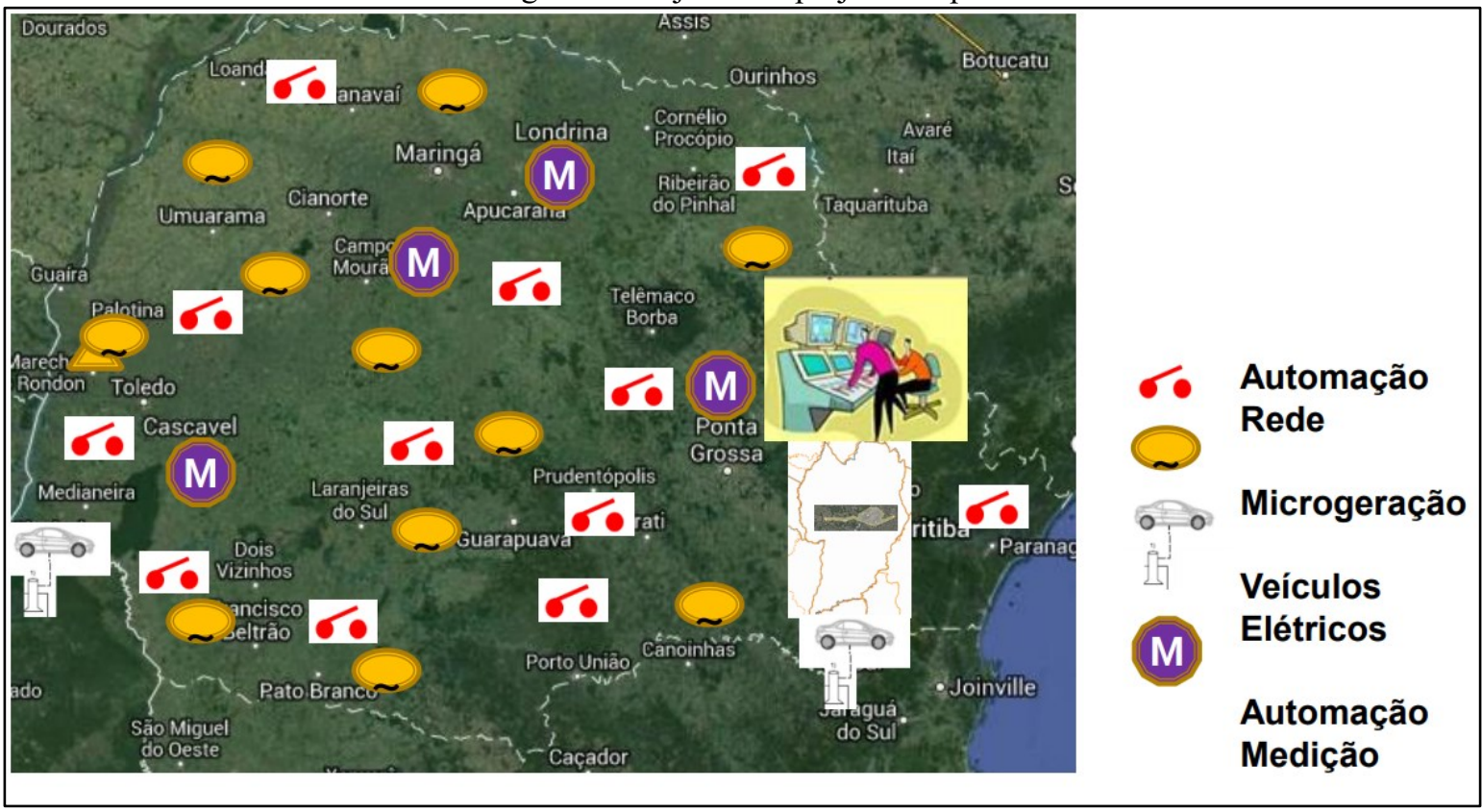

Fonte: COPEL (2014).

Na Figura 6 é mostrado algumas características do planejamento dos projetos da COPEL, que inclui a utilização de veículos elétricos, aliados com a microgeração, automação da rede e da medição em pontos estratégicos nos grandes centros urbanos.

A concretização da modernização apresentada pela COPEL na $14^{\mathrm{a}}$ semana de engenharia (COPEL, 2014) pode ser vista na cidade de Ipiranga/PR, que se tornou a primeira cidade brasileira a possuir distribuição de energia 100\% inteligente (GOVERNO DO PARANÁ, 2020). As unidades consumidoras possuem medidores inteligentes, o que possibilita o controle de gastos de energia pelos consumidores, e a estrutura da rede conta com sistema de SelfHealing, o que possibilita uma resposta rápida a falhas da rede.

\subsection{CONCLUSÕES PARCIAIS DO CAPITULO}

Para a análise do estado da arte, foram apontados alguns casos existentes e funcionais da implantação de microrredes ao redor do mundo na área rural, mostrando os seus benefícios, como o aproveitamento de fontes renováveis de energia e redução de consumo energético e a questão social intimamente envolvida nos casos reais.

Para o Brasil, é observado um crescimento na implementação de redes inteligentes, como apontam as referências citadas. Atualmente pode se dizer que o estado da arte se encontra em nível médio para nosso país, onde há a utilização de tecnologias para a 
automação das redes de distribuição de energia elétrica em regiões pontuais, mas ainda há diversas áreas menos desenvolvidas que não possuem estas ferramentas de otimização.

A implementação de projetos pilotos, realizados pelas concessionárias locais de cada estado é vista de forma benéfica para o sistema em um todo. A parceria com instituições de ensino e pesquisa possibilitam o desenvolvimento e estudo mais aprofundados de tecnologias da área que visam suprir as necessidades locais apresentadas pelas topologias, geografia e condições de operação do nosso país e, sobretudo as zonas tão diversificadas encontradas sobre todo o território.

Como visto, a Companhia Paranaense de Energia vem investindo em novas tecnologias e implementação de projetos. Um dos principais incentivos para o produtor de geração de distribuída vem sendo a possibilidade de obtenção de créditos para abatimento futuro na utilização de energia fornecida pela rede de distribuição local, um dos projetos pilotos apresentados pela Copel, que já vem sendo testado na própria companhia (SMART ENERGY, 2020). 


\section{PROTOTIPAGEM DE UMA MICRORREDE}

Tuballa (2016) apresenta como características gerais de uma rede a sua digitalização, comunicação bidirecional em tempo real, geração distribuída de energia, rede dispersa, grande volume de dados, vários sensores e monitores, ótimo monitoramento automático, controle e restabelecimento automático, segurança, proteção adaptativa, uso de sistemas de armazenamento, resposta rápida a emergências e vastas escolhas do usuário.

Neste capítulo serão apresentados alguns conceitos e sistemas importantes na implementação de redes inteligentes, em subsequência, serão apresentados fabricantes e equipamentos com as soluções mais recentes, que compõem os sistemas mencionados, fornecendo segurança, gerenciamento e controle da rede.

\subsection{DISPOSITIVOS DE PROTEÇÃO}

Os sistemas de proteção são responsáveis pela segurança na operação dos processos de geração, transmissão e distribuição de energia elétrica. Assim, todos os dispositivos utilizados para proteção, devem ser dimensionados e escolhidos de acordo com o equipamento ou sistema a ser protegido. Na elaboração de um sistema de proteção ideal, os equipamentos selecionados devem garantir sensibilidade, seletividade, velocidade, confiabilidade, disponibilidade e segurança como requisitos básicos de operação (Frazão, 2019).

A coordenação dos dispositivos de segurança é essencial para a proteção da rede de distribuição. Além da proteção, a coordenação dos dispositivos é o que possibilita a reconfiguração e isolamento de falhas em redes inteligentes. Para realizar tal demanda, é necessário ter bem definidas as zonas primárias de proteção, que são responsáveis por proteger partes específicas do sistema (Frazão, 2019).

Figura 7 - Zonas primárias de proteção.

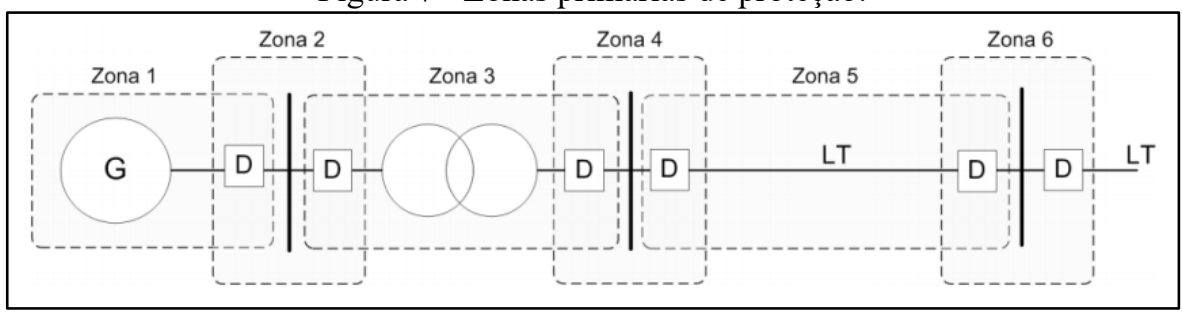

Fonte: Frazão (2019). 
Como ilustra a Figura 7, cada Zona primária de proteção engloba um equipamento ou sistema, e possui seus próprios dispositivos de proteção, sinalizados com a letra D. A Zona 1 enquadra um grupo gerador, na Zona 2, o barramento que interliga os geradores ao transformador presente na Zona 3, na Zona 4 encontra-se o barramento que interliga o transformador a linha de transmissão da zona 5 e por fim na Zona 6 encontram-se outros barramentos que interligam as várias linhas de transmissão de uma rede. Em seu livro, Frazão afirma que a sobreposição de zonas evita pontos cegos na proteção da linha, assim, para toda zona, um dispositivo de proteção deve ser instalado na entrada de tensão e na saída, em casos aplicáveis (Frazão, 2019).

\subsubsection{SISTEMAS DE PROTEÇÃO}

Os dispositivos de proteção podem ser divididos em 3 grupos: os controladores, os dispositivos de medição e os dispositivos atuadores. Os controladores, muitas vezes citados como relés, são responsáveis por analisar as informações da rede, obtidas pelos dispositivos medidores, e dar comando para abrir/fechar os dispositivos acionadores. Os dispositivos de medição são sensores de tensão e corrente, normalmente chamados de transformadores de potencial (TP), para medida de tensão, e transformadores de corrente (TC), para medida de corrente. Os dispositivos atuadores recebem os comandos dos relés e isolam falhas, protegendo as redes, os elementos mais utilizados deste grupo são (Frazão, 2019):

- Disjuntores: São dispositivos de ação eletromecânica, ou mais conhecidos como dispositivos de manobra, utilizados para isolar correntes elétricas dentro das condições normais de operação, ou em correntes muito superiores, em caso de curto circuito, sendo sua principal finalidade. Operando junto a relés de controle, a interrupção ocorre quando as bobinas de abertura/fechamento do disjuntor são alimentadas por sinais elétricos proveniente dos relés (Frazão, 2019).

- Religadores: Os religadores são dispositivos de interrupção que trabalham sem a necessidade de relés controladores para isolar a rede elétrica. Estes dispositivos possuem sensores capazes de detectar uma corrente de falta, que se persistirem por um instante de tempo configurável, a ação de interrupção é realizada. Os religadores realizam rotinas de verificação, e caso a falta tenha deixado de existir, o circuito é religado automaticamente (Frazão, 2019). 
- Fusíveis: Os fusíveis são os dispositivos de interrupção de sobrecorrente mais utilizados nas redes de distribuição primária. Este dispositivo possui um filamento interno elaborado com material termo sensível, que aquece e derrete em casos de sobre corrente, interrompendo o fluxo, e em caso de restabelecimento das faltas os fusíveis devem ser substituídos (Frazão, 2019).

- Seccionador: Os seccionadores são dispositivos de manobra utilizados para isolar o circuito protegido, porém, ao contrário dos religadores e disjuntores, os seccionadores não são capazes de realizar a interrupção em caso de sobrecorrente. Assim, estes dispositivos devem, obrigatoriamente, ser empregados aliados de dispositivos com capacidade de interrupção em faltas de sobrecorrentes.

\subsection{RECONFIGURAÇÃO AUTOMÁTICA}

O termo reconfiguração é definido por Pfitscher (2013) como a mudança na topologia da rede, através de fechamento e abertura de chaves, com o objetivo de reduzir perdas, melhorar níveis de tensão, balancear cargas e melhorar a qualidade do serviço. $\mathrm{O}$ funcionamento consiste desde um estudo, no qual são realizadas coletas de informação da rede e da carga, cálculo de fluxo de potência e a definição do grau de necessidade da reconfiguração, até a aplicação para otimização da rede.

Segundo Pfitscher (2013), a reconfiguração de uma rede pode acontecer em três situações: quando há a necessidade de atender consumidores que estão sem energia por alguma falha na distribuição, quando há a necessidade de manutenção de alguma região ou quando visa a melhora do desempenho da rede.

Sendo o evento mais prejudicial ao consumidor, as falhas podem acontecer como variações de tensão, sobrecorrentes e danos em cabos. Em consideração a estes fatores, a implementação da reconfiguração automática possibilita a identificação do trecho que contém falhas e reorganiza a rede para continuar trabalhando com eficiência, visando o abastecimento de todas as regiões que necessitam da energia elétrica.

De acordo com a S\&C (2019) as tecnologias de reconfiguração automática também apresentam baixos índices de DEC, FEC e FIC que são indicadores que a ANEEL (2012) utiliza para avaliar a qualidade relacionada ao fornecimento de energia elétrica, e são descritos como: 
- DEC - Duração Equivalente de Interrupção por Unidade Consumidora: Intervalo de tempo que, em média, no período de apuração, em cada unidade consumidora do conjunto considerado ocorreu descontinuidade da distribuição de energia elétrica.

- FEC - Freqüência Equivalente de Interrupção por Unidade Consumidora: Número de interrupções ocorridas, no período de apuração, em cada unidade consumidora ou ponto de conexão.

- FIC - Freqüência de Interrupção Individual por Unidade Consumidora: Número de interrupções ocorridas, no período de apuração, em cada unidade consumidora ou ponto de conexão.

Na comparação das estratégias comuns de proteção usadas nos sistemas, é possível se observar que a escolha de cada uma tem um impacto diferente nos principais fatores a serem escolhidos como prioritário. No nosso caso, atentarmos ao uso de tecnologias ligadas ao restabelecimento otimizado.

\subsubsection{TECNOLOGIAS HABILITADORAS}

Atualmente, existem alguns sistemas que realizam a reconfiguração automática e nesta seção são abordados alguns deles como o IntelliRupter da S\&C, o SelfHealing da Cooper Power Systems e os religadores automáticos OSM da NOJA Power, que são abordados nessa seção.

O IntelliRupter, mostrado na Figura 8, é o religador detector de falhas da S\&C que se baseia na tecnologia de PulseClosing, a qual tem seu funcionamento explicado por McCarthy (2017) como a criação de um pequeno pulso de corrente para identificação de falhas, utilizando 95\% menos energia que os testes de falha padrão. A S\&C [201-?] mostra algumas vantagens no uso deste sistema como tornar obsoleto o método de religamento convencional, diminuir os danos causados pelos testes de falha e preparar a rede para possíveis incógnitas futuras. 


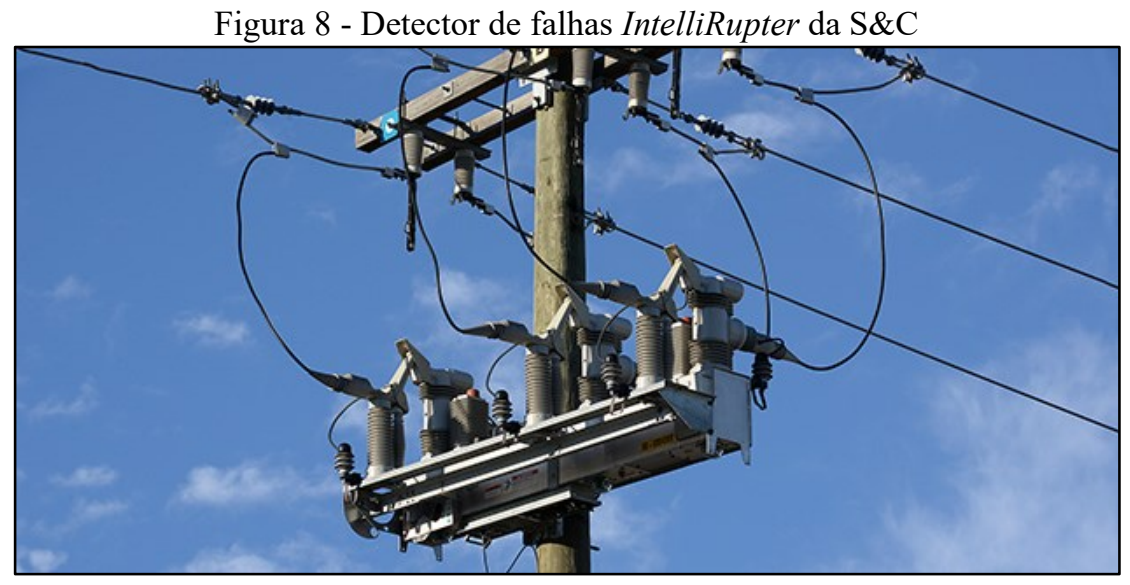

Fonte: S\&C [201-?]

A S\&C (2017) mostra os benefícios oriundos da interligação de dispositivos IntelliRupter em uma rede, dentre eles estão a melhor qualidade da energia, maior vida útil dos equipamentos, identificação e isolamento as falhas em todos os trechos sem necessidade de interromper o fluxo completo e monitoramento em tempo real destas falhas por meios de sensores precisos.

Outro dispositivo de reconhecimento de falha é disponibilizado pela S\&C (2020), o TripSaver ${ }^{\circledR}$ II Cutout-Mounted Recloser, mostrado na Figura 9, é um dispositivo que reconhece se uma falha em um segmento de uma rede é temporário ou permanente e toma uma ação baseada na sua leitura da situação. Se a falha é temporária, o segmento continua conectado a rede, porém, se a falha é permanente, o dispositivo isola aquele segmento com falha da rede de distribuição.

Figura 9 - TripSaver ${ }^{\circledR}$ II Cutout-Mounted Recloser.

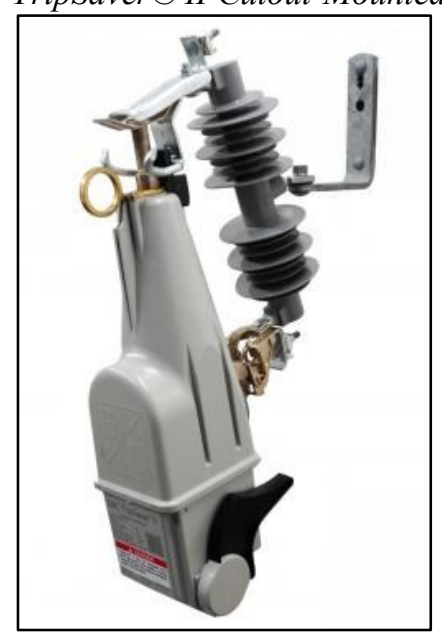

Fonte: S\&C (2020) 
O SelfHealing, solução da Cooper Power Systems, é composto por sensores, controles automatizados e software avançado, que em conjunto conseguem detectar e isolar falhas, reconfigurando a rede e garantindo assim a minimização dos impactos aos clientes.

Um dos sensores utilizados na solução da Cooper Power Systems é o GridAdvisor Série II da EATON [201-?], mostrado na Figura 10. Este sensor inteligente possui todas as funções para medição de tensão, corrente, sobrecarga e para proteção em uma única unidade, além disso, pode indicar com precisão as falhas, possui alarme de sobrecarga e indicação para interruptor manual e para manutenção.

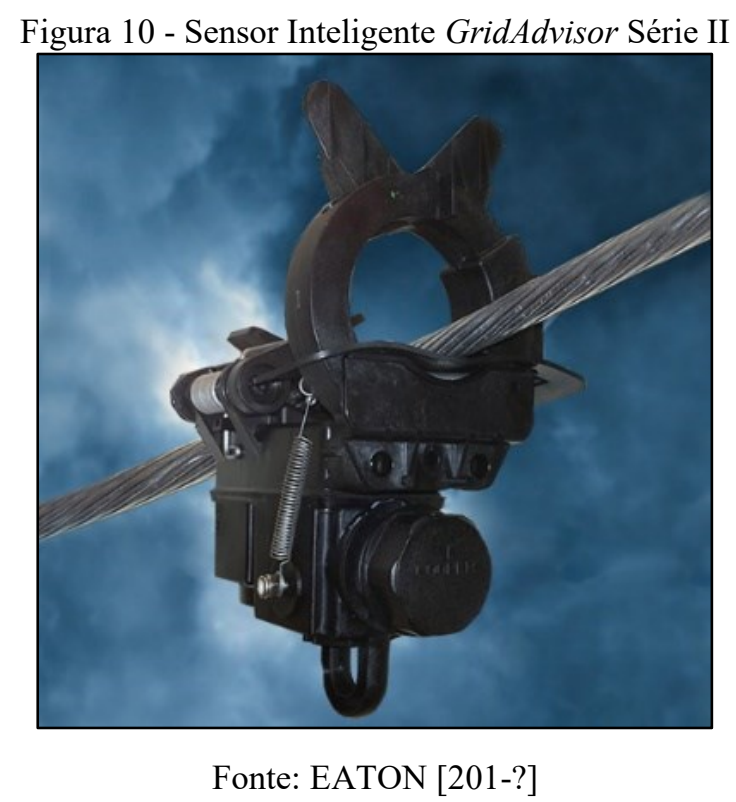

Outra ferramenta utilizada por essa solução é o software de automação YFA, o qual usa os dados gerados em tempo real pelos sensores para detectar distúrbios no sistema e reconfigurá-lo automaticamente, melhorando a confiabilidade.

A Cooper Power Systems [201-?] define o principal objetivo dessa solução como o de melhorar a confiabilidade da rede, realizando a reconfiguração dos interruptores isolando a seção defeituosa e restabelecendo o serviço para a maioria dos clientes.

Os religadores automáticos da NOJA Power, chamados de OSM, são projetados para operar em três diferentes classes de tensão $(15 \mathrm{kV}, 27 \mathrm{kV}$ e $38 \mathrm{kV})$ e podem ser trifásicos, bifásicos e monofásicos, como é mostrado na Figura 11. 
Figura 11 - Modelos de religador automático OSM

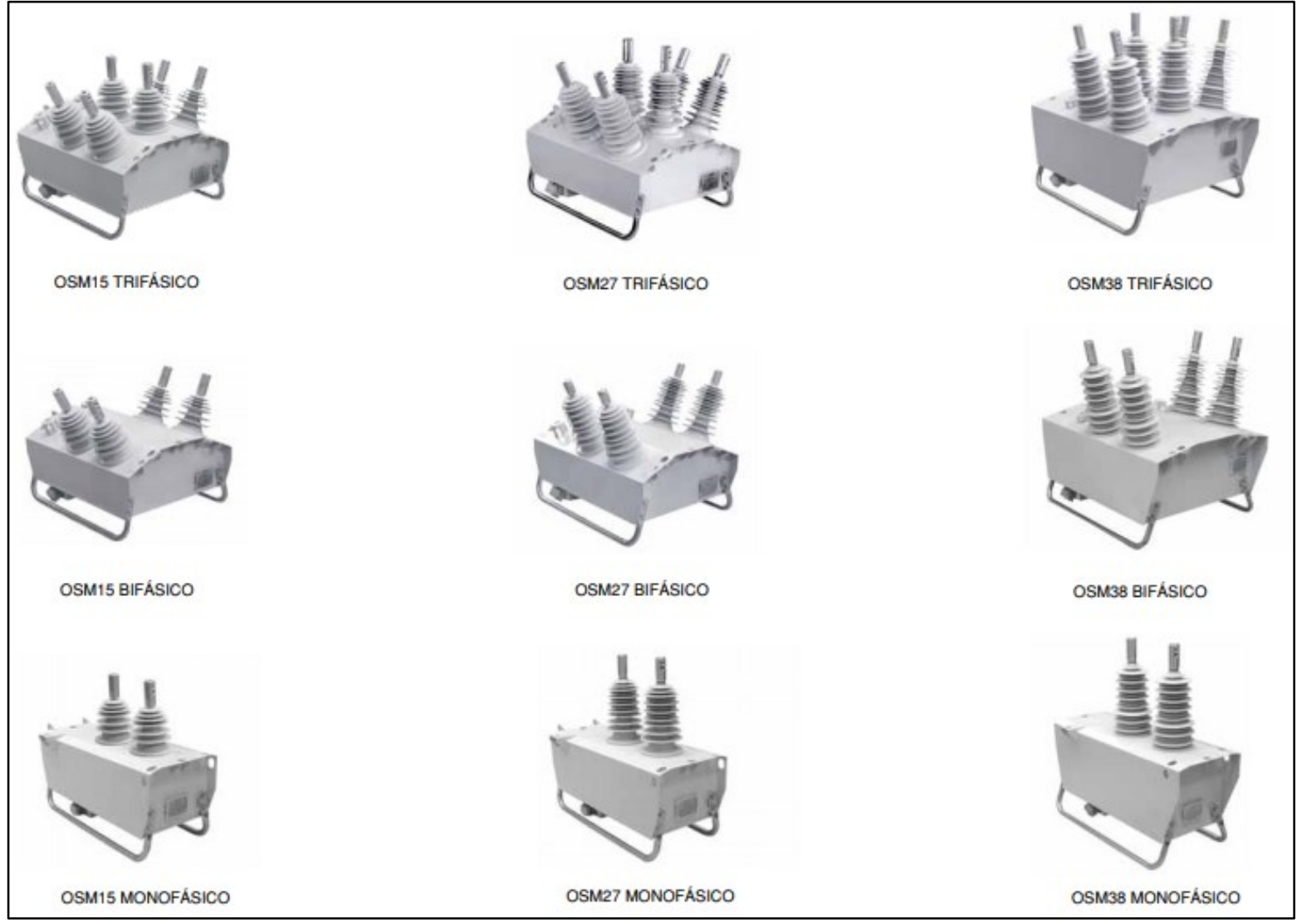

Fonte: NOJA Power [20-?]

O religador OSM é fornecido com uma cabine de controle e comunicação, a qual é responsável por algumas funções como proteção de sobrecorrente, autoreligamento, registro de dados, medição instantânea e comunicação. Essa cabine é mostrada na Figura 12.

Figura 12 - Cabine de Controle e Comunicação

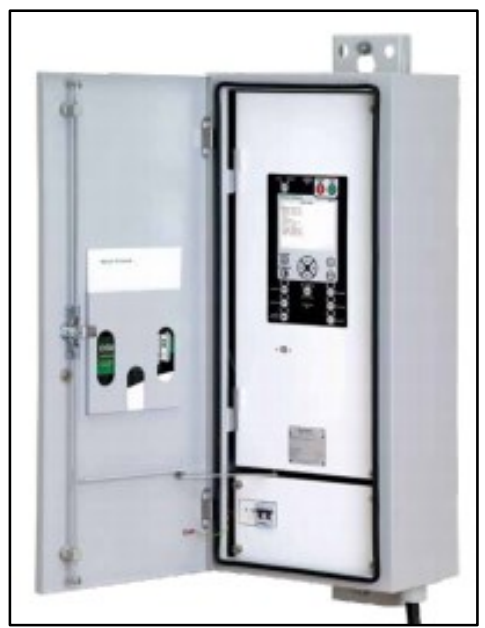

Fonte: NOJA Power [20-?]. 
A NOJA Power [20-?] define o religador como um disjuntor que dispara quando uma falha é detectada e possui a funcionalidade de permitir uma restauração automática de energia. Possui também a função que permite detectar um condutor rompido e pode funcionar em modo alarme. Complementando o sistema, há o software de automação de redes inteligentes da NOJA Power, o qual aumenta a flexibilidade dos religadores a partir da possibilidade de controle e automação dos grupos de religadores, e o software de qualidade de energia da NOJA Power, que permite o entendimento dos problemas na rede a partir da análise dos dados obtidos.

\subsection{OS COMPONENTES DE UMA MICRORREDE}

Nesta sessão são apresentados exemplos de tecnologias existentes que podem ser utilizadas na construção de uma microrrede.

\subsubsection{RECURSOS DISPONÍVEIS}

KG Di Santo (2015) apresenta a necessidade de que os sistemas de potência sejam modificados para atender a novas tecnologias e aos variados perfis de cargas, então é preciso saber quais cargas estão na rede para que elas recebam o fornecimento de energia.

A S\&C [20-?] apresenta em um dos seus documentos sobre construção de microrredes dois tipos gerais de carga, as críticas e as descartáveis, que de acordo com a empresa são importantes por permitirem que a microrrede priorize cargas através de seu controle automatizado. Matallanas (2012) ressalta que é importante, no critério relacionado às cargas, que o conforto do cliente deve ser mantido inalterado e suas preferências respeitadas.

\subsubsection{HARDWARE}

A S\&C [20-?] define Hardware como vários tipos de tecnologias e equipamentos a serem considerados. As opções são vastas e dependem amplamente de como a rede vai ser utilizada e dos recursos financeiros disponíveis. O hardware precisará ser avaliado cuidadosamente e se considerando os diferentes cenários que vai estar sendo utilizado.

De acordo com Tuballa (2016), os aprimoramentos irão contribuir para com a robustez, capacidade de self-healing, e integração da rede. 
Geração Distribuída: Nosso trabalho trata de gerações renováveis e viáveis no cenário do agronegócio, que incluem: Energia Hidrelétrica, Biomassa e Biogás, Energia Eólica e Energia Solar Fotovoltaica. Além das considerações feitas para escolher a combinação certa de geração distribuída para uma microrrede, é preciso selecionar os seguintes elementos: Inversores, Equipamentos de Rotação (pás e turbinas dos geradores), Tipos de combustível (como por exemplo, os que serão usados para geração de energia a partir de biomassa) e Intermitência (a geração depende muito das condições do meio). Algumas empresas oferecem produtos e serviços prontos para atender a específicas necessidades, como por exemplo:

- Biodigestores: CH4 Solution e Rastro Biodigestores (Ambas do Paraná).

- Micro Usinas Hidrelétricas: Turbulent (Belga), Hidreo (Paraná) e Energética Serviços (São Paulo).

- Painéis Solares: Balfar Solar (Paraná) e Porta Solar (São Paulo).

Reconfiguração Automática: De acordo com KG Di Santo (2015) o restabelecimento automático é um dos elementos que constituem a distribuição inteligente de uma microrrede. Para realizar a reconfiguração da rede são utilizados dispositivos de interrupção, como disjuntores, seccionadores e religadores. Exemplos:

- Religador IntelliRupter - S\&C Eletric;

- Sistema de selfhealing - Cooper Power Systems;

- Religadores OMS - NOJA Power;

- Seccionador Asulti-Rupter - S\&C Electric;

- Disjuntores de média tensão - Schneider Electric.

Armazenamento: $O$ armazenamento de energia pode ou não ser necessário dependendo da situação em que a microrrede está atuando e da severidade de sua aplicação. Em qualquer caso é necessário um estudo para se saber se existe a necessidade do uso ou não de armazenamento e caso exista a necessidade, qual o tipo a ser utilizado, por exemplo através de baterias ou armazenamento térmico. ML Tuballa (2016) coloca também a questão da flutuação da geração de eletricidade através das fontes renováveis, que torna o uso de sistemas de armazenamento essenciais em algumas aplicações. Como por exemplo armazenamento de energia fotovoltaica, que carrega na parte da manhã e pode ser usada em períodos noturnos. Exemplos: 
- Schneider Electric Galaxy VM - Schneider Electric;

- Fimer React 2 - FImer;

- Aggreko Y.Cube - 30 minutes - aggreko;

- Serviços da AES Tietê.

Medidores Inteligentes: KG Di Santo (2015) define medidores inteligentes como sendo digital e bidirecional, sendo uma interface entre o consumidor e a unidade elétrica. Dileep. G. (2020) coloca os medidores como uma ferramenta que possibilita fornecer aos consumidores o conhecimento sobre como e quando usam energia e como quanto pagam por quilowatt-hora de energia. R. Bayindir (2016) aponta que muitos problemas de uma rede podem ser resolvidos com medidores inteligentes. E que isso junto ao gerenciamento de dados e comunicação bidirecional facilita a geração, transmissão e distribuição de energia. Exemplos:

- SMW Smart Energy Meters - WEG

- EcoStruxure ${ }^{\mathrm{TM}}$ Smart Metering Advisor - Schneider Electric

- Fronius Smart Meter 63A-1 - Fronius

- devolo SMGWplus - devolo

\subsubsection{SERVIÇOS DE INTEGRAÇÃO}

De acordo com Tuballa (2016), os componentes da rede devem ser capazes de trabalhar juntos para permitir o transporte confiável de eletricidade da geração ao consumo. A interoperabilidade é crucial no planejamento e implementação da rede. A complexidade, o número e a escala dos sistemas e os dispositivos envolvidos em Smart Grids tornam a interoperabilidade indispensável. A S\&C [20-?] em seus guias sobre construção de redes reforçam que nenhuma microrrede funciona sem serviços de integração - a função essencial que garante que hardware, software e controles se comuniquem claramente e respondam rapidamente. São necessários vários serviços, desde estudos do sistema a testes, para levar a microrede do conceito à conclusão e garantir seu correto funcionamento.

- EcoStruxure ${ }^{\mathrm{TM}}$ Microgrid Operation - Schneider Electric

- Engineering Services - S\&C Electric Company

- Grid Integration Service - ABB

- Serviços de Smart Grid - accenture 
Cibersegurança: A engenharia envolvida na proteção e controle é necessária para toda a microrrede, bem como para os níveis de controle. Esses controles agem quase instantaneamente e devem ser cuidadosamente programados por especialistas em proteção e controle para diferenciar entre o modo conectado à rede e o modo de ilhamento.

Aloul (2012) em sua pesquisa sobre segurança em Smart Grids aponta que as vulnerabilidades são mais comuns em medidores inteligentes, dispositivos inteligentes na oferta e demanda de eletricidade, componentes em locais físicos inseguros, equipamentos desatualizados, comunicação entre dispositivos e componentes baseados em IP. Por esse motivo, Tuballa (2016) aponta que existem várias partes interessadas no estabelecimento de padronizações no que diz respeito à segurança nas redes inteligentes. A S\&C [20-?] complementa adicionando a questão da indispensabilidade de um sistema de cibersegurança, capaz de lidar com ataques e vírus cibernéticos.

- Cybersecurity Consulting Services - Schneider Electric

- $\quad$ SIPROTEC 5 - Siemens

- IntelliRupter ${ }^{\circledR}$ PulseCloser ${ }^{\circledR}$ Fault Interrupter - S\&C Electric Company

- Cisco Secure - Cisco

Interconexão da Geração: De acordo com a S\&C [20-?], novos ativos de geração distribuída não podem simplesmente ser conectados ao sistema vigente. Qualquer novos ativos de geração distribuída exigirão serviços de interconexão para torná-los parte da microrrede.

\subsubsection{CONTROLE}

Tuballa (2016) em sua descrição sobre sistemas de controle inteligente, descreve sua necessidade para se ter uma programação do uso das fontes de energia, para maximizar o transporte de energia, para estabilidade transitória e para controle de potência. Otimização da geração de energia através do rastreamento das flutuações de demanda na carga e pode ser usado para detecção automática de falhas e sua reconfiguração, controle de potência reativa para geração distribuída além de outras aplicações. Sendo ele presente do processo de geração ao processo de consumo de energia.

Annaswamy (2013) apresenta que a prática do controle na rede de energia elétrica tem 4 grandes áreas de foco, sendo o controle da geração, controle para regulação de 
frequência e balanço de potência, controle de potência reativa e controle de tecnologias de sensoriamento e comunicação. É apresentado também que as dificuldades do design do sistema de controle destas áreas envolvem: transferência de potência por longas distâncias, transmissão de alta tensão, acoplamento dinâmico de sistemas eletromecânicos, resposta mecânica de geradores e cargas que causam distúrbios por toda a rede. Por causa da dependência do controle com as diversas formas de geração e de comportamento de carga, é importante que os sistemas de controle sejam entendidos em um contexto muito amplo.

Conforme a descrição da S\&C [20-?] a respeito de microrredes, de maneira geral é necessário o controle em três diferentes níveis:

- Ciclos: Os controles em nível de ciclo detectam e se comunicam em eventos quase instantâneos na microrrede.

- Segundos: Os controles de nível de segundo capturam as informações e tomam decisões inteligentes para equilibrar e adaptar constantemente o sistema de micro-redes.

- Minutos a dias: Os controles em minutos e horas reagem mais lentamente após o controle imediato é tomado e permitem alterações de longo prazo em uma microrrede.

Comunicação: Tanto a S\&C em seu paper sobre construção de microrredes e Tuballa (2016) em sua revisão sobre tecnologias de Redes Inteligentes, explicitam que a arquitetura de rede envolve como a microrrede conversa, que depende de qualquer comunicação que já existe e as aplicações da microrrede. As comunicações são tipicamente divididas em com fio ou sem fio. Também é preciso decidir qual idioma ou protocolos todos os controles e hardwares estão usando. E garantir a comunicação nos protocolos entre diferentes equipamentos. Tuballa (2016) ainda acrescenta a necessidade da comunicação resiliente para rede de sensores, comunicações tolerantes a falhas e evolução das tecnologias de comunicação dada a sua importância para o funcionamento da rede como um todo.

Modos de funcionamento: A S\&C (2019) apresenta os modos Ilha (mais detalhado abaixo, pela sua importância nas microrredes), Perda de carga, Picos energéticos, Inicialização, Economia de energia e Retomada.

Ilha: Bakar (2017) explica que a manutenção e o isolamento forçado devido a falhas na rede farão com que a microrrede se desconecte da rede principal. Nessa situação de emergência, a microrrede operaria de forma autônoma como uma ilha separada. Durante esta 
circunstância ela deve ser capaz de trabalhar de forma constante com a ajuda de geração e armazenamento distribuído para manter a sua integridade. Ser uma rede de energia implica que a microrrede pode se conectar e se separar da rede principal para permitir sua operação autônoma durante o modo conectado à rede ou em modo ilha.

\subsection{O QUE PROCURAR EM UM EQUIPAMENTO}

Segundo a S\&C (2019), nem todos os equipamentos são compatíveis com microrredes. Quando se procura antigos e novos equipamentos para uma microrrede, é importante levar em conta que eles se adaptarão ao novo contexto:

Equipamentos Remotamente Controláveis: A capacidade de controle remoto dependerá das funções que cada equipamento serve. Por exemplo, pode-se encontrar geradores que desligam-se remotamente, mas não podem ser ligados remotamente. Para uma microrrede, é preciso fazer a transição para dentro e fora do modo de ilhamento. $\mathrm{O}$ equipamento pode ser ligado remotamente? O equipamento pode ser desligado remotamente? Outros parâmetros operacionais podem ser ajustados remotamente?

Comunicação: Os equipamentos devem conversar entre si, mas isso pode ser desafiador se os equipamentos forem comprados de vários fornecedores. A fluência do equipamento é importante tanto para a funcionalidade quanto para a segurança. Além disso, quanto mais variáveis o equipamento for familiarizado, mais valioso ele se torna, porque pode-se entender melhor a microrrede e ajustá-la para obter um desempenho otimizado. $\mathrm{O}$ equipamento pode aceitar comandos do sistema de controle? O equipamento pode desempenhar a função pretendida como resultado da comunicação com o sistema de controle? Pode-se visualizar os registros de desempenho e monitorar o equipamento remotamente? O equipamento pode enviar informações sobre seu status ao sistema de controle? $\mathrm{O}$ equipamento pode enviar informações em tempo real ao sistema de controle além do status que monitora os detalhes de desempenho?

Desempenho flexível e ajustável: $\mathrm{O}$ controle flexível permite controlar com eficiência a geração e as cargas na microrrede. Por exemplo, usinas fotovoltaicas geralmente liberam $100 \%$ da energia que geram. Se a potência exceder o que a microrrede pode usar, o painel fotovoltaico normalmente será desligado completamente. Mas há momentos em que 
pode-se querer apenas $60 \%$ da produção disponível, e um sistema configurado com redução dinâmica e um controlador de microrrede pode permitir esta flexibilidade. Foi determinado quais equipamentos precisam de parâmetros ajustáveis? Do equipamento que precisa de parâmetros ajustáveis, esses parâmetros são flexíveis o suficiente para atender aos objetivos da micro-rede?

Esquemas de proteção: Os esquemas de proteção dos dispositivos são diferentes quando a grade principal não está mais disponível. Normalmente, as tolerâncias para o equipamento na rede são tão rígidas porque são projetadas para disparar o dispositivo rapidamente quando há um problema, mas o equipamento em uma microrrede precisa de um maior grau de tolerância para permitir que a microrrede se ajuste e responda a mudanças em seu microambiente. As configurações de proteção do dispositivo impedirão que ele funcione em uma microrrede? Foi definido quais serão os novos esquemas de proteção e controle? Foi planejado novos estudos de arco-elétrico nos equipamentos?

Vida-útil dos equipamentos: O equipamento deteriora-se com o tempo, portanto, deve-se ter certeza de que o equipamento ainda pode lidar com as cargas da microrrede a qualquer momento. Se for preciso uma bateria para durar duas horas por 10 anos, pode ser necessário comprar uma bateria com uma classificação de vida útil inicial de três horas. $\mathrm{O}$ equipamento durará a vida útil da microrrede (normalmente 20 anos ou mais)? Se um equipamento não foi projetado para durar a duração da microrrede, foi feito o orçamento e planejado quando essas substituições precisam ocorrer?

\subsection{ALGUMAS CONFORMIDADES}

A Copel (2019) disponibiliza as normas técnicas (NTC) para o acesso de geração distribuída em seu sistema elétrico, as quais estabelecem padrões que visam à uniformização e à adoção de procedimentos, observando as exigências técnicas e de segurança recomendadas, em conformidade com as prescrições vigentes nos Procedimentos de Distribuição PRODIST, nas Resoluções Normativas da Agência Nacional de Energia Elétrica - ANEEL e Normas Técnicas da ABNT.

As seguintes normas técnicas são aplicáveis para a geração distribuída (COPEL, 2019): 


\section{NTC 905100 - Acesso de Geração Distribuída ao Sistema da Copel (com} comercialização de energia): Esta norma fornece os requisitos para acesso de geradores de energia elétrica ao sistema elétrico de distribuição da Copel em Média Tensão - MT (13,8 e $34,5 \mathrm{kV}$ ) e em Alta Tensão - AT (69 e $138 \mathrm{kV}$ ), excluindo as Demais Instalações de Transmissão - DIT pertencentes às transmissoras e os casos de adesão ao Sistema de Compensação de Energia Elétrica (Micro e Minigeradores).

Aplica-se aos geradores de energia elétrica que pretendem implantar empreendimentos de geração conectando-se ao sistema de distribuição da Copel para comercialização da energia.

\section{NTC 905200 - Acesso de Micro e Minigeração Distribuída ao Sistema da Copel}

(com compensação de energia): Esta norma técnica fornece os requisitos para acesso de geradores de energia elétrica conectados através de unidades consumidoras optantes pelo Sistema de Compensação de Energia Elétrica, instituído pela Resolução Normativa ANEEL $n^{\circ} 482 / 2012$.

Aplica-se às centrais geradoras com potência instalada de geração até $5 \mathrm{MW}$ que façam a adesão ao Sistema de Compensação de Energia Elétrica e que acessem o sistema elétrico através de unidades consumidoras.

NTC 903105 - Geração Própria - Operação em Paralelismo Momentâneo: A unidade consumidora poderá possuir sistema de geração própria, destinado a operar nos casos emergenciais ou a critério do consumidor, com a possibilidade de operação em paralelismo momentâneo com o sistema de fornecimento da Copel. A instalação deverá ser precedida da aprovação do projeto elétrico por parte da Copel, e a sua operação será liberada após a aprovação do projeto e da respectiva vistoria das instalações por parte da Copel.

NTC 903107 - Geração Própria - Operação Isolada em Emergência: A unidade consumidora poderá possuir sistema de geração própria, destinado a operar nos casos emergenciais ou a critério do consumidor, sem a possibilidade de operação em paralelo com o sistema de fornecimento da Copel. A solicitação para uso desta modalidade de geração deverá atender às prescrições da NTC 903107, e a sua operação será liberada após a aprovação da vistoria das instalações por parte da Copel. 


\subsection{CONCLUSÕES PARCIAIS DO CAPÍTULO}

Mesmo com a definição de algumas das necessidades gerais de uma microrrede, pode ser fácil ignorar alguns dos detalhes envolvidos na concepção do projeto. Ter uma elaboração geral do projeto, contemplando o máximo de detalhes e possíveis mudanças antecipadamente pode ajudar, e muito, na longevidade e resiliência da rede. O planejamento a longo prazo é muito importante, especialmente se existe a possibilidade da expansão da microrrede.

Pela natureza da rede envolver muito o serviço de terceiros em diversas áreas, como manutenção e engenharia, é importante incluir no orçamento essa relação que terá a função de manter a rede funcional ao longo do tempo e também contemplar as possíveis atualizações de hardware e software. Um exemplo seria que propriedades próximas que usem serviços associados a microrrede tivessem apenas um provedor de serviços para todas, facilitando sua integração e resolução de possíveis problemas. 


\section{ESTUDO DE CASO}

Neste capítulo é apresentado um projeto conceitual de uma microrrede para fins de análise. O projeto apresenta a integração das fontes estudadas ao decorrer do trabalho (microgeração hidrelétrica, fotovoltaica e biomassa), abordando a geração de energia em três propriedades do estado do Paraná, cada uma com potencial e recursos para cada fonte de geração.

A primeira propriedade trata-se de uma granja, com grandes galpões aviários que permitem a instalação de painéis solares no telhado do mesmo, a segunda propriedade é voltada para criação de porcos para carne, e seus potenciais energéticos de biomassa são apresentados mais detalhadamente a seguir e por fim, a terceira propriedade abordada é focada em produção agrícola, possui um riacho que é utilizado para irrigação das plantações e também será aproveitado para geração hidrelétrica.

\subsection{PROPRIEDADE COM GERAÇÃO FOTOVOLTAICA}

Em propriedades voltadas para criação agrícola, poucas horas sem energia elétrica podem acarretar em grandes perdas, como ocorrido numa propriedade em Adamantina (G1, 2020). Estas propriedades possuem grandes galpões que podem ser utilizados para a instalação de painéis fotovoltaicos atrelados a um banco de baterias, o que resolveria os problemas com queda de energia e não necessitaria de geradores poluentes, como os a diesel.

\subsubsection{CONSUMO DA PROPRIEDADE}

A propriedade em questão tem equipamentos que possuem cargas de acordo com as apresentadas na Tabela 3 para residência principal e a do caseiro, e na Tabela 4 para o galpão da criação de aves, para o sistema de coleta de água para abastecimento da caixa d'água, que abastece toda a propriedade, e demais instalações, como iluminação da casa de máquinas e garagem. 
Tabela 3 - Tabela de cargas de consumo residências propriedade 1.

\begin{tabular}{|c|c|c|c|c|c|c|}
\hline TIPO & QTDE & $\begin{array}{l}\text { POT UN } \\
\text { (W) }\end{array}$ & $\begin{array}{l}\text { POT*QTDE } \\
(\mathrm{W})\end{array}$ & $\begin{array}{l}\text { USO } \\
\text { DIÁRIO } \\
\text { (H) }\end{array}$ & $\begin{array}{c}\text { USO } \\
\text { SEMANAL } \\
\text { (DIAS) }\end{array}$ & $\begin{array}{c}\text { CONSUMO } \\
\text { MENSAL } \\
\text { (KWH) }\end{array}$ \\
\hline CHUVEIRO ELÉTRICO & 5 & 5500 & 27500 & 2 & 7 & 1540 \\
\hline GELADEIRA DUPLEX & 1 & 500 & 500 & 24 & 7 & 336 \\
\hline GELADEIRA SIMPLES & 1 & 250 & 250 & 24 & 7 & 168 \\
\hline FREEZER VERTICAL & 2 & 300 & 600 & 24 & 7 & 403,2 \\
\hline TELEVISOR & 5 & 90 & 450 & 6 & 7 & 75,6 \\
\hline MÁQUINA DE LAVAR ROUPA & 2 & 1000 & 2000 & 3 & 3 & 72 \\
\hline FORNO DE MICRO ONDAS & 1 & 2000 & 2000 & 1 & 7 & 56 \\
\hline CONDICIONADOR DE AR & 4 & 1400 & 5600 & 8 & 7 & 1254,4 \\
\hline FERRO ELÉTRICO & 1 & 1000 & 1000 & 2 & 3 & 24 \\
\hline FOGÃO ELÉTRICO DE 4 BOCAS & 1 & 6000 & 6000 & 2 & 7 & 336 \\
\hline FREEZER HORIZONTAL & 1 & 500 & 500 & 24 & 7 & 336 \\
\hline PONTO DE ILUMINAÇÃO & 25 & 20 & 500 & 6 & 7 & 84 \\
\hline SECADOR DE CABELO & 3 & 1000 & 3000 & 1 & 7 & 84 \\
\hline LIQUIDIFICADOR & 2 & 200 & 400 & 1 & 7 & 11,2 \\
\hline EXAUSTOR & 1 & 150 & 150 & 2 & 7 & 8,4 \\
\hline TOTAL & - & - & 50450 & - & - & 4788,8 \\
\hline
\end{tabular}

Fonte: Autoria Própria (2020) com dados retirados do Manual de Eletrificação Rural (1997).

Tabela 4 - Tabela de cargas de consumo dos galpões, sistema de bombeamento água e fazenda da propriedade 1.

\begin{tabular}{lcccccc}
\multicolumn{1}{c}{ TIPO } & QTD & POT UN & POT*QTD & USO & USO & CONSUM \\
& $E$ & $(\mathrm{~W})$ & $\mathrm{E}(\mathrm{W})$ & $\begin{array}{c}\text { DIÁRI } \\
\text { O (H) }\end{array}$ & $\begin{array}{c}\text { SEMANAL } \\
\text { (DIAS) }\end{array}$ & $\begin{array}{c}\text { MENSAL } \\
\text { (KWH) }\end{array}$ \\
\hline COMEDOURO & 2 & 1470 & 2940 & 4 & 7 & 329,28 \\
VENTILADOR & 24 & 400 & 9600 & 12 & 7 & 3225,6 \\
MOTOR NEBULIZADOR & 2 & 3700 & 7400 & 6 & 7 & 1243,2 \\
LÂMPADAS & 60 & 20 & 1200 & 6 & 7 & 201,6 \\
CORTADOR DE GRAMA & 1 & 1300 & 1300 & 2 & 2 & 20,8 \\
$\begin{array}{l}\text { CONJ. MOTOBOMBA } \\
\text { SUBMERSO }\end{array}$ & 1 & 22000 & 22000 & 8 & 7 & 4928 \\
BOMBA ALTA PRESSÃO & 1 & 11000 & 11000 & 8 & 7 & 2464 \\
TOTAL & - & - & $\mathbf{5 5 4 4 0}$ & - & - & $\mathbf{1 2 4 1 2 , 4 8}$ \\
\hline
\end{tabular}

Fonte: Autoria Própria (2020) com dados retirados do Manual de Eletrificação Rural (1997).

As colunas de uso diário e uso semanal são uma previsão de utilização de cada equipamento. Para o cálculo do consumo mensal é utilizada a equação (2).

$$
C=\operatorname{Pot}_{\text {tot }} * h_{\text {dia }} * d_{\text {sem }} * 4 / 1000
$$


onde, $C$ representa o consumo mensal em $\mathrm{kWh}$, Pot $_{\text {tot }}$ a Potência em $\mathrm{W}$ de acordo com a quantidade de equipamentos, $h_{\text {dia }}$ as horas de uso diário e $d_{s e m}$ a quantidade de dias de uso semanal. A multiplicação por 4 é feita para representar um mês, aproximadamente contendo quatro semanas, e a divisão por 1000 para transformar de Wh para kWh.

Realizando a soma do consumo total resultante de ambas as tabelas, é obtido o valor de 17.201,28 kWh por mês. Utilizando a equação (3) é possível calcular o custo mensal (C\$) com a energia elétrica para a propriedade, levando em consideração as tarifas convencionais para propriedades rurais disponibilizadas pela Copel (2020) de 0,31537 R $\$ / \mathrm{kWh}$ para TE e 0,30207 R\$/kWh para TUSD, ambas com impostos inclusos.

$$
C \$=C *(T E+T U S D)
$$

Com o cálculo é obtido um custo mensal de R \$ 10620,76.

Utilizando-se o simulador de consumo da Copel (com a tela geral apresentada no Figura 13 e a tela para adicionar equipamentos na Figura 14), para essa propriedade tem-se um consumo mensal de 17.226,03 $\mathrm{kWh}$, resultando em um custo de $\mathrm{R} \$ 10.636,01$ na tarifa convencional. Os detalhes da fatura resultante da simulação são mostrados no Anexo I.

Figura 13 - Tela Geral do simulador de consumo Copel.

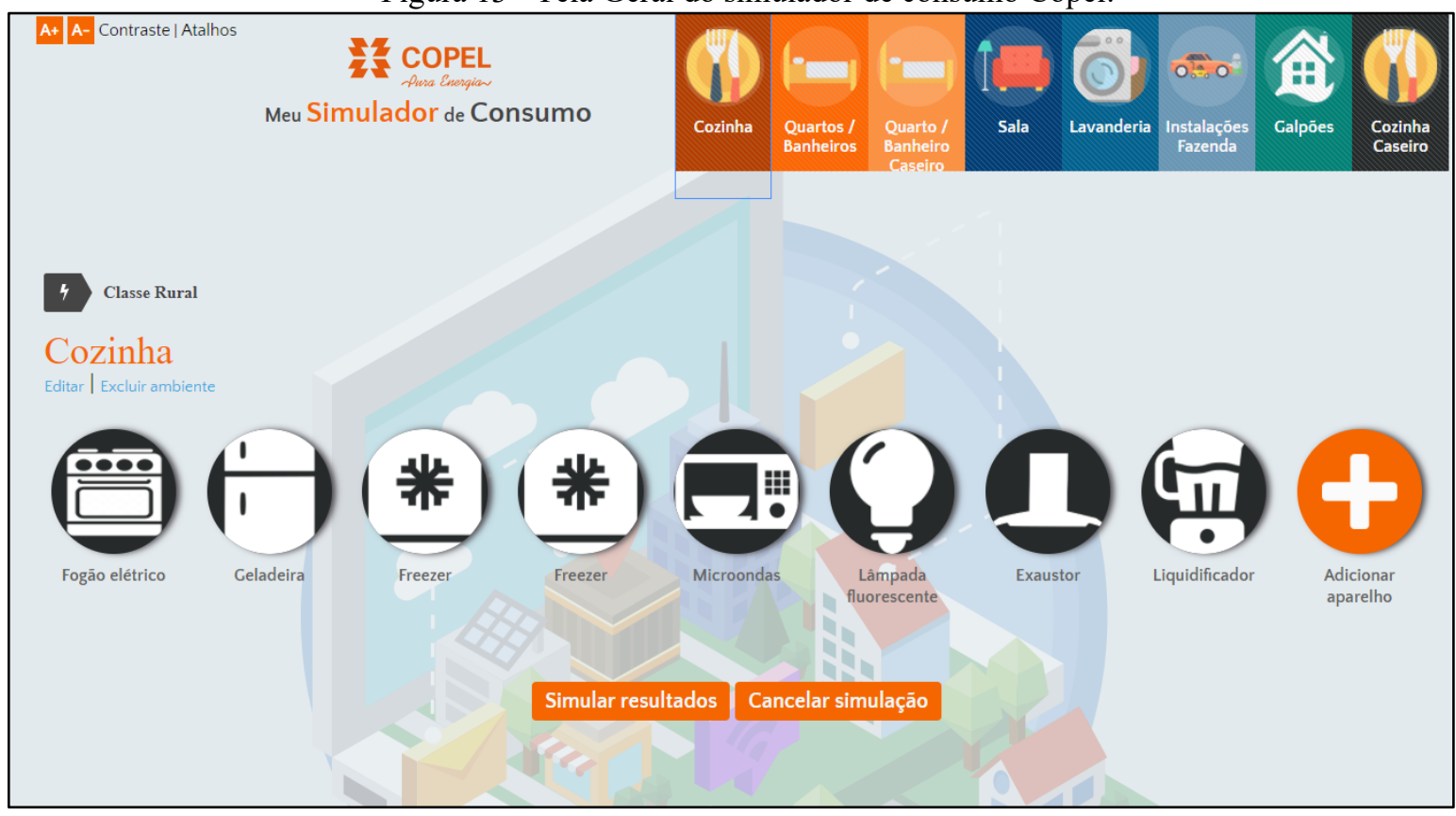

Fonte: Copel (2020) 


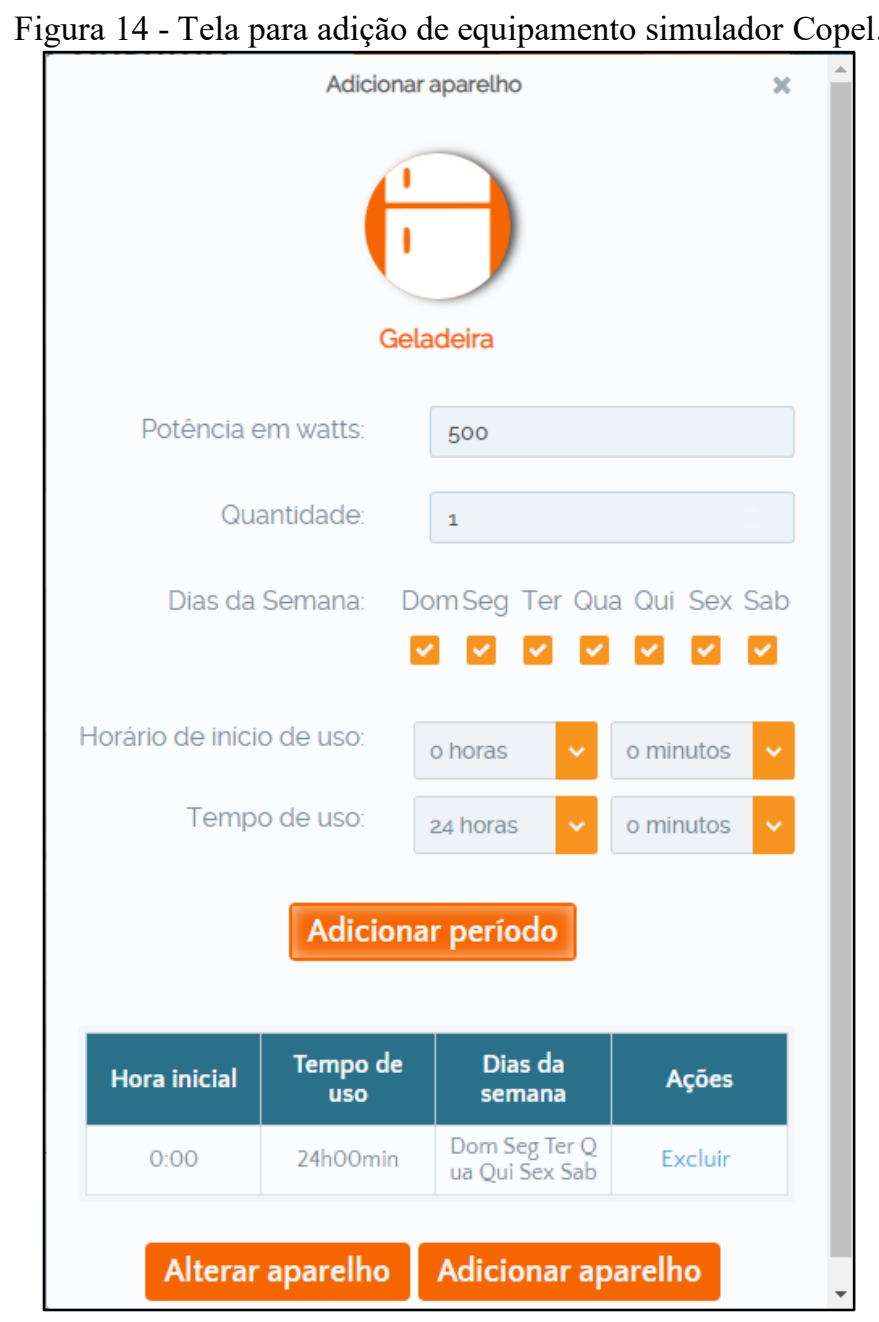

Fonte: Copel (2020)

Os resultados obtidos por meio da simulação podem ser considerados satisfatórios para a projeção de custo mensal da propriedade ao serem comparados com os valores calculados, com uma diferença de apenas $0,1 \%$.

\subsubsection{GERAÇÃO FOTOVOLTAICA}

Para a propriedade, é considerado um conjunto de painéis numa potência nominal de 488,4 kWp. A potência de pico dos painéis solares (Wp), são mensurados a uma exposição a radiação solar de $1000 \mathrm{~W} / \mathrm{m}^{2}$, a eficiência desses equipamentos também são afetadas pela temperatura ambiente, todas essas características estão disponíveis na folha de dados do equipamento, fornecida pelo fabricante, mostrado na Figura 15. Para o projeto desta propriedade, serão usados painéis solares da empresa paranaense Balfar Solar. 
Figura 15 - Especificações Elétricas Painel Fotovoltaico Balfar Solar.

\begin{tabular}{|lcc|}
\hline \multicolumn{2}{|c|}{ ESPECIFICAÇÕES ELÉTRICAS (STC) } \\
\hline Watts de potência de Pico Máxima & $\mathrm{Pm}(\mathrm{W})$ & 370 \\
Tensão de Potência Máxima & $\mathrm{Vm}(\mathrm{V})$ & 40,7 \\
Corrente de Potência Máxima & $\operatorname{Im}(\mathrm{A})$ & 9,11 \\
Tensão de Circuito Aberto & $\operatorname{Voc}(\mathrm{V})$ & 50,2 \\
Corrente de Curto-circuito & $\operatorname{Isc}(\mathrm{A})$ & 9,55 \\
Eficiência do Módulo & $(\%)$ & $19 \%$ \\
\hline
\end{tabular}

Fonte: Balfar Solar (2019).

Para atingir a potência nominal desejada é utilizada a equação (4).

$$
P=P_{u n} * Q t d e
$$

Sendo P a potência nominal desejada, sendo considerada a de $488,4 \mathrm{kWp}, P_{u n}$ a potência de cada painel, no projeto são utilizados painéis de $370 \mathrm{Wp}$. Assim, são necessários 1320 painéis para totalizar $488,4 \mathrm{kWp}$, satisfazendo o valor desejado.

Os painéis são instalados em um modelo chamado de arranjo fotovoltaico, como é apresentado no capítulo 2, seção 2.3. Para o cálculo da área ocupada pelo arranjo é utilizada a equação (5).

$$
A_{\text {tot }}=A_{\text {un }} * Q t d e
$$

Sendo $A_{\text {tot }}$ a área total ocupada pelos painéis, $A_{u n}$ a área de cada painel individual e Qtde a quantidade de painéis. Segundo dados da Balfar Solar (2019), os painéis solares possuem uma área de aproximadamente $1,94 \mathrm{~m}^{2}(0,992 \times 1,956 \mathrm{~m})$, assim a área total dos 1320 painéis ocupará uma área com cerca de $2560,8 \mathrm{~m}^{2}$, instalados no telhado dos galpões presentes na propriedade.

A instalação é capaz de fornecer $488,4 \mathrm{~kW}$ por hora, com irradiação média mínima de $1000 \mathrm{~W} / \mathrm{m}^{2}$, segundo dados do Atlas Solar Paraná (2017) a irradiação anual média para o estado está entre 4 a 5,5 horas por dia, como mostrado na Figura 16. 
Figura 16 - Irradiação Solar média.

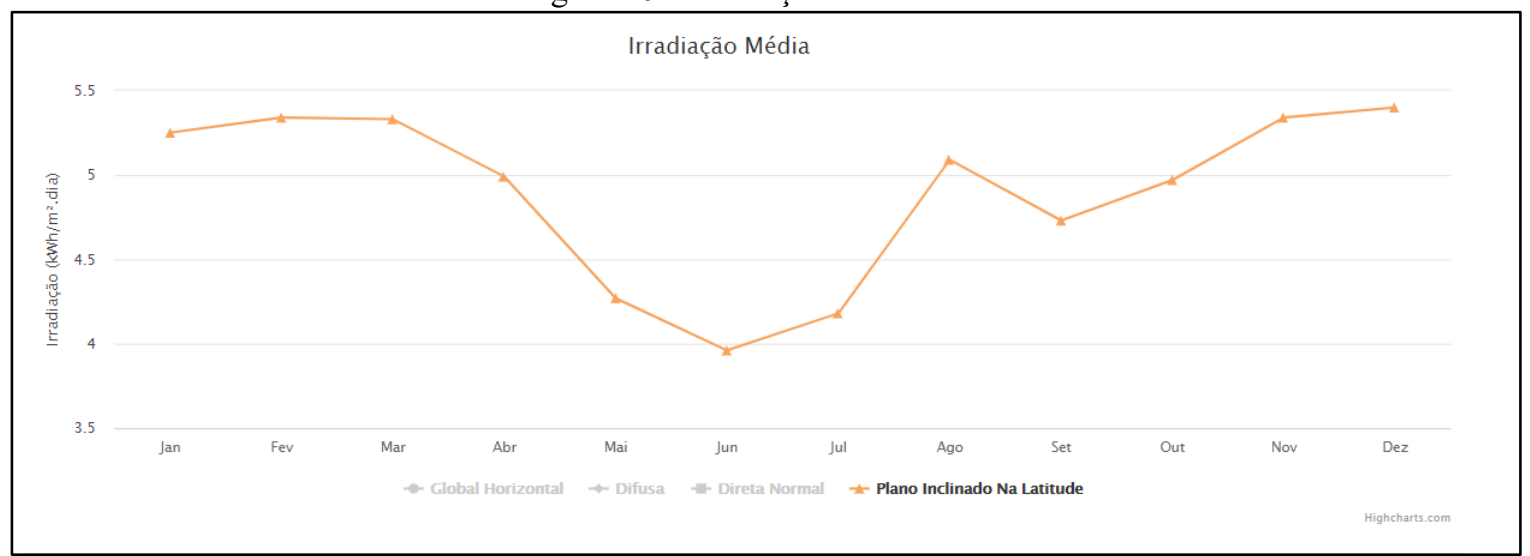

Fonte: Atlas Solar do Paraná (2017).

Utilizando a equação (6) é possível calcular o valor gerado médio de energia por dia.

$$
E=t_{m e d} * P_{h r} * I r r_{m e d}
$$

Considerando $t_{\text {med }}$ o tempo médio de $5 \mathrm{~h}$ diárias, $P_{h r}$ a potência gerada por hora e $I r r_{m e d}$ a irradiação média mínima, é possível concluir que a instalação é capaz de fornecer $2442 \mathrm{kWh}$ de energia por dia.

\subsubsection{CONVERSÃO DE CARGA E ARMAZENAMENTO}

No cenário nacional, há vários fabricantes de transformadores e inversores, que possibilitam a transmissão de energia nas redes de distribuições locais de média tensão e nas linhas de longas distâncias de alta tensão. Os grandes fabricantes desses equipamentos normalmente são estrangeiros, mas, dentre os grandes, existe um fabricante nacional, a WEG, que é reconhecida mundialmente como fabricante de transformadores CA-CA e motores paras variadas aplicações, e dentro de seu portfólio. A WEG disponibiliza soluções para energia solar, como o inversor SIW500H - ST100 M1, apresentado na Figura 17, modelo de 100 kW de saída, que é utilizado no projeto. 
Figura 17 - Inversor SIW500H - ST100 M1.

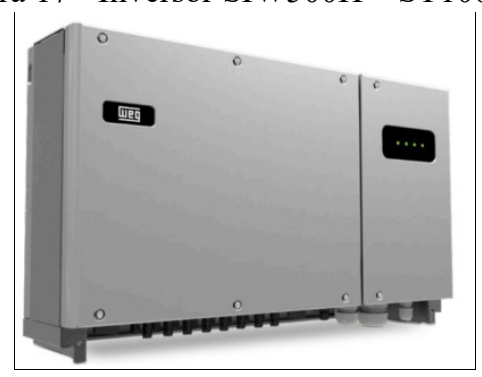

Fonte: WEG [201-?].

Figura 18 - Especificações Técnicas inversor SIW500H - ST100 M1.

\begin{tabular}{|c|c|}
\hline Especificações técnicas & ST100 M1 \\
\hline Eficiência máxima & $98,80 \%$ \\
\hline Tensão de entrada máxima & $1.100 \mathrm{~V}$ \\
\hline Corrente de curto-circuito máxima & $26 \mathrm{~A}$ \\
\hline Faixa de tensão MPPT em máxima potência & $200 \mathrm{~V} \sim 1.000 \mathrm{~V}$ \\
\hline Número máximo de entradas & 20 \\
\hline Número de rastreadores MPPT & 10 \\
\hline Potência ativa CA nominal & $100.000 \mathrm{~W}$ \\
\hline Potência Aparente Máxima & $110.000 \mathrm{VA}$ \\
\hline Tensão de saída nominal (FN/FF) & $\begin{array}{c}220 \mathrm{~V}(\mathrm{~F}-\mathrm{N}) / 380 \mathrm{~V}(\mathrm{~F}-\mathrm{F}) \text {, } \\
3 \mathrm{~F}+\mathrm{N}+\mathrm{T} ; 3 \mathrm{~F}+\mathrm{T} \text { opcional nas } \\
\text { configuraçōes }\end{array}$ \\
\hline Frequência de rede CA nominal & $50 \mathrm{~Hz} / 60 \mathrm{~Hz}$ \\
\hline Corrente de saída máxima & $168,8 \mathrm{~A}$ \\
\hline Fator de potência ajustável & 0,8 adiantado/ 0,8 atrasado \\
\hline Distorção harmônica total máxima & $\leq 3 \%$ \\
\hline Seccionadora lado CC & Sim \\
\hline Proteção anti-ilhamento & Sim \\
\hline Proteção contra polaridade CC invertida & Sim \\
\hline Monitoramento de falha de string no arranjo PV & Sim \\
\hline Supressor de surto CC & Sim \\
\hline Supressor de surto CA & Sim \\
\hline Monitoramento da isolação & Sim \\
\hline Detecção de corrente de fuga & Sim \\
\hline RS485 & Sim \\
\hline USB & Sim \\
\hline Bluetooth +APP & Sim \\
\hline Power Line Communication (PLC) & Sim \\
\hline Dimensões $(\mathrm{L} \times \mathrm{A} \times \mathrm{P})$ & $1.035 \times 700 \times 365 \mathrm{~mm}$ \\
\hline Peso & $90 \mathrm{~kg}$ \\
\hline Faixa de temperatura de operação & $-25^{\circ} \mathrm{C} \sim 60^{\circ} \mathrm{C}$ \\
\hline Grau de proteção & IP66 \\
\hline Consumo interno noturno & $<1 \mathrm{~W}$ \\
\hline Topologia & Sem transformador \\
\hline
\end{tabular}

Fonte: WEG [201-?].

Conforme mostra a Figura 18, o inversor WEG modelo SIW500H - ST100 M1 possui 20 entradas, com tensões que variam de $200 \mathrm{~V}$ a $1000 \mathrm{~V}$, para uma saída de $380 V_{C A}$ $60 \mathrm{~Hz}$, que é a utilizada neste projeto, e uma corrente de 26 A por MPPT. O rastreamento do MPPT é feito em duas entradas paralelas, conforme mostra a Figura 19, onde é ilustrado a 
representação do circuito interno de um equipamento de modelo similar ao utilizado, porém de menor potência (40kVA).

Liu (2008) define MPPT como uma técnica que é usada para o rastreamento de máxima potência em sistemas fotovoltaicos, para fazer uma utilização completa da potência de saída, que depende da irradiação solar e temperatura ambiente.

Figura 19 - Circuito interno do inversor SIW500H - ST040.

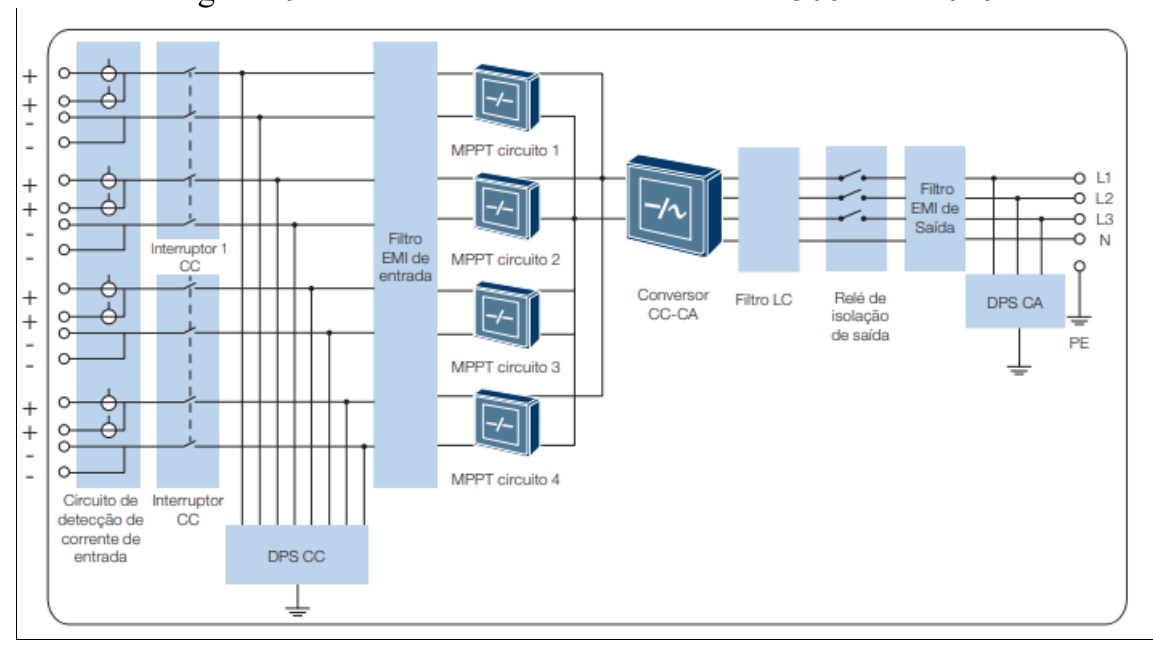

Fonte: WEG [201-?].

Com estas informações em mãos, é possível mensurar o arranjo dos painéis em strings a serem conectadas e monitoradas pelo inversor, que possui monitoramento e diagnóstico de falhas para cada string instalado. Da Silva (2015) relata que como a instalação de strings e arrays devem ser elaboradas para a conexão em inversores de carga.

Para calcular a quantidade de painéis por entrada é utilizada a equação (4), substituindo os valores de potência pelos respectivos valores de tensão, assim, considera-se P o valor de tensão na entrada do inversor, para o caso do estudo de $1000 V_{C C}, P_{u n}$ a tensão de operação em potência máxima de cada painel de 40,7 $V_{C C}$ conforme Balfar Solar (2019). Com isso, obtém-se o valor de 24,6 painéis, que é arredondado para 25 , totalizando-se $976,8 V_{C C}$ na entrada do inversor.

Cada string possui uma potência total de $8.880 \mathrm{~W}$, que é dada pela multiplicação direta da quantidade de painéis pela potência de cada um, conforme a equação (7).

$$
P_{\text {string }}=P_{\text {un }} * Q t d e
$$

Como os painéis estão em série, cada string fornece uma corrente máxima de 9,11 A, que é a corrente em cada painel, como mostrado na Figura 15. Dessa forma, instalando 1 
string por entrada, e utilizando 6 entradas é possível respeitar a corrente máxima do equipamento de 26 A por MPPT.

Com a utilização de 11 entradas, conectando uma string por entrada, é possível atingir a potência de 97,68 kW por inversor (11 strings, 24 painéis por string, 370W por painel). Assim, serão instalados 5 inversores SIW500H - ST100 M1 nesta configuração, totalizando $488,4 \mathrm{~kW}$ instalados.

Considerando a eficiência de 98\%, obtém-se um valor de 2393,1 kWh de geração diária, em relação aos 2442 kWh diários, calculado na seção 6.1.2.

Para o armazenamento de energia, a WEG possui uma linha completa de nobreaks em seu portfólio, dentre os produtos, destaca-se o modelo Enterprise de $380 \mathrm{~V}$, com especificações apresentadas na Figura 20.

Figura 20 - Especificação técnica nobreak.

\begin{tabular}{|c|c|c|c|c|c|c|c|c|c|c|c|c|c|}
\hline \multicolumn{14}{|l|}{ Equipamentos $380 \mathrm{~V}$} \\
\hline Modelo & \multicolumn{13}{|c|}{ Enterprise } \\
\hline Potência (kVA) & 10 & 15 & 20 & 25 & 30 & 40 & 50 & 60 & 80 & 100 & 120 & 160 & 200 \\
\hline Potência $(\mathrm{kW})$ - FP 0,8 ou $0,9^{4}$ & 8 & 12 & 16 & 20 & 24 & 32 & 40 & 48 & 64 & 80 & 96 & 128 & 160 \\
\hline \multicolumn{14}{|c|}{ Entrada do retificador } \\
\hline Tensắo nominal|2] & \multicolumn{13}{|c|}{$380 \mathrm{~V} \mathrm{ca}$} \\
\hline Variação máxima da tensão & \multirow{2}{*}{\multicolumn{13}{|c|}{$\begin{array}{c} \pm 20 \% \\
50 / 60 \mathrm{~Hz}\end{array}$}} \\
\hline Frequência nominal & & & & & & & & & & & & & \\
\hline Faixa de frequência em operaçăo & \multicolumn{13}{|c|}{$40 / 70 \mathrm{~Hz}$} \\
\hline Configuração & \multicolumn{6}{|c|}{ Tritásica $(\mathrm{F}+\mathrm{F}+\mathrm{F}+\mathrm{N}) /$ monotásica $(\mathrm{F}+\mathrm{N})$} & \multicolumn{7}{|c|}{ Triftásica $(F+F+F+N)$} \\
\hline Fator de potência & \multicolumn{13}{|c|}{0,98} \\
\hline Máx. corrente de entrada $(A)^{n}$ & $20 / 60$ & $30 / 90$ & $40 / 120$ & $45 / 135$ & $55 / 165$ & $72 / 216$ & 100 & 120 & 160 & 200 & 240 & 320 & 400 \\
\hline Distorçắo harmônica total (THDi) & \multicolumn{13}{|c|}{$<5 \%$} \\
\hline Rampa de partida & \multicolumn{13}{|c|}{30 segundos } \\
\hline Proteçōes & \multicolumn{13}{|c|}{ Subtensăo, sobretensão, variaçăo de frequência, isolaçăo galvãnicaª, curto-circuito, filtro de EMI, sobretemperatura } \\
\hline Conexão & \multicolumn{13}{|c|}{ Borneira } \\
\hline \multicolumn{14}{|c|}{ Saida do inversor } \\
\hline Rendimento & \multicolumn{13}{|c|}{$>90 \%$} \\
\hline Tensắo nominaa ${ }^{3 /}$ & \multicolumn{6}{|c|}{$380 \mathrm{~V} \mathrm{ca}$ (trifásica) / $220 \mathrm{~V} \mathrm{ca}$ (monotásica) } & \multicolumn{7}{|c|}{$380 \mathrm{~V} \mathrm{ca}$} \\
\hline Corrente nominal de saida (A) & $15,7 / 46$ & $22,8 / 68,2$ & $30,3 / 90,9$ & $37,8 / 115$ & $45,5 / 136,4$ & $60,5 / 184$ & 76 & 91 & 121 & 151 & 182 & 243 & 304 \\
\hline Frequência nominal & \multicolumn{13}{|c|}{$50 / 60 \mathrm{~Hz}$} \\
\hline Variaçắo de frequência & \multicolumn{13}{|c|}{ $\pm 1 \%$ ou $\pm 2 \%$ ou $\pm 5 \%$ ou $\pm 10 \%$ (ajustável) } \\
\hline Regulaçấo dinâmica da tensão & \multicolumn{13}{|c|}{$-5 \% /+6 \%$} \\
\hline Regulação estática da tensão & \multicolumn{13}{|c|}{ $\pm 1 \%$} \\
\hline $\begin{array}{l}\text { Regulação para carga } \\
\text { desbalanceada }\end{array}$ & \multicolumn{13}{|c|}{ $\pm 3 \%$ para $100 \%$ de carga } \\
\hline Distorçăo harmônica total (TDHV) & \multicolumn{13}{|c|}{$<3 \%$ (carga linear) $/<7 \%$ (carga năo linear) } \\
\hline Capacidade de sobrecarga & \multicolumn{6}{|c|}{$\begin{array}{c}100 \%-125 \% 10 \mathrm{~min} \\
>125 \% 2 \mathrm{~s}\end{array}$} & \multicolumn{7}{|c|}{$\begin{array}{c}125 \% \text { - } 150 \% \text { 30s } \\
>150 \% \text { imediato }\end{array}$} \\
\hline Proteçōes & \multicolumn{13}{|c|}{ Subtensăo, sobretensăo, limitaçăo de corrente, sobrecarga, curto-circuito, sobretemperatura } \\
\hline Conexắo & \multicolumn{13}{|c|}{ Borneira } \\
\hline
\end{tabular}

Fonte: WEG [2020].

O equipamento possui uma saída trifásica $380 \mathrm{VAC} 60 \mathrm{~Hz}$, o mesmo valor de sua entrada, e não coincidentemente, o mesmo valor de trabalho do inversor dos painéis, o que possibilita o trabalho integrado destes equipamentos sem a utilização de transformadores no conjunto. A eficiência máxima do equipamento é de $90 \%$, o que nos indica que para a potência instalada de $160 \mathrm{~kW}$, é possível utilizar $144 \mathrm{~kW}$, como calculado na equação (8). 
Figura 21 - Especificação técnica nobreak - baterias.

\begin{tabular}{|c|c|c|c|c|c|c|c|c|c|c|c|c|c|}
\hline \multicolumn{14}{|l|}{ Equipamentos $380 \mathrm{~V}$} \\
\hline \multicolumn{14}{|c|}{ Baterias } \\
\hline Tensão nominal & \multicolumn{6}{|c|}{$720 \mathrm{~V} \mathrm{cc}$} & \multicolumn{7}{|c|}{$744 \mathrm{~V} \mathrm{cc}$} \\
\hline Tensão de equalizaçăo & \multicolumn{6}{|c|}{$810 \mathrm{Vcc}$} & \multicolumn{7}{|c|}{$837 \mathrm{~V} \mathrm{cc}$} \\
\hline Tensão de flutuaçắo & \multicolumn{6}{|c|}{$810 \mathrm{Vcc}$} & \multicolumn{7}{|c|}{$837 \mathrm{~V} \mathrm{cc}$} \\
\hline Tensăo mínima & \multicolumn{6}{|c|}{$600 \mathrm{Vcc}$} & \multicolumn{7}{|c|}{$651 \mathrm{Vcc}$} \\
\hline Número de baterias & \multicolumn{6}{|c|}{60} & \multicolumn{7}{|c|}{62} \\
\hline $\begin{array}{l}\text { Máx. corrente de carga } \\
\text { de bateria (A) }\end{array}$ & 15 & 15 & 12 & 12 & 10 & 10 & 17 & 20 & 26 & 33 & 40 & 50 & 63 \\
\hline Limitação de corrente de carga & \multicolumn{13}{|c|}{ Ajustável } \\
\hline $\begin{array}{l}\text { Carga da bateria ajustável em funçắo } \\
\text { de compensaçăo de temperatura }\end{array}$ & \multicolumn{13}{|c|}{ Disponivel mediante instalação de medidor de temperatura opcional } \\
\hline Potência (kVA) & 10 & 15 & 20 & 25 & 30 & 40 & 50 & 60 & 80 & 100 & 120 & 160 & 200 \\
\hline Teste de bateria & \multicolumn{13}{|c|}{ Disponivel/programável } \\
\hline
\end{tabular}

Fonte: WEG [2020].

Como visto na Figura 21, que mostra as especificações de baterias para equipamentos 380V, retirada de um catálogo da WEG (2020), para a operação do equipamento devem ser instaladas 62 baterias.

A partir do valor de consumo mensal obtido na seção 6.1 .1 de $17.201,28 \mathrm{kWh}$, temse uma média de consumo diária de $573,38 \mathrm{kWh}$ ou ainda $23,89 \mathrm{~kW}$ médio por hora. Considerando a utilização média de potência da propriedade por hora, o nobreak instalado teria a autonomia de 6,02 horas, como calculado na equação (9).

$$
160 \mathrm{~kW} / 23,89 \mathrm{~kW}=6,02
$$

Para aumentar o tempo de utilização da carga armazenada no nobreak, equipamentos não essenciais podem ser desligados durante o período de falha. Caso a potência armazenada seja utilizada apenas para a alimentação elétrica dos galpões, que possui um consumo mensal obtido na seção 6.1 .1 de 12.412,48 kW, tem-se uma média de consumo diária de 413,75 kWh ou ainda 17,24 kW médio por hora, a autonomia de fornecimento do nobreak fica 8,35 horas, utilizando a equação (9) com os valores de potência média referente aos galpões.

A duração da potência armazenada pode variar de acordo com os equipamentos ligados, que variam também com o período do dia, conforme apresentado na seção 6.1.1.

\subsubsection{DISTRIBUIÇÃO E INTEGRAÇÃO COM A REDE LOCAL}

Por padronização dos equipamentos e manutenções futuras, é utilizado o menor número possível de fabricantes em uma mesma instalação, assim, pela vasta gama de equipamento e pelo atendimento de nível mundial, é utilizado o transformador WEG no projeto. 
O transformador CST ONAN, mostrado na Figura 22, de 500 kVA são ideais para esta aplicação, com tensão de $0,38 \mathrm{kV} 60 \mathrm{~Hz}$ na entrada/saída de baixa e 13,8 kV na entrada/saída de alta, é instalado em postes ou com suporte com rodas.

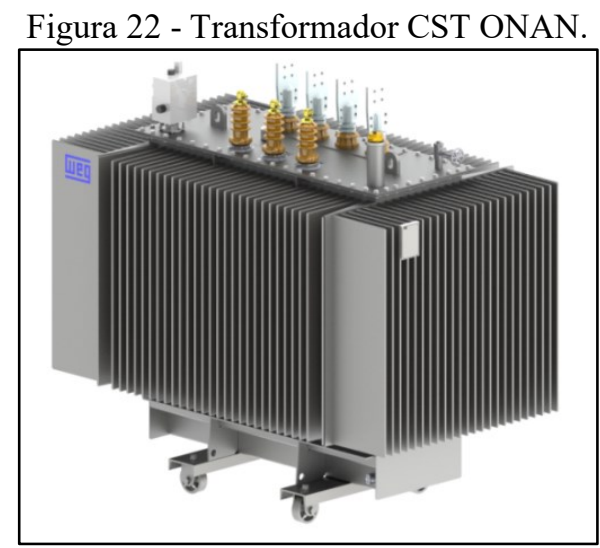

Fonte: WEG (2020).

Assim como demonstrado no capítulo 5.1, equipamentos principais, como geradores, transformadores e barramentos, formam zonas primárias de proteção, que devem possuir dispositivos de segurança na entrada e na saída da energia elétrica de cada zona. Os dispositivos geradores comumente possuem o seu próprio sistema de proteção, já dimensionado para a sua operação. Na configuração proposta, a proteção é feita em diferentes níveis de tensão, no primário do transformador é conectado uma rede de baixa tensão, com diferença de potencial de $380 \mathrm{~V}$, no secundário do transformador é conectado uma rede de média tensão, com diferença de potencial de $13,8 \mathrm{kV}$.

Para a proteção de circuitos elétricos em baixa tensão, é comum a aplicação de disjuntores de caixa moldada, e a fabricante WEG disponibiliza uma linha completa de soluções, denominada Disjuntores em Caixa Moldada DW, que disponibiliza, em alguns modelos com correntes mais elevadas, proteção eletrônica e ajustes para correntes de trabalho e falha (WEG, 2021).

A configuração da conexão em baixa tensão é padronizada pela concessionária, e deve ser utilizado o método estrela aterrado (Copel, 2018). A corrente trifásica do circuito pode ser calculada com a equação (10).

$$
I=\frac{P o t}{V * \sqrt{3}}
$$


Com a instalação de potência total de $488,4 \mathrm{~kW}$ e tensão de linha (diferença de potencial entre duas fases) de $380 \mathrm{~V}$, a corrente de linha total calculada é de 742,05 A. A configuração estrela aterrada disponibiliza um nível de tensão de fase (diferença de potencial entre fase e neutro) igual a 220V (segundo equação (11)) e corrente de neutro máxima igual a corrente de linha máxima. Assim, o disjuntor comercial para esta aplicação é o de corrente nominal (In) igual a 800A modelo DWB800S800-4DA, com capacidade de interrupção de 50kA, atendendo às normas da concessionária (Copel, 2018).

$$
V_{f}=\frac{V_{l}}{\sqrt{3}}
$$

De acordo com a WEG, para a proteção térmica (sobre carga) em circuitos de distribuição, a corrente de ajuste é a própria In, ou seja $800 \mathrm{~A}$, e para a proteção magnética (curto circuitos) a corrente de ajuste é na faixa de cinco vezes a In, 4000 A. O dispositivo possui ajuste para proteção de condutor neutro, que pode ser feito em $100 \%$ do valor da corrente de fase, $50 \%$ ou sem proteção, que para este projeto, a proteção deve estar no nível de 100\% (WEG, 2020). Os cabos elétricos para a transmissão de energia devem suportar a corrente nominal dos dispositivos de segurança que é de $800 \mathrm{~A}$, e nesta faixa de corrente, o fabricante General Cable disponibiliza o modelo ENERGY RV/XV 0,6/1kV E, condutor singelo com bitola de $400 \mathrm{~mm}^{2}$, que suporta uma corrente máxima de $823 \mathrm{~A}$, e deve ser instalado 1 condutor por fase (General Cable, 2020).

Para a proteção em média tensão, com nível de $13,8 \mathrm{kV}$, utiliza-se o interruptor de falhas IntelliRupter da S\&C, apresentado na Figura 8 e já mencionado no capítulo 5 , seção 5.2. O dispositivo possui, além de monitoramento de falhas e religamento automático, opções para configuração e monitoramento remoto, o que amplia a faixa de controle da rede, com modelos comerciais para nível de tensão até $15,5 \mathrm{kV}$ e segurança até 630 amperes.

A corrente do projeto pode ser calculada usando a equação (11). Por norma da rede de concessionária, o enrolamento do transformador do lado do acessante é ligado na configuração estrela aterrado (Copel, 2018), onde a corrente de linha é igual a corrente de fase.

A conexão em média tensão, de acordo com a concessionária de energia, é realizada na configuração delta, com nível de tensão de linha de 13,8 kV (Copel, 2018). Para o cálculo da corrente de linha (IL), utiliza-se a equação (10), obtendo-se o valor de 20,33 A. Para esta configuração, a corrente de fase (IF) se da pela equação (12), ou seja, 11,80 A. Para a média 
tensão, a corrente de ajuste adotada é igual a 1,3 vezes a In, ou seja, 26,43 A para corrente de linha, e 15,34 A para corrente de neutro. Para esta faixa de corrente, pode-se utilizar o modelo cabo para média tensão FOREX $8,7 / 15 \mathrm{kV}$, sendo utilizado 1 cabo por fase, com bitola mínima de $25 \mathrm{~mm}^{2}$ e capacidade de corrente de 156 A (General Cable, 2021).

$$
I_{f}=\frac{I_{l}}{\sqrt{3}}
$$

O diagrama unifilar do projeto de instalação é mostrado na Figura 23, onde os religadores da fonte fotovoltaica estão simbolizados como um único religador, como deverá ser o funcionamento dos mesmos em conjunto.

Figura 23 - Projeto de propriedade com Geração Fotovoltaica.

F: Dispositivo de proteção;

G: Geradores / Fontes de energia;

Q: Dispositivo de interrupção controlável:

$\mathrm{T}$ : Transformador de potêncial elétrico.

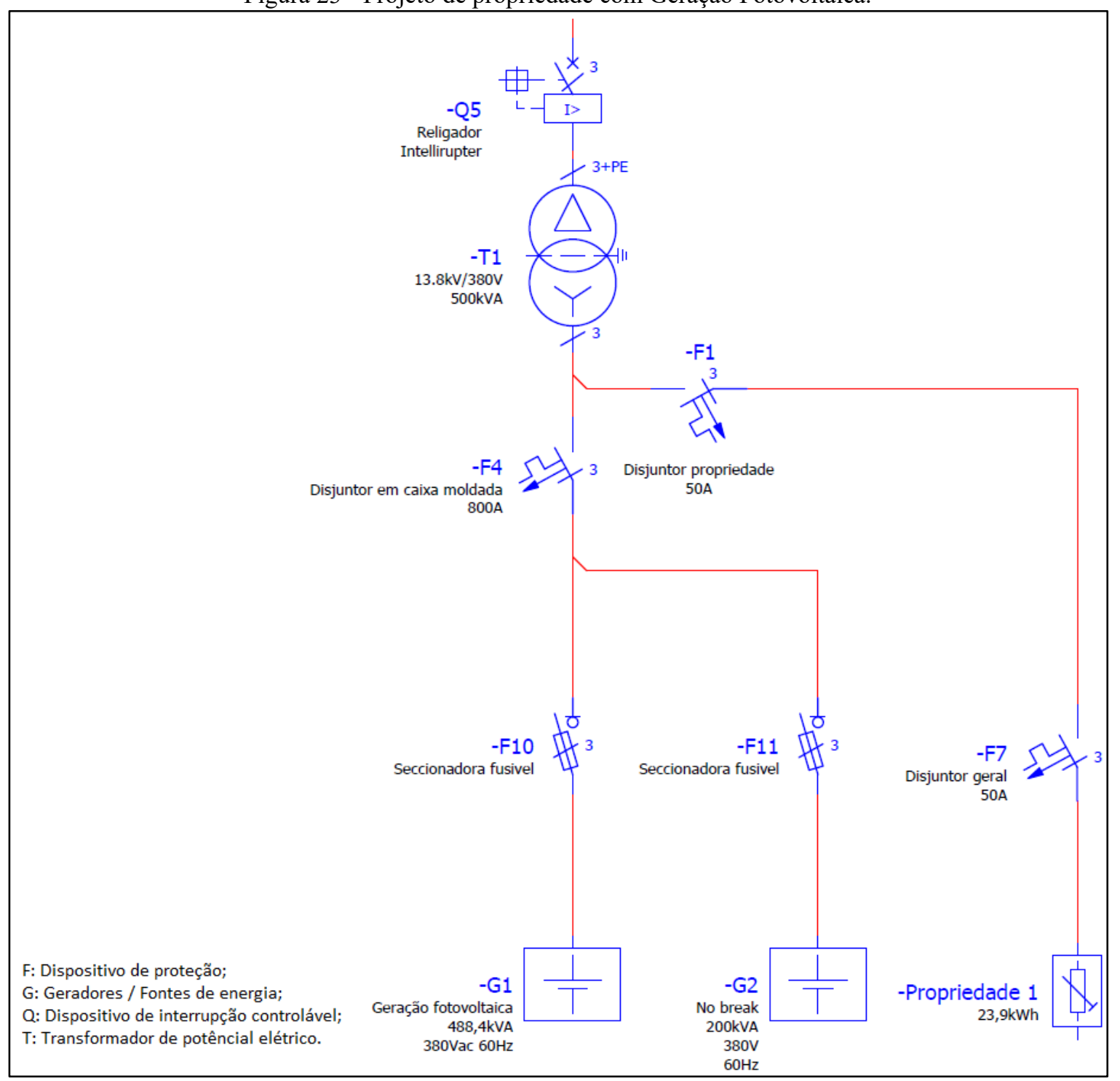

Fonte: Autoria Própria (2021). 


\subsection{PROPRIEDADE COM GERAÇÃO A BIOMASSA}

Assim como já mencionado neste trabalho, propriedades agrícolas brasileiras possuem um grande recurso muitas vezes não utilizado, a biomassa. Nesta propriedade apresentada, em específico, a biomassa provém das fezes de porcos, que são criados para consumo, e se não utilizada um grande potencial energético será desperdiçado. Para o projeto de geração, é considerado uma produção média de 2000 porcos a cada trimestre.

Para a geração do biogás a partir das fezes de suínos, a propriedade deve possuir biodigestores, que armazenam as fezes até que o biogás seja gerado, a partir da digestão de bactérias (NUNES, 2017). Franzon (2020) analisa mais a fundo os biodigestores e as questões específicas da transformação de biomassa em biogás, por fugir do escopo deste trabalho, este tema não será abordado e a leitura do trabalho citado é recomendada para mais detalhes sobre o assunto.

Esta propriedade não necessita de fornecimento ininterrupto de energia, então serão somente abordados a estrutura de geração de energia, transformação e conexão à rede elétrica local. Na parte de geração, serão considerados a biomassa já transformada em biogás e filtrada, pois o manejo e técnicas empregadas para a transformação dos resíduos em energia consumível pelos geradores fogem do escopo deste trabalho.

\subsubsection{CONSUMO DA PROPRIEDADE}

Os equipamentos presentes na residência principal e na do caseiro são mostrados na Tabela 5 e nas dependências de criação de porcos e sistema de bombeamento de água da fazenda, assim como demais dependências como casa de máquinas e garagem, na Tabela 6 . 
Tabela 5 - Tabela de cargas consumo residência propriedade 2.

\begin{tabular}{lcccccc}
\hline \multicolumn{1}{c}{ TIPO } & $\begin{array}{c}\text { QTD } \\
\text { E }\end{array}$ & $\begin{array}{c}\text { POT UN } \\
(\mathrm{W})\end{array}$ & $\begin{array}{c}\text { POT*QTD } \\
\mathrm{E}(\mathrm{W})\end{array}$ & $\begin{array}{c}\text { USO } \\
\text { DIÁRI } \\
\mathrm{O}(\mathrm{H})\end{array}$ & $\begin{array}{c}\text { USO } \\
\text { SEMANAL } \\
\text { (DIAS) }\end{array}$ & $\begin{array}{c}\text { CONSUM } \\
\text { O MENSAL } \\
(\mathrm{KWH})\end{array}$ \\
\hline CHUVEIRO ELÉTRICO & 5 & 5500 & 27500 & 2 & 7 & 1540 \\
GELADEIRA DUPLEX & 1 & 500 & 500 & 24 & 7 & 336 \\
GELADEIRA SIMPLES & 1 & 250 & 250 & 24 & 7 & 168 \\
FREEZER VERTICAL & 2 & 300 & 600 & 24 & 7 & 403,2 \\
TELEVISOR & 6 & 90 & 540 & 6 & 7 & 90,72 \\
MÁQUINA DE LAVAR ROUPA & 2 & 1000 & 2000 & 2 & 3 & 48 \\
FORNO DE MICRO ONDAS & 2 & 2000 & 4000 & 1 & 7 & 112 \\
CONDICIONADOR DE AR & 6 & 1400 & 8400 & 8 & 7 & 1881,6 \\
FERRO ELÉTRICO & 2 & 1000 & 2000 & 1 & 3 & 24 \\
FOGÃO ELÉTRICO DE 4 BOCAS & 1 & 6000 & 6000 & 4 & 7 & 672 \\
PONTO DE ILUMINAÇÃO & 35 & 20 & 700 & 6 & 7 & 117,6 \\
SECADOR DE CABELO & 3 & 1000 & 3000 & 1 & 7 & 84 \\
LIQUIDIFICADOR & 2 & 200 & 400 & 1 & 7 & 11,2 \\
AQUECEDOR DE AMBIENTE & 5 & 1000 & 5000 & 5 & 7 & 700 \\
TOTAL & - & - & $\mathbf{6 0 8 9 0}$ & - & - & $\mathbf{6 1 8 8 , 3 2}$ \\
\hline
\end{tabular}

Fonte: Autoria Própria (2020) com dados retirados do Manual de Eletrificação Rural (1997).

Tabela 6 - Tabela de cargas consumo galpão e bombeamento água propriedade 2.

\begin{tabular}{lcccccc}
\hline \multicolumn{1}{c}{ TIPO } & $\begin{array}{c}\text { QTD } \\
\mathrm{E}\end{array}$ & $\begin{array}{c}\text { POT UN } \\
(\mathrm{W})\end{array}$ & $\begin{array}{c}\text { POT*QTD } \\
\mathrm{E}(\mathrm{W})\end{array}$ & $\begin{array}{c}\text { USO } \\
\text { DIÁRI } \\
\mathrm{O}(\mathrm{H})\end{array}$ & $\begin{array}{c}\text { USO } \\
\text { SEMANAL } \\
\text { (DIAS) }\end{array}$ & $\begin{array}{c}\text { CONSUM } \\
\text { O MENSAL } \\
(\mathrm{KWH})\end{array}$ \\
\hline LÂMPADAS & 20 & 20 & 400 & 6 & 7 & 67,2 \\
CORTADOR DE GRAMA & 1 & 1300 & 1300 & 2 & 2 & 20,8 \\
$\begin{array}{l}\text { MISTURADOR DE RAÇÃO } \\
\text { CONJ. MOTOBOMBA }\end{array}$ & 1 & 4500 & 4500 & 4 & 7 & 504 \\
SUBMERSO & 1 & 22000 & 22000 & 8 & 7 & 4928 \\
BOMBA ALTA PRESSÃO & 1 & 11000 & 11000 & 8 & 7 & 2464 \\
TOTAL & - & - & $\mathbf{3 9 2 0 0}$ & - & - & $\mathbf{7 9 8 4}$ \\
\hline
\end{tabular}

Fonte: Autoria Própria (2020) com dados retirados do Manual de Eletrificação Rural (1997).

Para o cálculo do consumo total da propriedade é realizada a soma do consumo mensal de ambas as tabelas, obtendo o valor de 14.172,32 kWh por mês. Utilizando a equação (2) é obtido o custo mensal com a energia elétrica para a propriedade de $\mathrm{R} \$ 8750,55$, levando em consideração as tarifas convencionais para propriedades rurais disponibilizadas pela Copel (2020) de 0,31537 R\$/kWh para TE e 0,30207 R\$/kWh para TUSD, ambas com impostos inclusos.

Para essa propriedade tem-se um consumo mensal de 14.353,89 kWh, resultando em um custo de $\mathrm{R} \$ 8.862,65$ na tarifa convencional de acordo com o simulador da Copel, com detalhes da fatura mostrados no Anexo II. 
Ao comparar com os valores calculados, os resultados obtidos por meio da simulação podem ser considerados satisfatórios para a projeção de custo mensal da propriedade, com uma diferença de apenas $1,3 \%$.

\subsubsection{GERAÇÃO A BIOMASSA}

Segundo Nunes (2017), porcos geram cerca de 0,1431 a 0,2400 $\mathrm{m}^{3}$ de biogás ao dia, e foi adotado, para este trabalho, uma geração média de $0,2 \mathrm{~m}^{3}$ ao dia, e com um total de 2500 porcos a propriedade é capaz de gerar $20,83 \mathrm{~m}^{3} / \mathrm{h}$, seguindo os cálculos da equação (13), que será filtrado para geração de energia.

$$
0,2 \mathrm{~m}^{3} \text { por dia por porco } * 2500 \text { porcos } / 24 h=20,83 \mathrm{~m}^{3} / \mathrm{h}
$$

O fabricante paranaense ERBR, possui variados produtos para aplicação em biogás, como o gerador apresentado na Figura 24, biodigestores para transformação das fezes em biogás, mini refinarias e filtros, que entregam o metano limpo para utilização em motores a combustão, sistemas de armazenamento e distribuição em pequenas montas do gás para uso doméstico e também grupo de geradores a biogás, que serão adotados para este projeto.

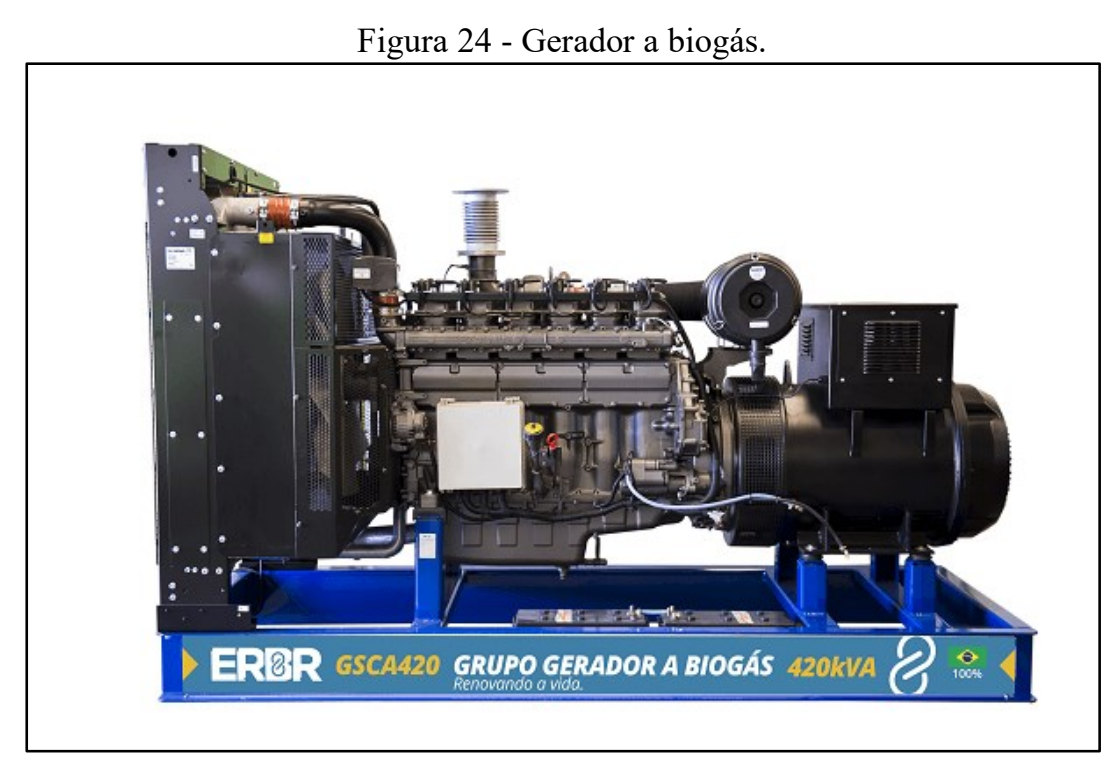

Fonte: ERBR (2021).

Para a utilização do biogás em geradores de energia, o combustível base deve ser filtrado e separado de agentes nocivos, porém, para o dimensionamento correto do sistema de 
filtragem do biogás, é necessário análise de amostras, e assim como em outros trabalhos acadêmicos, será adotado um biogás com um nível energético baixo, com $65 \%$ de metano em sua composição (NUNES, 2017).

Para biogás com $65 \%$ de concentração de metano, a ERBR possui os modelos de gerador GMWM30, GMWM50 e GMWM80, consumindo $14 \mathrm{~m} / \mathrm{h}, 20 \mathrm{~m}^{3} / \mathrm{h}$ e $34 \mathrm{~m}^{3} / \mathrm{h}$, gerando $20 \mathrm{kWh}, 32 \mathrm{kWh}$ e $55 \mathrm{kWh}$ respectivamente. Para este projeto, que tem um consumo mensal de $14.172,32 \mathrm{kWh}$ e com uma geração média de $20,83 \mathrm{~m}^{3} / \mathrm{h}$ de biogás, foi adotado o modelo GMWM50, que consome $20 \mathrm{~m}^{3} / \mathrm{h}$, com uma geração máxima de $32 \mathrm{kWh}$ em 24 horas. Considerando o tempo de manutenção mensal que o gerador necessita e o consumo da propriedade, foi utilizado um fator de utilização de $62,5 \%$, totalizando uma geração diária de $480 \mathrm{kWh} /$ dia, como calculado na equação (14) e uma produção mensal de até 14.400 kWh, como mostrado nos cálculos da equação (15).

$$
\begin{gathered}
32 k W * 24 h * 0,625=480 k W h \\
32 k W * 24 h * 30 \text { dias } * 0,625=14.400 \mathrm{kWh}
\end{gathered}
$$

A propriedade tem um consumo mensal de 14.172,32 kWh e será gerado um total de $14.400 \mathrm{kWh}$, isso significa que sobrará $227,68 \mathrm{kWh}$ por mês, como mostrado na equação (16).

$$
14.400 \mathrm{kWh}-14.172,32 \mathrm{kWh}=227,68 \mathrm{kWh}
$$

Apesar da baixa potência gerada ao dia, o gerador a biogás irá suprir a demanda energética da propriedade, além de dar um destino útil a material energético anteriormente desperdiçado.

Além da utilização de geradores desenvolvidos para consumo de biogás, outra alternativa é a utilização de motores a combustão interna, como os a gasolina, convertidos para utilização a biogás conforme analisa Bruna Campos (2019), no trabalho citado é abordado um projeto de $\mathrm{P} \& \mathrm{D}$ na cidade de Entre Rios do Oeste no estado do paraná, e financiado pela fornecedora de energia local COPEL. 


\subsubsection{DISTRIBUIÇÃO E INTEGRAÇÃO COM A REDE LOCAL}

O modelo de gerador utilizado disponibiliza energia na saída em 380 VAC $60 \mathrm{~Hz}$, trifásico, que pode facilmente ser utilizado pela propriedade e somente necessita de transformador para ligação à rede local.

A fabricante nacional WEG também atende esta de potência, disponibilizando o menor transformador de seu portfólio, mostrado na Figura 25, com uma potência de $45 \mathrm{kVA}$, com entrada/saída em baixa de $380 \mathrm{VAC} 60 \mathrm{~Hz}$, e entrada/saída 13,8 kV AC $60 \mathrm{~Hz}$.

Figura 25 - Transformador WEG.

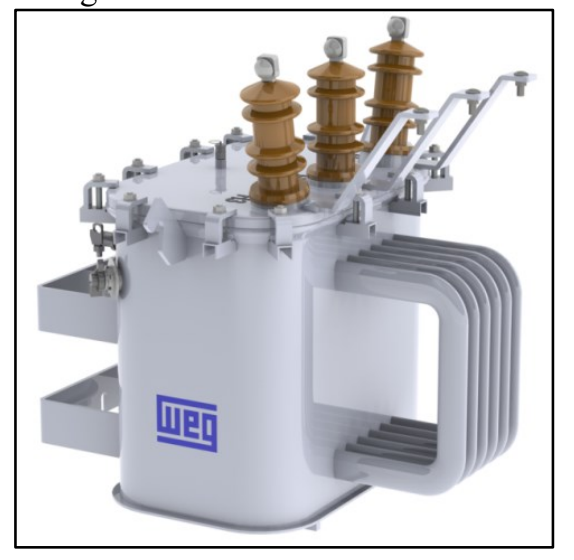

Fonte: WEG (2020).

Assim como no projeto de geração da propriedade de energia solar, o transformador forma uma zona primária, necessitando um dispositivo de proteção na entrada e na saída de energia elétrica. Para a proteção em baixa tensão será utilizado disjuntores em caixa moldada, e para a média tensão a ligação com a rede é feita a partir do IntelliRupter. A conexão em baixa tensão é feita em estrela aterrado, e em média tensão em delta.

Com a equação (10), pode-se calcular o valor de corrente trifásica que é fornecido quando a geração está em potência máxima, de $32 \mathrm{~kW}$ com diferença de potencial de $380 \mathrm{~V}$. A corrente de linha e de fase calculada é de 48,62 A. O valor comercial de disjuntor para esta faixa é de 50 A de corrente nominal (In) com código DWB160N50-4DF, com capacidade de interrupção de até 36kA (WEG, 2021). Este modelo possui ajuste térmico (sobrecarga) na ordem de $50 \mathrm{~A}$, e proteção magnética fixa (curto circuito), conforme critérios de curva de disparo disponíveis na norma NBR IEC 60947-2 (WEG, 2021).

Os cabos indicados para a instalação de baixa tensão são do modelo ENERGY $\mathrm{RV} / \mathrm{XV} 0,6 / 1 \mathrm{kV}$ E, um condutor por fase, com bitola $6 \mathrm{~mm}^{2}$, com capacidade de até $54 \mathrm{~A}$ (General Cable, 2021). 
A corrente trifásica em alta tensão pode ser calculada com a equação (10), com potência máxima de $32 \mathrm{~kW}$ e nível de tensão de $13,8 \mathrm{kV}$, o valor obtido é de 1,34 A para corrente de linha, e de 0,77 A para corrente de neutro. $\mathrm{O}$ ajuste de corrente de falta deve ser feito com 1,3 x In, 1,74 A para corrente de linha e 1 A para corrente de neutro. Para esta faixa de corrente, pode-se utilizar o modelo cabo para média tensão FOREX 8,7/15 kV, sendo utilizado 1 cabo por fase, com bitola mínima de $25 \mathrm{~mm}^{2}$ e capacidade de corrente de $156 \mathrm{~A}$ (General Cable, 2021).

O gerador utilizado deve possuir sistema de segurança próprio, com chave seccionadora, fusíveis ou disjuntores, conforme indicação do fabricante, o diagrama unifilar do projeto de instalação é mostrado na Figura 26. 
Figura 26 - Projeto de propriedade com geração a biomassa.

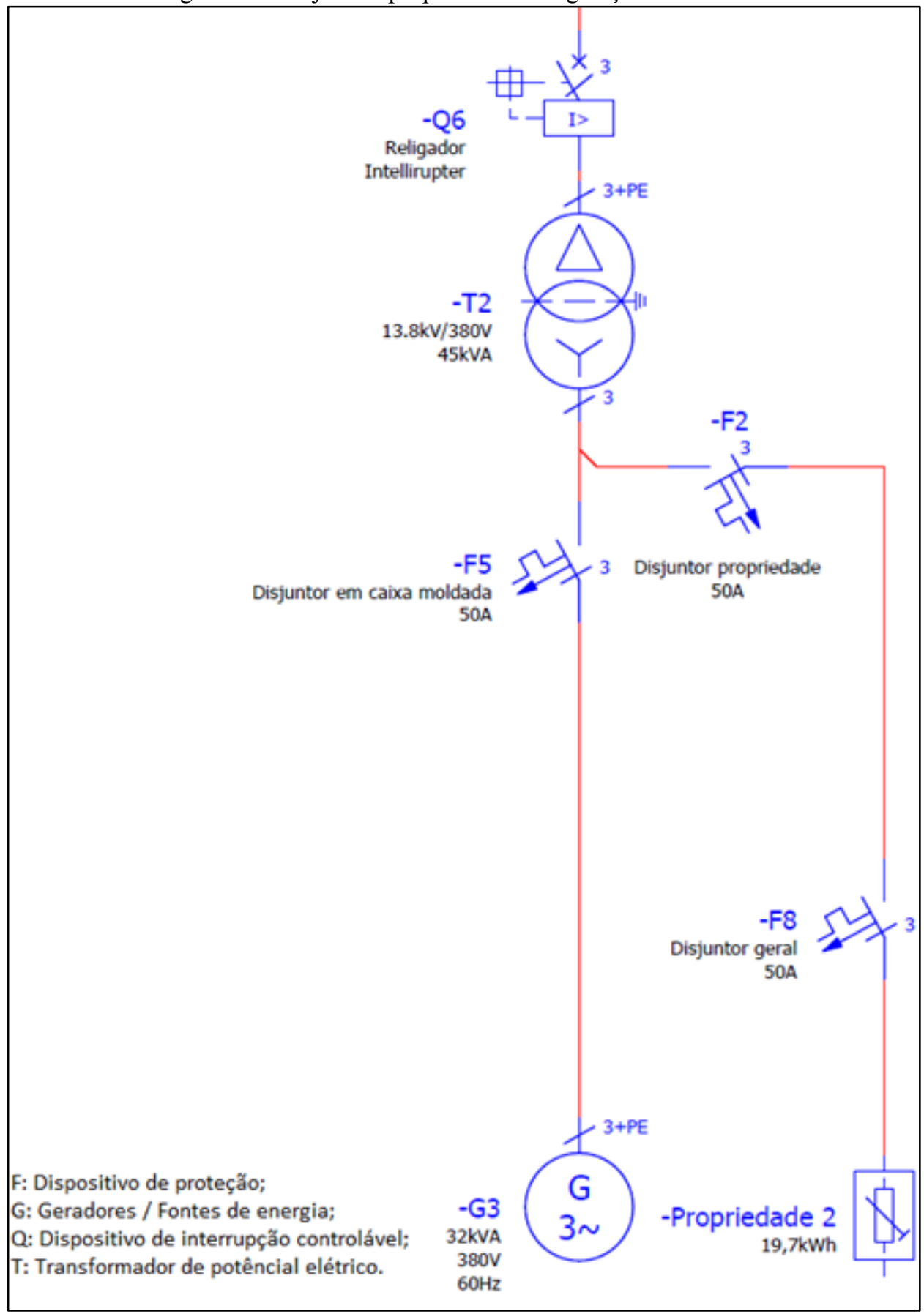

Fonte: Autoria Própria (2021). 


\subsection{PROPRIEDADE COM MICROGERAÇÃO HIDRELÉTRICA}

A terceira e última propriedade conta com recursos naturais privilegiados, dentro da propriedade passa um córrego que já é utilizado para irrigação das lavouras. Este é aproveitado no estudo para a microgeração hidrelétrica, que já é utilizada em meio urbano e alguns fabricantes possuem soluções com esta finalidade.

\subsubsection{CONSUMO DA PROPRIEDADE}

Os equipamentos da propriedade possuem carga de acordo com a Tabela 7 para residência principal e do caseiro e a Tabela 8 para a lavoura e o sistema de coleta de água para abastecimento da caixa d'água, que abastece toda a propriedade.

Tabela 7 - Tabela de cargas consumo residências propriedade 3.

\begin{tabular}{|c|c|c|c|c|c|c|}
\hline TIPO & $\begin{array}{c}\text { QTD } \\
E\end{array}$ & $\begin{array}{l}\text { POT UN } \\
\text { (W) }\end{array}$ & $\begin{array}{c}\text { POT }^{*} \text { QTD } \\
\text { E (W) }\end{array}$ & $\begin{array}{l}\text { USO } \\
\text { DIÁRI } \\
\mathrm{O}(\mathrm{H})\end{array}$ & $\begin{array}{l}\text { USO } \\
\text { SEMANAL } \\
\text { (DIAS) }\end{array}$ & $\begin{array}{c}\text { CONSUM } \\
\text { O MENSAL } \\
\text { (KWH) }\end{array}$ \\
\hline CHUVEIRO ELÉTRICO & 2 & 5500 & 11000 & 2 & 7 & 616 \\
\hline GELADEIRA SIMPLES & 2 & 250 & 500 & 24 & 7 & 336 \\
\hline FREEZER VERTICAL & 2 & 300 & 600 & 24 & 7 & 403,2 \\
\hline TELEVISOR & 4 & 90 & 360 & 6 & 7 & 60,48 \\
\hline MÁQUINA DE LAVAR ROUPA & 2 & 1000 & 2000 & 2 & 3 & 48 \\
\hline FORNO DE MICRO ONDAS & 2 & 2000 & 4000 & 1 & 7 & 112 \\
\hline CONDICIONADOR DE AR & 4 & 1400 & 5600 & 8 & 7 & 1254,4 \\
\hline FERRO ELÉTRICO & 2 & 1000 & 2000 & 1 & 3 & 24 \\
\hline FOGÃO ELÉTRICO DE 4 BOCAS & 1 & 6000 & 6000 & 2 & 7 & 336 \\
\hline PONTO DE ILUMINAÇÃO & 20 & 20 & 400 & 6 & 7 & 67,2 \\
\hline SECADOR DE CABELO & 2 & 1000 & 2000 & 1 & 7 & 56 \\
\hline TORRADEIRA & 1 & 800 & 800 & 1 & 7 & 22,4 \\
\hline LIQUIDIFICADOR & 2 & 200 & 400 & 1 & 7 & 11,2 \\
\hline AQUECEDOR DE AMBIENTE & 3 & 1000 & 3000 & 4 & 3 & 144 \\
\hline TOTAL & - & - & 38660 & - & - & 3490,88 \\
\hline
\end{tabular}


Tabela 8 - Tabela de cargas consumo lavoura e bombeamento água propriedade 3.

\begin{tabular}{|c|c|c|c|c|c|c|}
\hline TIPO & $\begin{array}{l}\text { QTD } \\
\text { E }\end{array}$ & $\begin{array}{l}\text { POT UN } \\
\text { (W) }\end{array}$ & $\begin{array}{l}\text { POT*QTD } \\
\text { E (W) }\end{array}$ & $\begin{array}{l}\text { USO } \\
\text { DIÁRI } \\
\mathrm{O}(\mathrm{H})\end{array}$ & $\begin{array}{c}\text { USO } \\
\text { SEMANAL } \\
\text { (DIAS) }\end{array}$ & $\begin{array}{c}\text { CONSUM } \\
\text { O MENSAL } \\
(\mathrm{KWH})\end{array}$ \\
\hline LÂMPADAS & 20 & 20 & 400 & 6 & 7 & 67,2 \\
\hline BOMBA PARA IRRIGAÇÃO & 1 & 7500 & 7500 & 8 & 7 & 1680 \\
\hline CORTADOR DE GRAMA & 1 & 1300 & 1300 & 2 & 2 & 20,8 \\
\hline $\begin{array}{l}\text { CONJ. MOTOBOMBA } \\
\text { SUBMERSO }\end{array}$ & 1 & 22000 & 22000 & 8 & 7 & 4928 \\
\hline BOMBA ALTA PRESSÃO & 1 & 11000 & 11000 & 8 & 7 & 2464 \\
\hline CATADOR LIMPEZA DO CAFÉ & 1 & 6000 & 6000 & 6 & 7 & 1008 \\
\hline CLASSIFICADOR DE CAFÉ & 1 & 7500 & 7500 & 6 & 7 & 1260 \\
\hline TOTAL & - & - & 55300 & - & - & 11360,8 \\
\hline
\end{tabular}

Fonte: Autoria Própria (2020) com dados retirados do Manual de Eletrificação Rural (1997).

Realizando a soma do consumo mensal de ambas as tabelas obtém-se o consumo total da propriedade no valor de $14.851,68 \mathrm{kWh}$. Utilizando a equação (2) para cálculo do custo mensal com a energia, é obtido o valor de R\$ 9170,02, levando em consideração as tarifas convencionais para propriedades rurais disponibilizadas pela Copel (2020) de 0,31537 $\mathrm{R} \$ / \mathrm{kWh}$ para TE e 0,30207 R\$/kWh para TUSD, ambas com impostos inclusos.

De acordo com a simulação realizada no simulador da Copel, para essa propriedade tem-se um consumo mensal de $15.228,60 \mathrm{kWh}$, com custo de $\mathrm{R} \$ 9.402,75$ na tarifa convencional. Os detalhes da fatura resultante da simulação são mostrados no Anexo III.

Ao fazer a comparação dos valores calculados com os valores da simulação, é possível considerar resultados satisfatórios para a projeção de custo mensal da propriedade, com uma diferença de apenas $2,5 \%$.

\subsubsection{MICROGERAÇÃO HIDRELÉTRICA}

A premissa fundamental para a elaboração de um sistema de microgeração hidrelétrica é a seleção da forma de conversão da energia potencial hídrica em energia elétrica, Assim, a propriedade dispõe de um reservatório de água utilizado para irrigação, que será utilizado para geração de energia.

O conjunto instalado na propriedade possui uma queda de 10 metros com uma vazão de $6 \mathrm{~m}^{3} / \mathrm{s}$ pelo conduto forçado (Estrutura de uma central por acumulação disponível no capítulo 2, seção 2.1).

Considerando um rendimento médio da turbina de 0,77 , e do gerador elétrico de 0,95, aplicando a equação (1), obtém-se um valor de 430,122 kW do conjunto instalado. 
Para auxiliar na escolha de turbinas de geração, a HISA, do Grupo WEG, disponibiliza um guia para seleção, mostrado na Figura 27, disponibilizando 3 modelos básicos de turbinas, modelo Pelton, Francis e Kaplan. Cada modelo é adotado a um tipo de vertedouro, com pequenas vazões e grandes quedas, ou pequenas quedas e grandes vazões. Estas características influenciam a construção das turbinas para o aproveitamento máximo daquele tipo específico de disposição da energia potencial, por se tratar de uma assunto muito detalhado e técnico que não é abordado neste trabalho.

Figura 27 - Gráfico guia para seleção de turbinas.

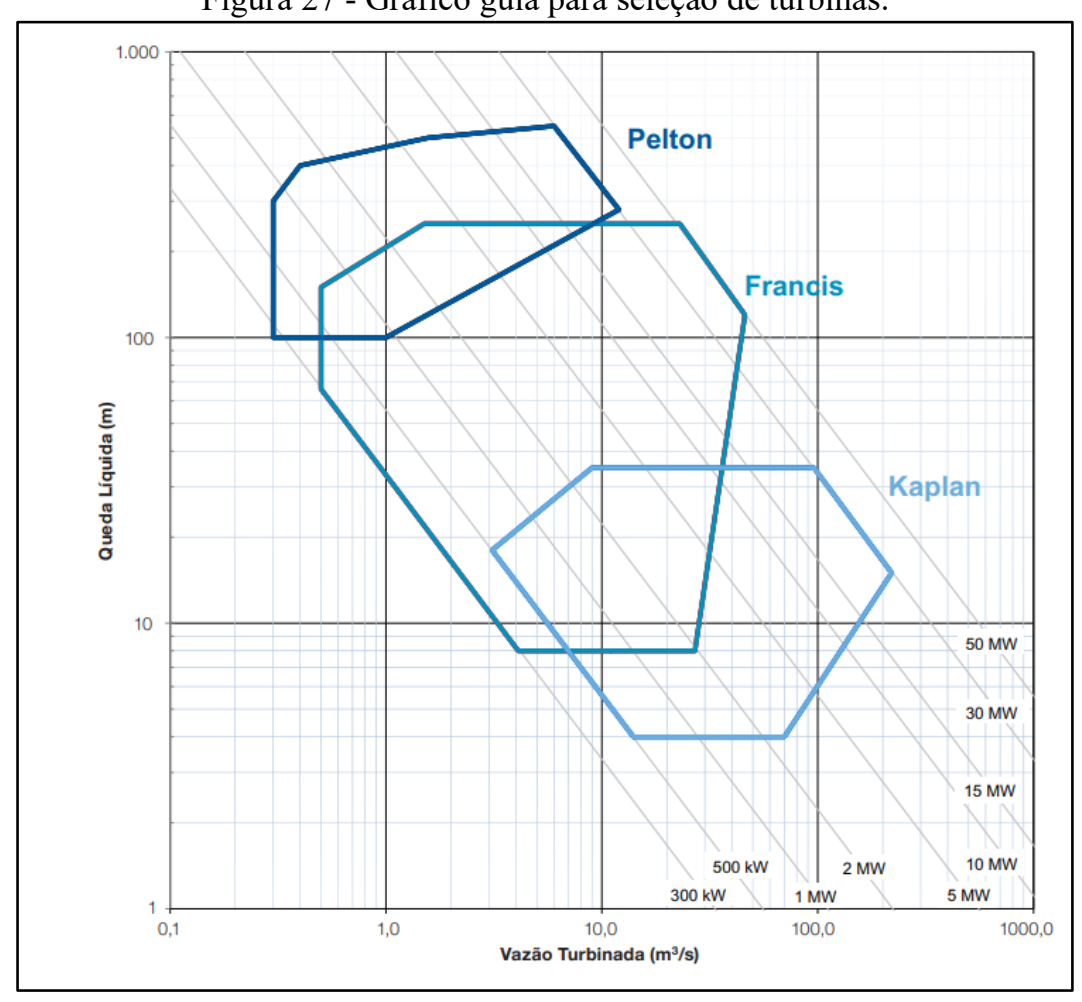

Fonte: HISA (2018).

Utilizando o gráfico guia para seleção de turbinas, mostrado na Figura 27, das informações da propriedade (queda de $10 \mathrm{~m}$ com vazão de $6 \mathrm{~m} / \mathrm{s}$ ), a turbina que mais se adequada ao projeto é o modelo Kaplan, apresentado na Figura 28 com capacidade de geração de $500 \mathrm{~kW}$, em conjunto com hidrogerador WEG GH10, mostrado ne Figura 29, de 500 kVA, fornecidos na tensão de $380 \mathrm{~V} 60 \mathrm{~Hz}$ (WEG, 2015), o que possibilita o aproveitamento total dos 430,122 kW disponíveis na planta de geração. 
Figura 28 - Turbina modelo Kaplan.

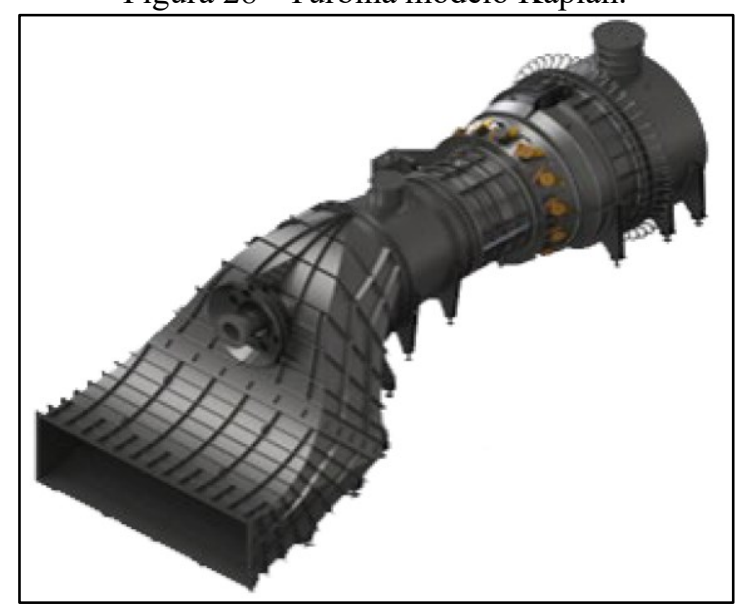

Fonte: HISA (2018).

Figura 29 - Hidrogerador modelo GH10.

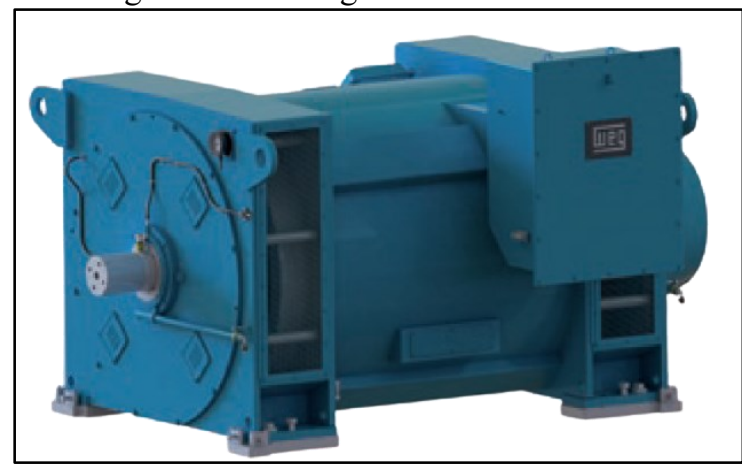

Fonte: WEG (2015).

Gerando energia 6 horas diárias, entre os meses de outubro a março (151 dias em anos não bisextos), que possuem os maiores volumes de chuva para o estado (CLIMATE , [20-?]), de modo que a irrigação das lavouras não sejam afetadas, utilizando a equação (1) para cálculo de $\mathrm{kWh}$, a propriedade gera $2.580,737 \mathrm{kWh} /$ dia e $389.690,532 \mathrm{kWh} / \mathrm{ano}$.

\subsubsection{DISTRIBUIÇÃO E INTEGRAÇÃO COM A REDE LOCAL}

Assim como mencionado nas seções anteriores, os transformadores constituem zonas primárias de proteção, que necessitam de dispositivos para segurança na entrada e na saída de energia elétrica. Para baixa tensão, será instalado disjuntor de caixa moldada, e em média tensão, religadores IntelliRupter. A conexão realizada em baixa tensão é na configuração estrela aterrada, e em média tensão delta.

Quando a fonte hidrelétrica estiver fornecendo a potência total de 430,122kW, com nível de tensão de linha igual a $380 \mathrm{~V}$, a corrente de linha e de neutro máxima da transmissão 
será de 653,50 A (calculado com a equação (10)). Nesta faixa de tensão, o disjuntor comercial é o mesmo utilizado para proteção de baixa tensão na fonte geradora fotovoltaica, apresentado na seção 6.1.4, código DWB800S800-4DA, e os parâmetros para ajuste são os mesmos calculados. Os cabos de distribuição são do modelo ENERGY RV/XV 0,6/1kV E, sendo um condutor singelo com bitola de $400 \mathrm{~mm}^{2}$ por fase, que suporta uma corrente máxima de $823 \mathrm{~A}$ (General Cable, 2020).

A corrente de linha em média tensão, para a potência de $430,122 \mathrm{~kW}$ e diferença de potencial em 13,8kV, é de 18,00 A, e a corrente de neutro é de 10,39 A (calculadas com a equação (10)). Para a corrente de ajuste de falta é de 1,3 x In, sendo 23,39 A para corrente de linha e 13,51 A para corrente de neutro.

São indicados para a instalação em média tensão, cabos com bitola mínima de $25 \mathrm{~mm}^{2}, 1$ condutor por fase, modelo FOREX 8,7/15 kV da General Cable, com capacidade máxima de 156A quando instalados em ar livre (General Cable, 2021).

O gerador de energia utilizado deve possuir seu próprio sistema de segurança, com chave seccionadora, fusíveis ou disjuntores, conforme indicação do fabricante, o diagrama unifilar do projeto de instalação é mostrado na Figura 30, os religadores estão ilustrados em uma única peça, assim como deve ser o seu funcionamento interligado. 
Figura 30 - Projeto de propriedade com geração hidrelétrica.

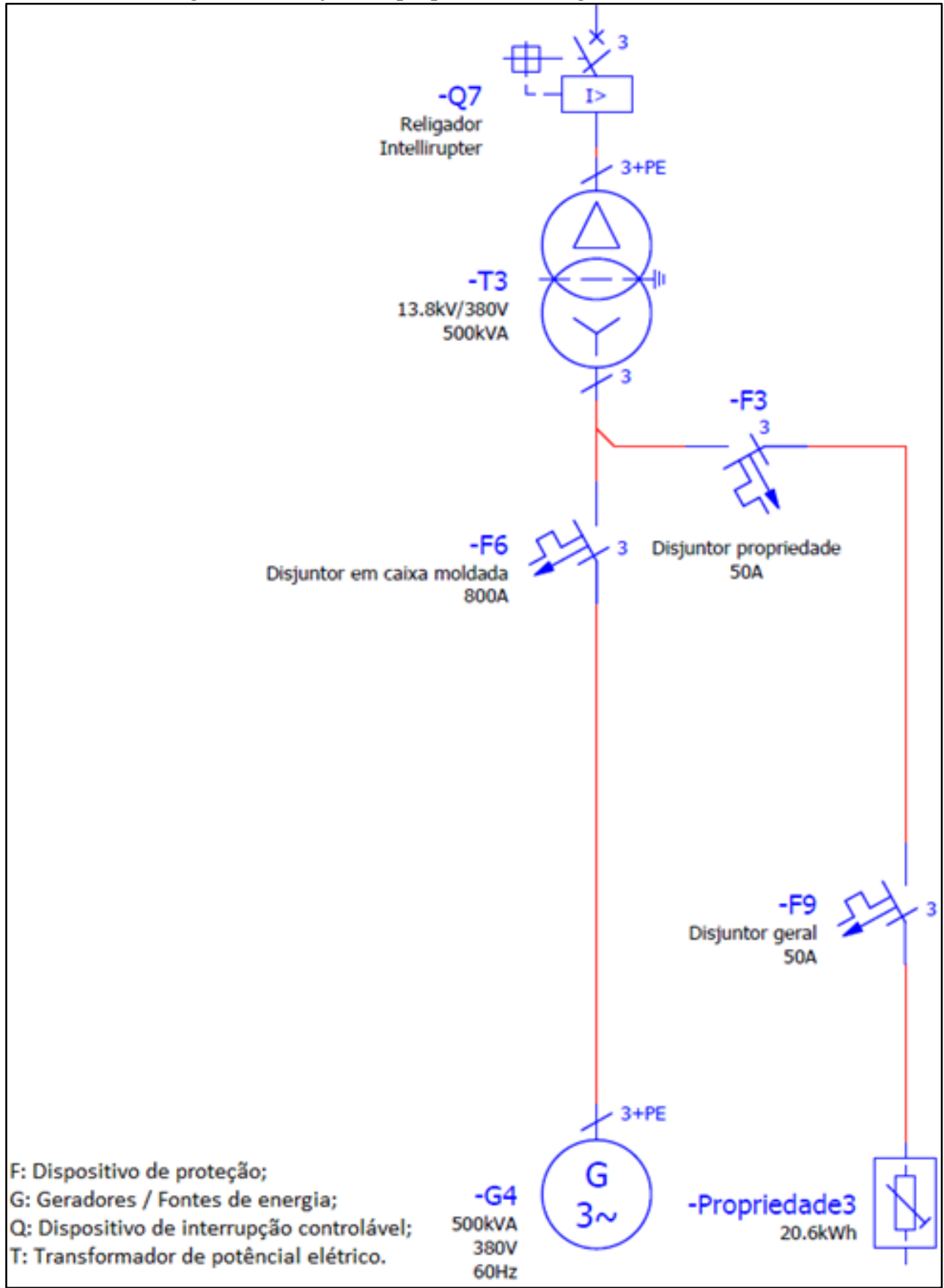

Fonte: Autoria Própria (2021).

\subsection{INTEGRAÇÃO DAS FONTES E GERENCIAMENTO DA MICRORREDE}

Os interruptores de falha com chaves seccionadoras com fusíveis integradas, IntelliRupter, utilizados para conexão das propriedades geradoras à rede, são essenciais para a integração e proteção das fontes de energia, além da instalação destes equipamentos em cada propriedade, é necessária instalação de mais dois religadores antes e depois da microrrede, o 
que possibilita o ilhamento e compartilhamento de carga entre as propriedades em momento de falhas na rede de distribuição local, projeto completo é mostrado na Figura 31.

Figura 31 - Projeto completo com interligação das três propriedades.

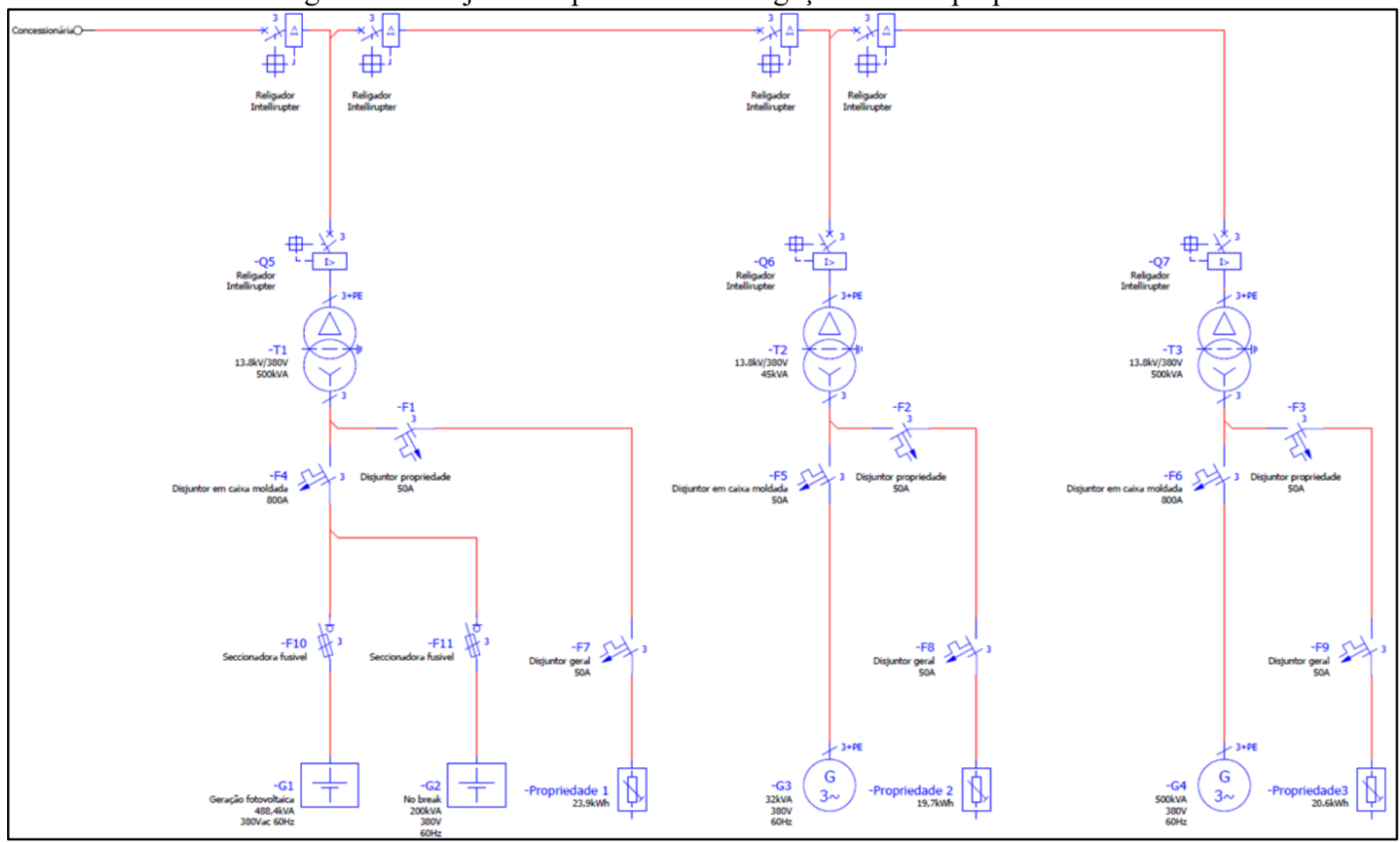

Fonte: Autoria Própria (2021).

A conexão das propriedades a rede de distribuição local em pontos distintos é peça chave para a geração distribuída, permitindo um controle descentralizado e a reconfiguração da rede conforme a falha acontece.

Conforme dados da S\&C, fabricante do IntelliRupter, cada equipamento possui um módulo de comunicação via rádio, que possibilita a troca de informações com outros religadores vizinhos. Estes equipamentos realizam o seccionamento automático em caso de falhas e resets quando a falha é normalizada, de forma independente e com troca de informações entre eles. Mas, para um maior controle da rede e desligamento das propriedades em caso de manutenção, é interessante a instalação de equipamentos com supervisório, e que possibilitem o seccionamento remoto, para manutenção das fontes geradores, ligação de novas fontes geradoras, etc. Para isto, cada propriedade está equipada com um módulo IntelliNode Interface Module do sistema IntelliTeam SG Automatic Restoration System da S\&C.

De acordo com a S\&C (20-?) o IntelliTeam SG Automatic Restoration System realiza a supervisão e controle da rede e automaticamente configura o sistema de distribuição depois de uma falha e rapidamente recompõe o serviço para os segmentos que não foram afetados 
pela falha. Ele usa o excesso de capacidade disponível de qualquer fonte alternativa convencional, eólica, recursos de geração distribuída e até mesmo bancos de baterias - para restaurar o serviço em segundos aos segmentos da linha que não sofreram falhas, com integração a sistemas SCADA da própria S\&C, instalados em computadores dedicados nas unidades de controle de carga de cada propriedade. Embora o sistema trabalhe em tempo real e unificado, a instalação em todas as propriedades traz redundância de segurança e controle sobre sua própria fonte geradora, e se for o caso, permissões de acesso ao software podem ser instaladas.

Para melhor reconfiguração da rede e imunidade a falhas, a topologia em anel pode ser aplicada a rede, suportada pelos equipamentos da S\&C, esta forma de distribuição de energia cria um laço contínuo, e falhas no caminho podem ser desviadas circulando a energia em sentido contrário.

\subsubsection{FLUXO DE POTÊNCIA PARA CENÁRIOS DE RECONFIGURAÇÃo DA REDE}

Foi utilizado o software ETAP (2021) para a realização da simulação do fluxo de potência. O programa é uma plataforma especializada em simulação, análise, monitoramento, controle, automatização e otimização de processos para projetos referentes à sistemas de energia, além de treinamento de operadores.

No estudo foram considerados cinco cenários, o primeiro deles é o padrão, com todos os equipamentos em pleno funcionamento; no segundo é considerada a perda da concessionária; e nos outros três cenários ocorre a perda de cada fonte geradora separadamente.

Para a simulação foram configurados os equipamentos de acordo com as tabelas presentes no ANEXO IV - CONFIGURAÇÃO EQUIPAMENTOS NO SOFTWARE ETAP. 


\subsubsection{CENÁRIO 1 - PADRÃO}

Na Figura 32 é mostrado o diagrama unifilar para a simulação do fluxo de potência no cenário padrão, onde não há perda de nenhum equipamento, sendo considerados todos em pleno funcionamento.

Figura 32 - Fluxo de potência para o cenário padrão.

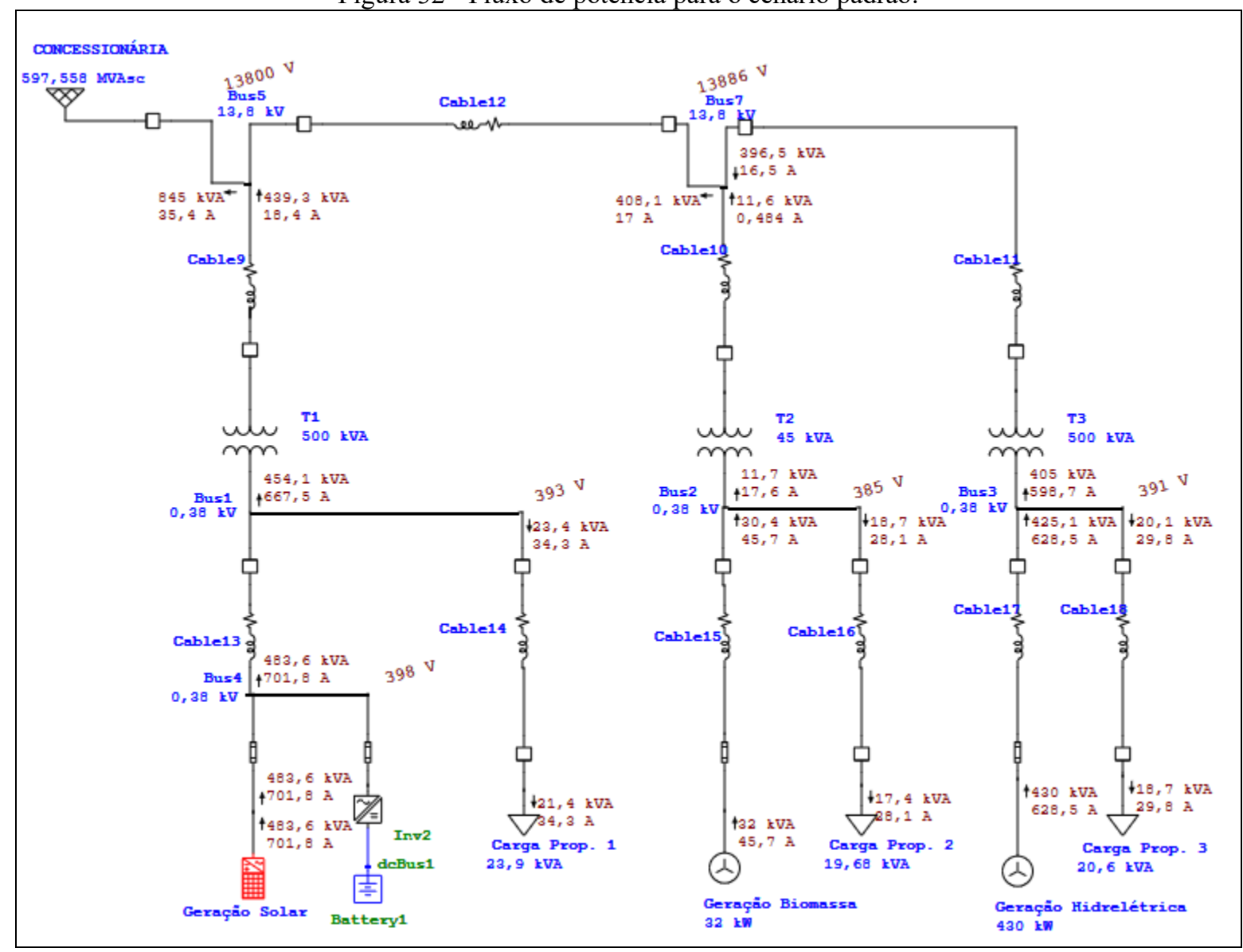

Fonte: Autoria própria (2021) com simulação ETAP.

A propriedade de geração solar gera $483,3 \mathrm{~kW}$, com corrente de 701,8 A, alimentando o ramo de sua carga com $23,4 \mathrm{~kW}$ e ficando com $454,1 \mathrm{~kW}$ de excedente enviado para a concessionária com 667,5 A na baixa tensão e 18,4 A na média tensão. Com a perda proveniente dos cabos, a carga dessa propriedade é abastecida com 21,4kW.

A propriedade de geração a biomassa gera $32 \mathrm{~kW}$, com corrente de 45,7 A, enviando $18,7 \mathrm{~kW}$ para o ramo de sua carga e disponibilizando para a concessionária o excedente de 11,7 kW com 17,6 A na baixa tensão e 0,48 A na média tensão. Com a perda gerada nos cabos, a carga dessa propriedade é abastecida com 17,4 kW. 
No caso da propriedade de geração hidrelétrica, há geração de $430 \mathrm{~kW}$, com corrente de 628,5 A, para a sua carga é enviado $20,1 \mathrm{~kW}$, após a perda relativa aos cabos, é abastecida com $18,7 \mathrm{~kW}$ e corrente de 29,8 A. Assim, a geração excedente é de $405 \mathrm{~kW}$ que é enviada para a concessionária com 596,7 A na baixa tensão e 16,5 A na média.

Então, para essa situação o fluxo tem a alimentação de cada propriedade feita pela sua própria fonte e o excedente total de $845 \mathrm{~kW}$, após as perdas, enviado para a concessionária.

\subsubsection{CENÁRIO 2 - SISTEMA EM ILHAMENTO}

Quando há a perda da conexão com a concessionária, oriunda de um rompimento de cabo ou falha de algum dispositivo, há a abertura do IntelliRupter Q1. Com isso, a configuração da rede fica de acordo com a apresentada na Figura 33.

Figura 33 - Fluxo de potência para modo ilha.

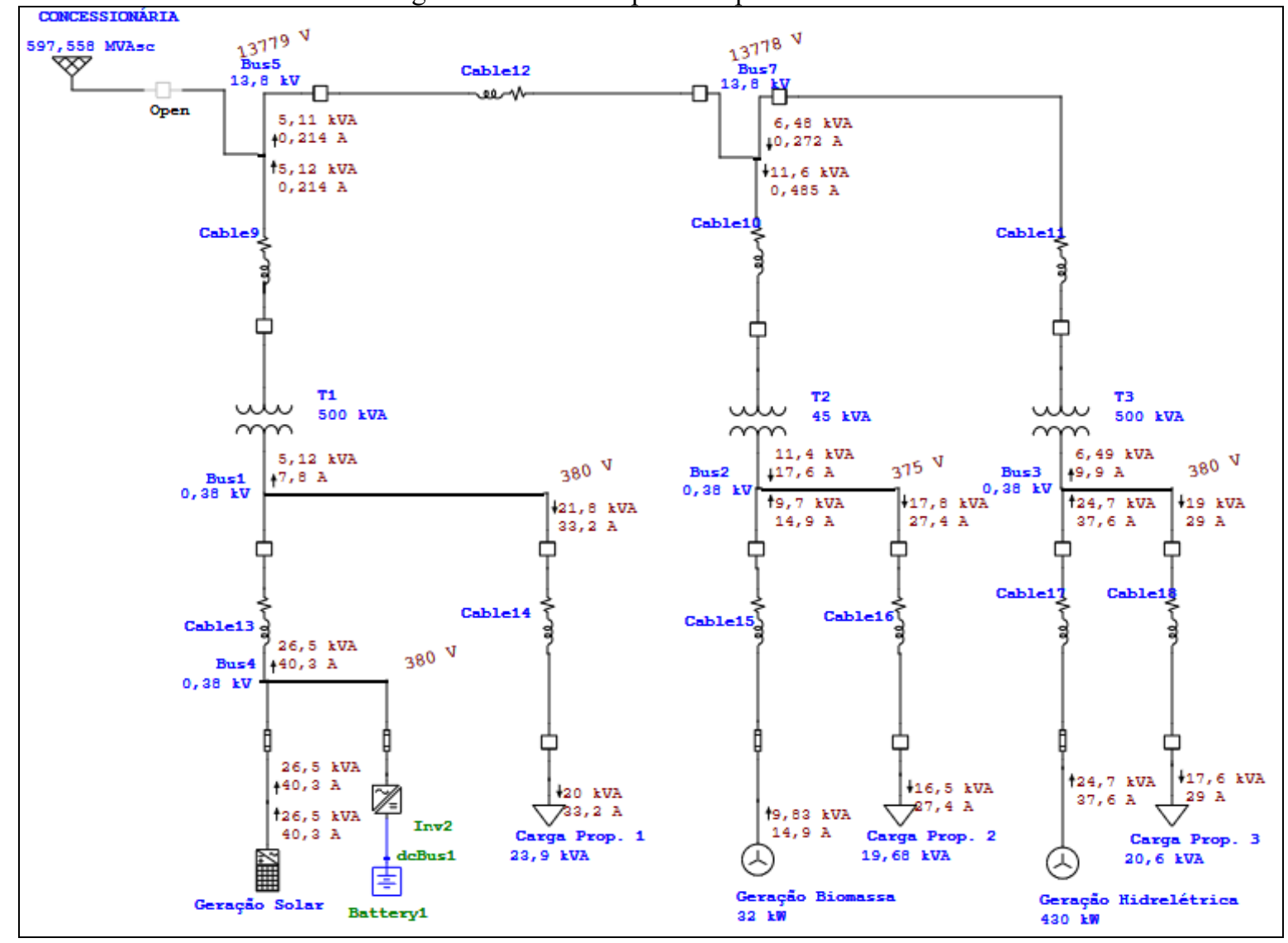

Fonte: Autoria própria (2021) com simulação ETAP. 
Para esse cenário não há geração excedente sendo enviada para a concessionária, dessa forma a propriedade de geração solar gera $26,5 \mathrm{~kW}$ que abastece suas próprias cargas com 21,8 kW (após perdas) e é enviado 5,12 kW para abastecimento da propriedade de geração de biomassa, a qual gera $9,82 \mathrm{~kW}$ que são enviados diretamente para abastecimento de suas próprias cargas, as quais além do valor oriundo da geração solar, também recebe 6,48 kW da geração hidrelétrica. A propriedade de geração hidrelétrica também gera 24,7 kW para abastecimento de suas próprias cargas.

\subsubsection{CENÁRIO 3 - FALTA GERAÇÃO PROPRIEDADE 01}

Para o cenário em questão o fluxo de potência da rede fica de acordo com o apresentado na Figura 34.

Figura 34 - Fluxo de potência para perda de geração da propriedade 01(Solar).

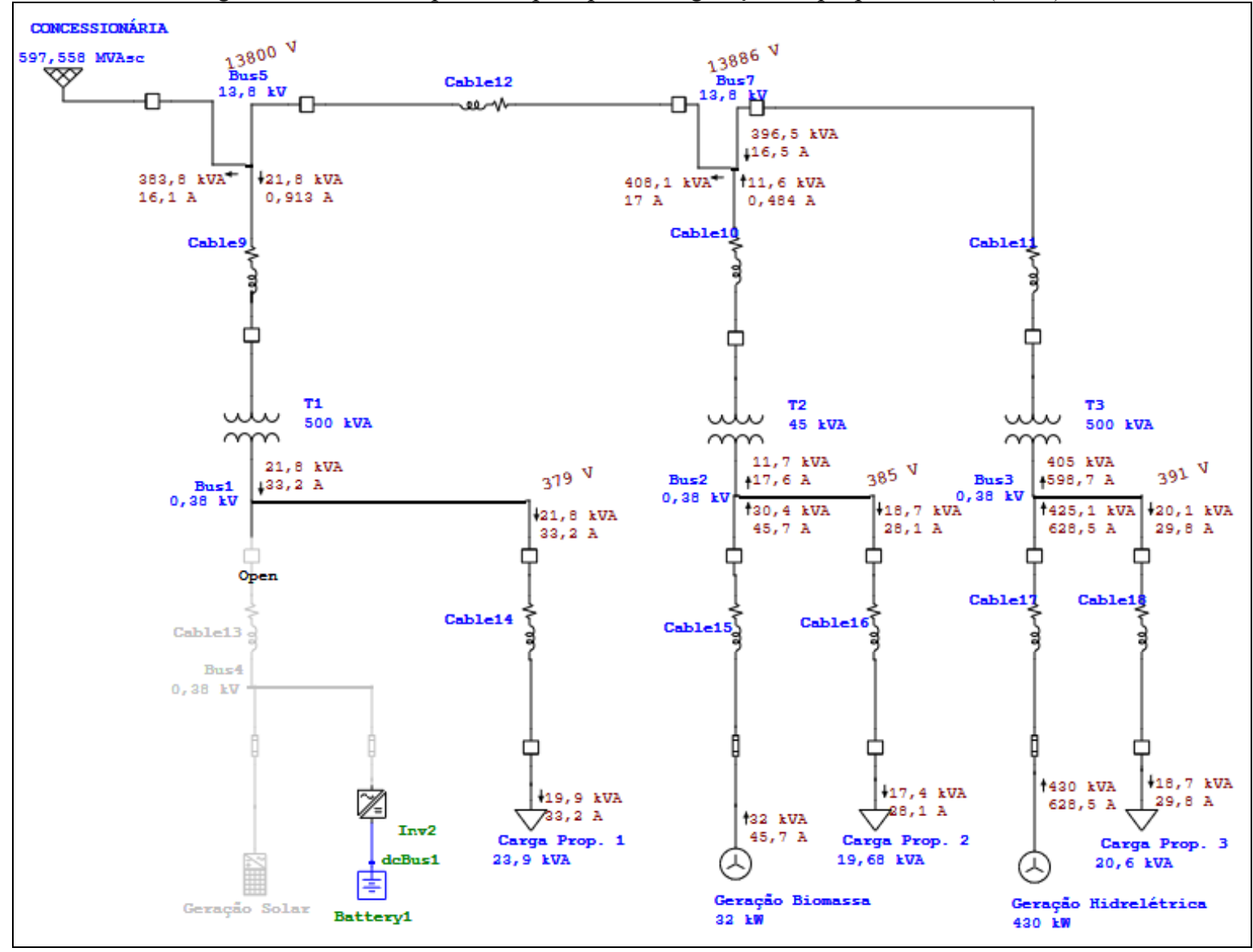

Fonte: Autoria própria (2021) com simulação ETAP. 
Com a abertura do disjuntor F4, devido a alguma falha na geração Solar, a geração da propriedade 03 (geração hidrelétrica), produzindo $430 \mathrm{~kW}$ e corrente de 628,5A, passa a fornecer energia para a propriedade 01 , com $21,8 \mathrm{~kW}$ e corrente de $33,2 \mathrm{~A}$, como visto nos valores próximos ao Bus1, e a propriedade 02 (geração a biogás) continua gerando sua própria energia. Os excedentes gerados, de $383,8 \mathrm{~kW}$, são enviados à concessionária, como mostrado pelos valores abaixo do Bus5.

\subsubsection{CENÁRIO 4 - FALTA GERAÇÃO PROPRIEDADE 02}

Neste cenário, o fluxo fica de acordo com a apresentada na Figura 35, há a abertura do disjuntor F5 devido a uma falha na geração da propriedade 02. Dessa maneira, a propriedade 03 (geração hidrelétrica) fornece energia para a propriedade 02, para as cargas da própria propriedade.

Figura 35 - Fluxo de potência para perda de geração da propriedade 02(Biomassa).

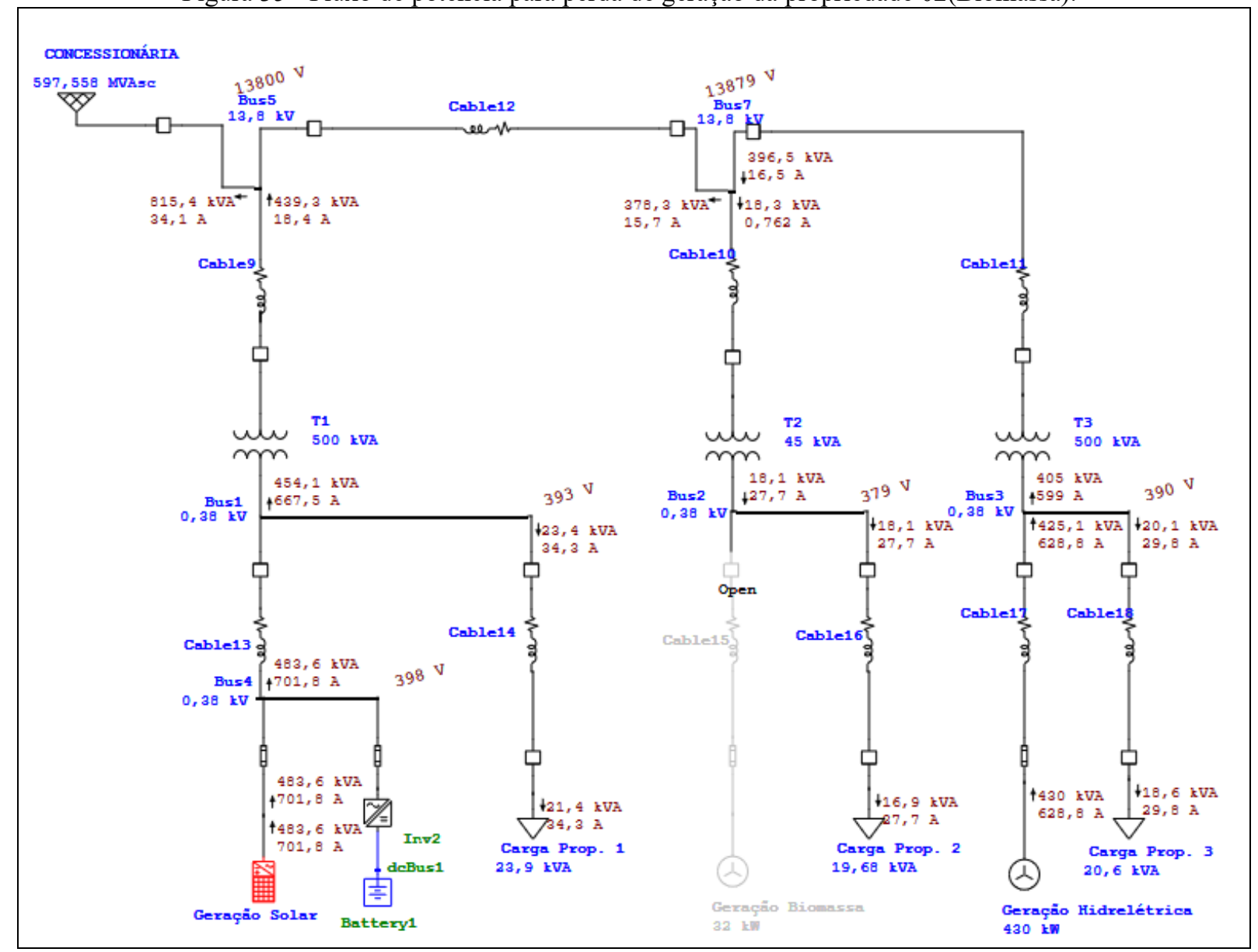

Fonte: Autoria própria (2021) com simulação ETAP. 
É possível analisar no fluxo de potência proveniente da geração hidrelétrica para abastecer a propriedade 02 de $18,3 \mathrm{~kW}$ e corrente de 0,76 A na média tensão e 27,7 A na baixa tensão do transformador. $\mathrm{O}$ excedente, de $815,4 \mathrm{~kW}$, proveniente da geração solar $(439,3 \mathrm{~kW})$ e da geração hidráulica $(378,3 \mathrm{~kW})$ como mostrado nos valores abaixo do Bus5 e Bus7, é enviado para a concessionária.

\subsubsection{CENÁRIO 5 - FALTA GERAÇÃO PROPRIEDADE 03}

Neste último cenário apresentado, a topologia da rede fica de acordo com a apresentada na Figura 36. Neste, ocorre a abertura do disjuntor F6 devido a falha na geração hidrelétrica.

Figura 36 - Fluxo de potência para perda de geração da propriedade 03(PCH).

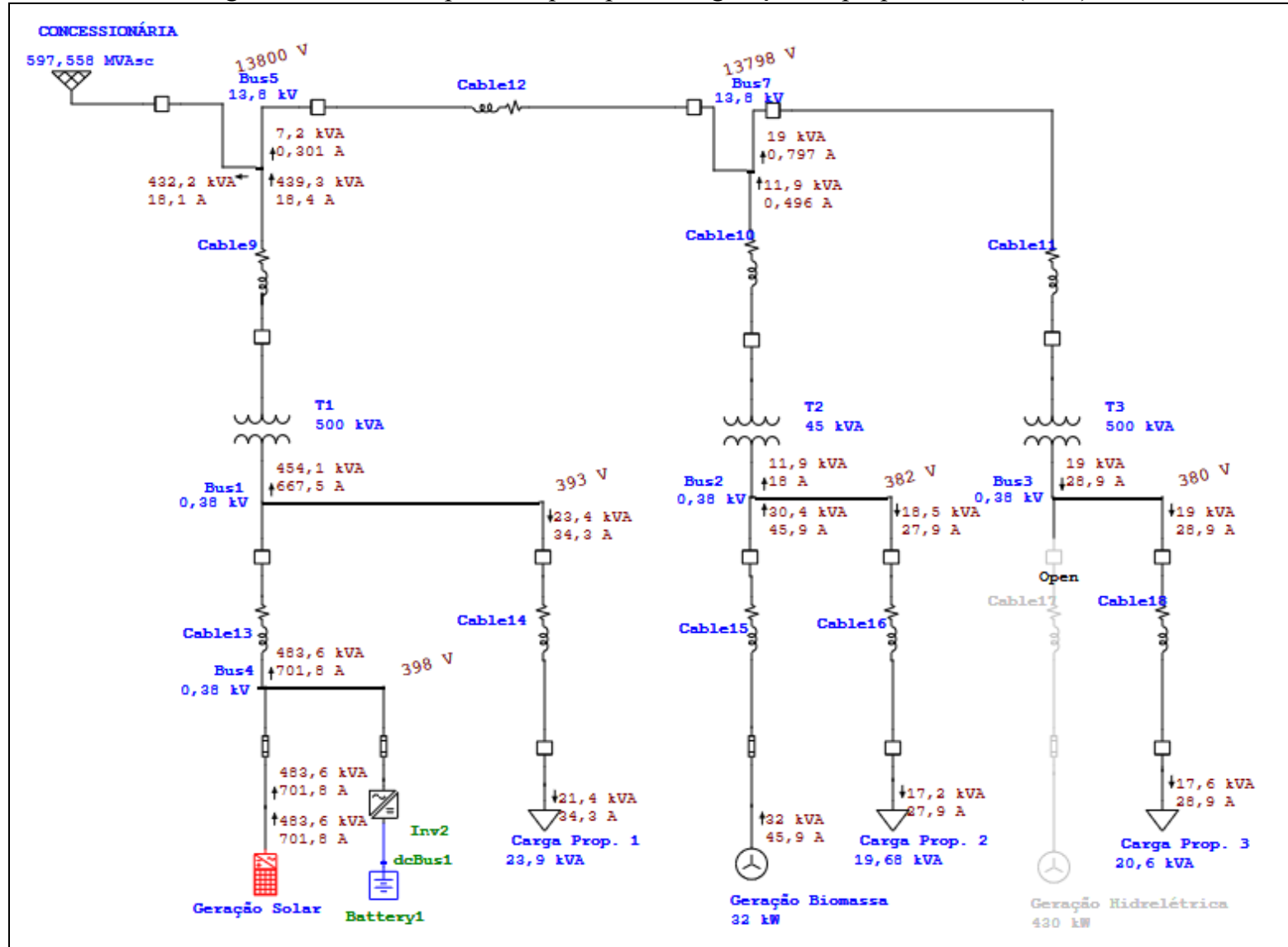

Fonte: Autoria própria (2021) com simulação ETAP.

Segundo o fluxo de potência, para o abastecimento da propriedade 03, são enviados $8,4 \mathrm{~kW}$ da geração solar e 11,8 kW proveniente da geração a biomassa, totalizando assim $20,1 \mathrm{~kW}$ para abastecer a propriedade 03 com corrente de 0,8 A na média tensão e 30,6 A na 
baixa tensão do transformador. O excedente, de 429,5 kW, oriundo da geração solar é enviado para a concessionária.

\subsection{VIABILIDADE TÉCNICO-ECONÔMICA}

A REN (Resolução Normativa) 482/2012 que estabelece as condições gerais para o acesso de micro e minigeração distribuída aos sistemas de distribuição elétrica. O Sistema de Compensação de Energia Elétrica (Figura 37), apresentado na REN 482/2012, permite que o excedente gerado pela unidade consumidora com micro ou minigeração seja injetado na rede da distribuidora.

De acordo com a ANEEL (2016), quando a energia injetada na rede for maior que a consumida, o consumidor receberá um crédito em energia $(\mathrm{kWh})$ a ser utilizado para abater o consumo em outro posto tarifário ou na fatura dos meses subsequentes. Os créditos de energia gerados continuam válidos por 60 meses. Há ainda a possibilidade de o consumidor utilizar esses créditos em outras unidades previamente cadastradas dentro da mesma área de concessão e caracterizada como autoconsumo remoto, geração compartilhada ou integrante de empreendimentos de múltiplas unidades consumidoras (condomínios), em local diferente do ponto de consumo.

A ANEEL (2016) ressalta que, para unidades consumidoras conectadas em baixa tensão (grupo B), ainda que a energia injetada na rede seja superior ao consumo, será devido o pagamento referente ao custo de disponibilidade. De forma análoga, para os consumidores conectados em alta tensão (grupo A) será devida apenas a parcela da fatura correspondente à demanda contratada. 
Figura 37 - Sistema de Compensação de Energia Elétrica.

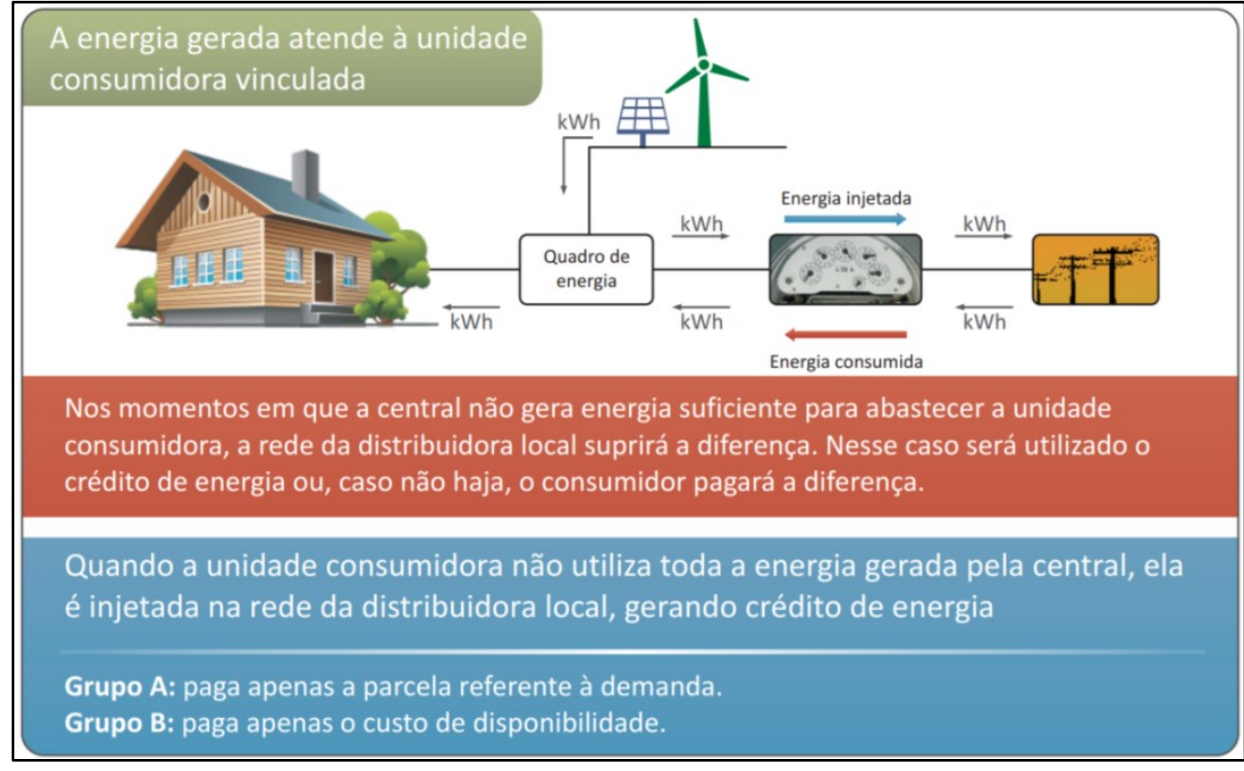

Fonte: ANEEL (2016).

No caso de estudo apresentado neste trabalho, os consumidores são do Grupo B e são unidades consumidoras trifásicas. Para os cálculos foi utilizado a tarifa de $0,61744 \mathrm{R} \$ / \mathrm{kWh}$ da COPEL para o grupo B2 - Rural, considerando os impostos federais e estaduais. A Propriedade 1 é a com Geração Fotovoltaica, a Propriedade 2 é a com Biogás e a Propriedade 3 é a com Geração Hidrelétrica. A Tabela 9 mostra a economia mensal das propriedades 1, a Tabela 10 da propriedade 2, e a Tabela 11 apresenta a economia mensal da propriedade 3, representada pela coluna 'Diferença'. A sigla 'GD' significa geração distribuída.

A Figura 38 é uma representação gráfica do fluxo de energia na propriedade 1 . O consumo médio mensal é o mesmo para todos os meses do ano, sendo de 17.226,03 kWh como já apresentado em 6.1.1, a diferença é na energia injetada na propriedade. Em condições normais de operação (todas as fontes conectadas entre si e com a concessionária COPEL), de outubro a março a propriedade 1 entrega todo o excedente gerado $(48.107,30 \mathrm{kWh})$ para a COPEL. E de abril a setembro parte da energia gerada pela propriedade 1 é destinada a propriedade $3(15.000,00 \mathrm{kWh})$ e parte para a COPEL $(50.333,33 \mathrm{kWh})$. Isso acontece pois, como explicado no capítulo 6.3.2, a propriedade 3 não estará produzindo energia durante esse período devido ao perfil das chuvas no estado. Durante todo ano a propriedade 1 gera energia suficiente para suprir o consumo anual de sua própria carga, fazendo com que a fatura cobrada pela COPEL para a propriedade seja de R $\$ 0$. 
Tabela 9 - Economia Mensal da Propriedade 01.

\begin{tabular}{ccccccc}
\hline MÊS & $\begin{array}{c}\text { CONSUMO } \\
(\mathrm{KWH})\end{array}$ & $\begin{array}{c}\text { INJETADO } \\
(\mathrm{KWH})\end{array}$ & $\begin{array}{c}\text { CRÉDITO } \\
(\mathrm{KWH})\end{array}$ & $\begin{array}{c}\text { FATURA } \\
\text { SEM GD } \\
(\mathrm{R} \$)\end{array}$ & $\begin{array}{c}\text { FATURA } \\
\text { COM GD } \\
(\mathrm{R} \$)\end{array}$ & $\begin{array}{c}\text { DIFERENÇA } \\
(\mathrm{R} \$)\end{array}$ \\
\hline $\mathbf{1}$ & $17.226,03$ & $65.333,33$ & $48.107,3$ & $10.636,04$ & 0 & $10.636,04$ \\
$\mathbf{2}$ & $17.226,03$ & $65.333,33$ & $48.107,3$ & $10.636,04$ & 0 & $10.636,04$ \\
$\mathbf{3}$ & $17.226,03$ & $65.333,33$ & $48.107,3$ & $10.636,04$ & 0 & $10.636,04$ \\
$\mathbf{4}$ & $17.226,03$ & $50.333,33$ & $33.107,3$ & $10.636,04$ & 0 & $10.636,04$ \\
$\mathbf{5}$ & $17.226,03$ & $50.333,33$ & $33.107,3$ & $10.636,04$ & 0 & $10.636,04$ \\
$\mathbf{6}$ & $17.226,03$ & $50.333,33$ & $33.107,3$ & $10.636,04$ & 0 & $10.636,04$ \\
$\mathbf{7}$ & $17.226,03$ & $50.333,33$ & $33.107,3$ & $10.636,04$ & 0 & $10.636,04$ \\
$\mathbf{8}$ & $17.226,03$ & $50.333,33$ & $33.107,3$ & $10.636,04$ & 0 & $10.636,04$ \\
$\mathbf{9}$ & $17.226,03$ & $50.333,33$ & $33.107,3$ & $10.636,04$ & 0 & $10.636,04$ \\
$\mathbf{1 0}$ & $17.226,03$ & $65.333,33$ & $48.107,3$ & $10.636,04$ & 0 & $10.636,04$ \\
$\mathbf{1 1}$ & $17.226,03$ & $65.333,33$ & $48.107,3$ & $10.636,04$ & 0 & $10.636,04$ \\
$\mathbf{1 2}$ & $17.226,03$ & $65.333,33$ & $48.107,3$ & $10.636,04$ & 0 & $10.636,04$ \\
TOTAL & $206.712,36$ & $693.999,96$ & $487.287,6$ & $127.632,48$ & 0 & $127.632,48$ \\
\hline \multicolumn{7}{c}{ Fonte: Autoria Própria $(2021)}$. \\
\end{tabular}

Figura 38 - Fluxo de Energia Médio Mensal - Propriedade 1.

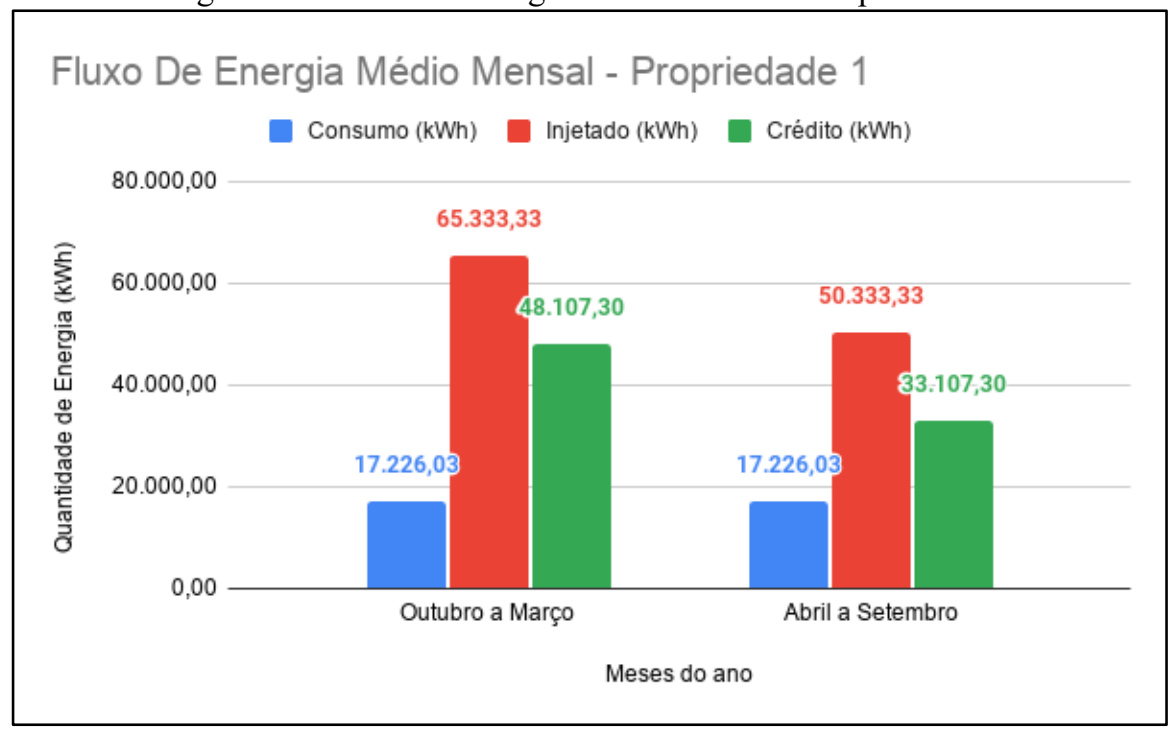

Fonte: Autoria Própria (2021).

A Figura 39 é uma representação gráfica do fluxo de energia na propriedade 2 . O consumo médio mensal é o mesmo para todos os meses do ano, sendo de 14.172,32 kWh como já apresentado em 6.2.1. Em condições normais de operação (todas as fontes conectadas entre si e com a concessionária COPEL) a propriedade 2 é capaz de produzir a própria energia que consome. Durante todo ano a propriedade 2 gera energia suficiente para suprir o consumo anual de sua própria carga, fazendo com que a fatura cobrada pela COPEL para a propriedade seja de R\$ 0. Essa propriedade é a que apresenta menor excedente de geração. 
Tabela 10 - Economia Mensal das Propriedade 02.

\begin{tabular}{ccccccc}
\hline MÊS & $\begin{array}{c}\text { CONSUMO } \\
(\mathrm{KWH})\end{array}$ & $\begin{array}{c}\text { INJETADO } \\
(\mathrm{KWH})\end{array}$ & $\begin{array}{c}\text { CRÉDITO } \\
(\mathrm{KWH})\end{array}$ & $\begin{array}{c}\text { FATURA } \\
\text { SEM GD } \\
(\mathrm{R} \$)\end{array}$ & $\begin{array}{c}\text { FATURA } \\
\text { COM GD } \\
(\mathrm{R} \$)\end{array}$ & $\begin{array}{c}\text { DIFERENÇA } \\
(\mathrm{R} \$)\end{array}$ \\
\hline $\begin{array}{c}\text { TOTAL } \\
\text { ANO }\end{array}$ & $14.172,32$ & $14.400,00$ & 227,68 & $8.750,56$ & 0 & $8.750,56$ \\
\hline
\end{tabular}

Fonte: Autoria Própria (2021).

Figura 39 - Fluxo de Energia Médio Mensal - Propriedade 2.

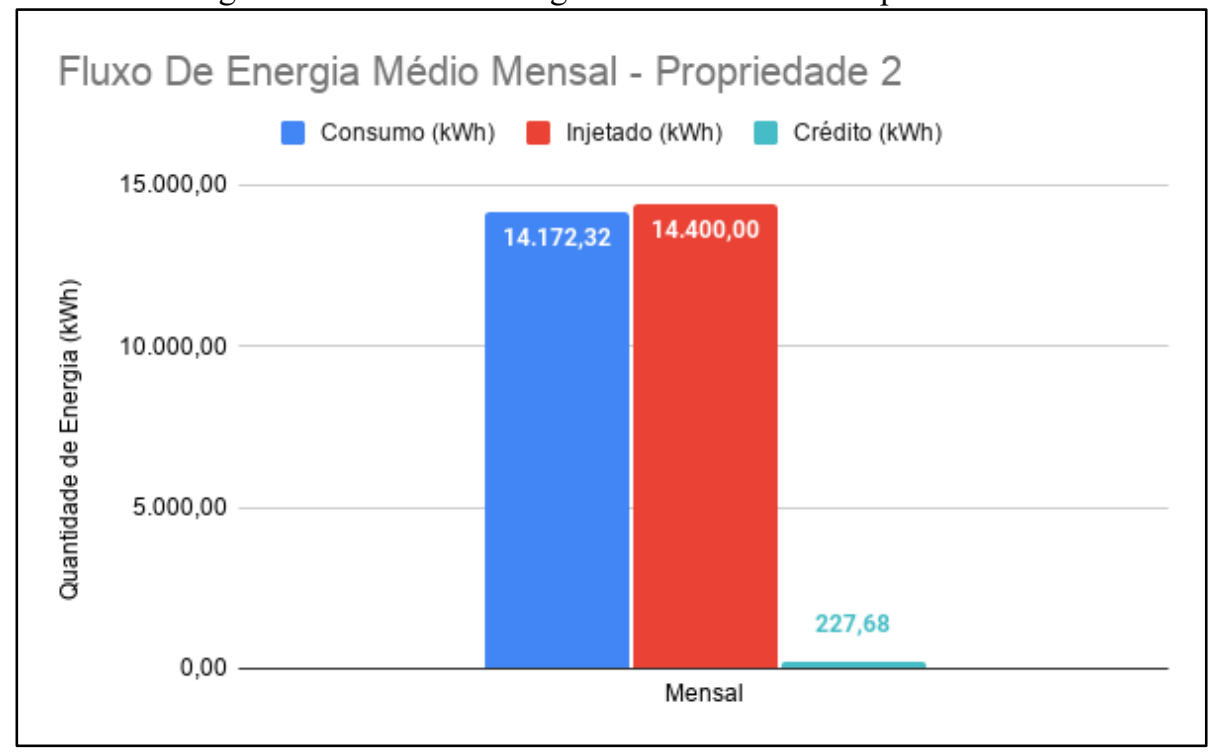

Fonte: Autoria Própria (2021).

A Figura 40 é uma representação gráfica do fluxo de energia na propriedade 3. O consumo médio mensal é o mesmo para todos os meses do ano, sendo de 14.851,6 kWh como já apresentado em 6.3.1, a diferença é na energia injetada na propriedade. Em condições normais de operação (todas as fontes conectadas entre si e com a concessionária COPEL), de outubro a março a propriedade 3 entrega todo o excedente gerado $(62.570,51 \mathrm{kWh})$ para a COPEL. E de abril a setembro recebe parte da energia gerada pela propriedade $1(15.000,00$ $\mathrm{kWh}$ ). Durante todo ano a propriedade 3 gera energia suficiente para suprir o consumo anual de sua própria carga, fazendo com que a fatura cobrada pela COPEL para a propriedade seja de $\mathrm{R} \$ 0$. 
Tabela 11 - Economia Mensal das Propriedade 03.

\begin{tabular}{ccccccc}
\hline MÊS & $\begin{array}{c}\text { CONSUMO } \\
(\text { KWH })\end{array}$ & $\begin{array}{c}\text { INJETADO } \\
(\text { KWH })\end{array}$ & $\begin{array}{c}\text { CRÉDITO } \\
(\text { KWH })\end{array}$ & $\begin{array}{c}\text { FATURA } \\
\text { SEM GD } \\
(\mathrm{R} \$)\end{array}$ & $\begin{array}{c}\text { FATURA } \\
\text { COM GD } \\
(\mathrm{R} \$)\end{array}$ & $\begin{array}{c}\text { DIFERENÇA } \\
(\mathrm{R} \$)\end{array}$ \\
$\mathbf{1}$ & $14.851,6$ & $77.422,11$ & $62.570,51$ & $9.170,02$ & 0 & $9.108,28$ \\
$\mathbf{2}$ & $14.851,6$ & $77.422,11$ & $62.570,51$ & $9.170,02$ & 0 & $9.108,28$ \\
$\mathbf{3}$ & $14.851,6$ & $77.422,11$ & $62.570,51$ & $9.170,02$ & 0 & $9.108,28$ \\
$\mathbf{4}$ & $14.851,6$ & $15.000,00$ & 148,4 & $9.170,02$ & 0 & $9.108,28$ \\
$\mathbf{5}$ & $14.851,6$ & $15.000,00$ & 148,4 & $9.170,02$ & 0 & $9.108,28$ \\
$\mathbf{6}$ & $14.851,6$ & $15.000,00$ & 148,4 & $9.170,02$ & 0 & $9.108,28$ \\
$\mathbf{7}$ & $14.851,6$ & $15.000,00$ & 148,4 & $9.170,02$ & 0 & $9.108,28$ \\
$\mathbf{8}$ & $14.851,6$ & $15.000,00$ & 148,4 & $9.170,02$ & 0 & $9.108,28$ \\
$\mathbf{9}$ & $14.851,6$ & $15.000,00$ & 148,4 & $9.170,02$ & 0 & $9.108,28$ \\
$\mathbf{1 0}$ & $14.851,6$ & $77.422,11$ & $62.570,51$ & $9.170,02$ & 0 & $9.108,28$ \\
$\mathbf{1 1}$ & $14.851,6$ & $77.422,11$ & $62.570,51$ & $9.170,02$ & 0 & $9.108,28$ \\
$\mathbf{1 2}$ & $14.851,6$ & $77.422,11$ & $62.570,51$ & $9.170,02$ & 0 & $9.108,28$ \\
TOTAL & $178.219,2$ & $554.532,66$ & $376.313,46$ & $110.040,24$ & 0 & $110.040,24$ \\
\hline \multicolumn{7}{c}{ Fonte: Autoria Própria $(2021)}$. \\
\end{tabular}

Figura 40 - Fluxo de Energia Médio Mensal - Propriedade 3

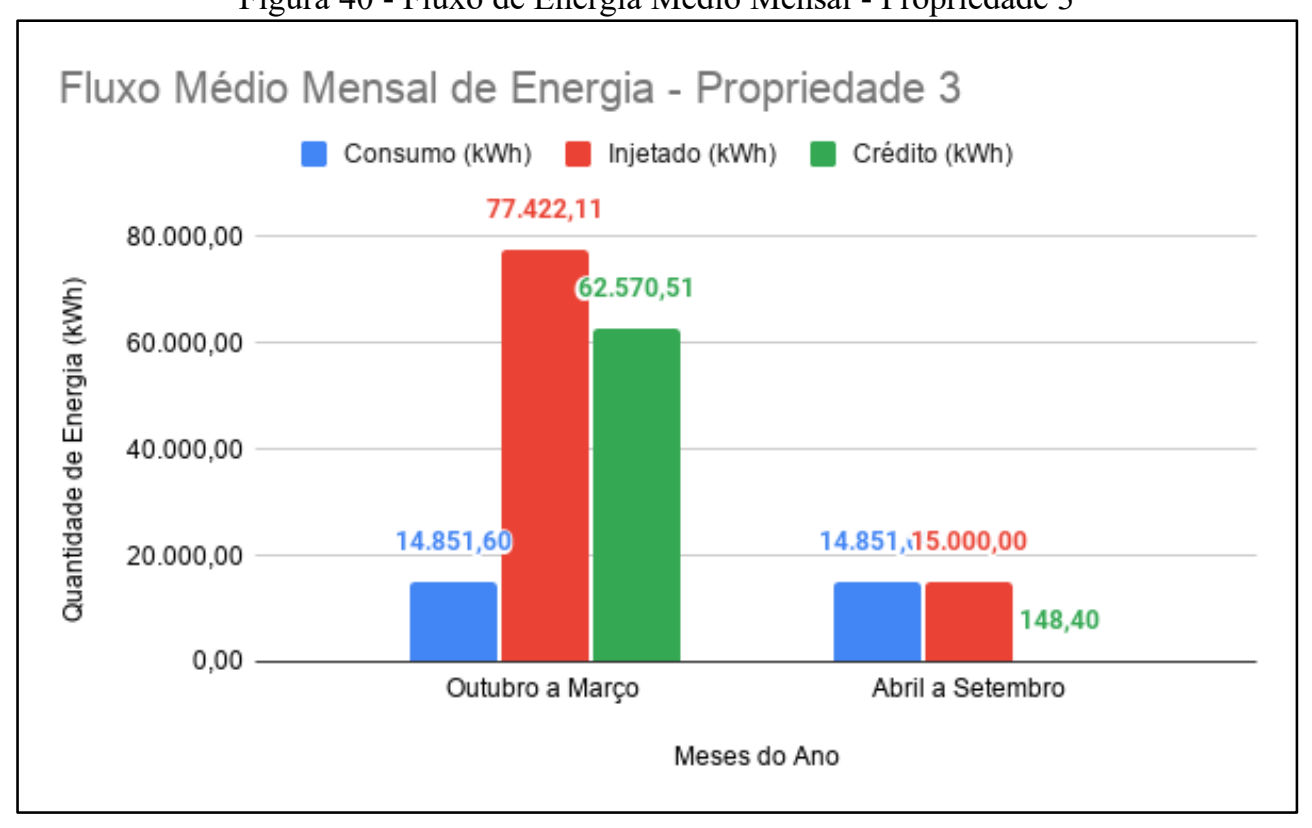

Fonte: Autoria Própria (2021).

A Tabela 12 apresenta o custo de instalação do projeto por kW. Esses são dados de 2019 apresentados pela International Renewable Energy Agency (IRENA) (2020) que levam em conta os custos médios de investimento do projeto e também os custos médios de operação e manutenção. Os dados da IRENA (2020) levam em conta uma vida útil de 25 anos para a propriedade com geração fotovoltaica, 20 anos para a propriedade com geração a biogás e 30 anos para a propriedade com mini geração hidráulica. Para a conversão do custo foi utilizado o valor do dólar comercial no mês de abril de 2021, sendo de R \$ 5,34, de acordo 
com dados do Instituto de Pesquisa Econômica Aplicada (2021). Também é levado em conta o preço de 3 IntelliRupters dividido entre as 3 propriedades, o preço foi retirados de City Of Rochelle (2017) como sendo de US\$ 52.985,00 ou R\$282.939,9. O preço dos outros 4 IntelliRupters são considerados como pagos pela concessionária de energia.

Tabela 12 - Custo da instalação e geração de energia.

\begin{tabular}{ccccc}
\hline GERAÇÃO & $\begin{array}{c}\text { CUSTO DE } \\
\text { INSTALAÇÃO } \\
(U S \$ / K W)\end{array}$ & $\begin{array}{c}\text { CUSTO DE } \\
\text { INSTALAÇÃO } \\
(\mathrm{R} \$ / \mathrm{KW})\end{array}$ & $\begin{array}{c}\text { POTÊNCIA } \\
\text { INSTALADA } \\
(\mathrm{KW})\end{array}$ & $\begin{array}{c}\text { CUSTO DE } \\
\text { INSTALAÇÃO } \\
(\mathrm{R} \$)\end{array}$ \\
$\begin{array}{c}\text { SOLAR } \\
\text { FOTOVOLTAICA }\end{array}$ & 1040 & $5.361,41$ & 488,4 & $2.618 .512,64$ \\
$\begin{array}{c}\text { BIOMASSA E } \\
\text { BIOGÁS }\end{array}$ & 2000 & $10.310,4$ & 20 & $206.208,00$ \\
$\begin{array}{c}\text { ENERGIA } \\
\text { HIDRELÉTRICA }\end{array}$ & 845 & $4.512,3$ & 500 & $2.256 .150,00$ \\
\hline
\end{tabular}

Fonte: Adaptado de IRENA (2020).

\subsubsection{COMERCIALIZAÇÃO DE ENERGIA}

No final do ano de 2020, a COPEL abriu uma chamada pública (Chamada Pública COPEL DIS GD 001/2020) com o interesse na compra de energia elétrica proveniente de empreendimentos de geração distribuída para a constituição de microrredes. Para a participação é necessário um mínimo de 1 MW de potência instalada, e o projeto aqui apresentado tem 1,0084 MW, e é necessário que todos os ativos devem estar aptos para a operação em modo ilha. O preço máximo estabelecido é de $311 \mathrm{R} \$ / \mathrm{MWh}$ e é o valor a ser utilizado no cálculo do retorno do investimento, em um cenário onde a energia excedente esteja sendo comercializada. Utilizando o sistema de comercialização de energia não é possível utilizar o sistema de créditos.

Para a execução do projeto, assim como MS Aziz (2020) e Nunes (2017) demonstram, é necessário, no mínimo, o cálculo do capital inicial, o Payback e taxa interna de retorno do projeto (TIR ou em inglês IRR). O payback e a TIR, são ferramentas que verificam a viabilidade econômica do projeto, o primeiro nos dá quantos anos são necessários para reaver o montante investido, já a TIR nos mensura qual será o percentual de retorno do projeto.

Para o cálculo do tempo de retorno do investimento (Payback) foi usada tanto a economia mensal quanto os valores de venda de energia. A economia mensal, de acordo com 
a equação (17) é dada pelos valores da coluna "Diferença" das tabelas Tabela 9, Tabela 10 e Tabela 11 e o tempo de Payback é apresentado na Tabela 13.

$$
\text { Payback = Investimento Inicial/(Economia Mensal }+ \text { Venda Mensal })
$$

Tabela 13 - Tempo para o Payback.

\begin{tabular}{ccccc}
\hline GERAÇÃO & $\begin{array}{c}\text { CUSTO DE } \\
\text { INSTALAÇÃO } \\
(\mathrm{R} \$)\end{array}$ & $\begin{array}{c}\text { ECONOMIA } \\
\text { MENSAL } \\
(\mathrm{R} \$)\end{array}$ & $\begin{array}{c}\text { VENDA } \\
\text { MENSAL DE } \\
\text { EXCEDENTE } \\
(\mathrm{R} \$)\end{array}$ & $\begin{array}{c}\text { PAYBACK } \\
\text { (ANOS) }\end{array}$ \\
$\begin{array}{c}\text { SOLAR } \\
\text { FOTOVOLTAICA }\end{array}$ & $2.995 .318,14$ & $10.575,00$ & $12.628,87$ & 10,76 \\
$\begin{array}{c}\text { BIOMASSA E } \\
\text { BIOGÁS }\end{array}$ & $624.699,90$ & $8.688,82$ & 70,81 & 5,94 \\
$\begin{array}{c}\text { ENERGIA } \\
\text { HIDRELÉTRICA }\end{array}$ & $2.539 .089,90$ & $9.108,28$ & $9.752,74$ & 11,22 \\
\hline
\end{tabular}

Fonte: Autoria Própria (2021).

A coluna da Tabela 13 que representa a venda de excedentes é o valor médio da venda mensal de cada propriedade. Esse valor é dado pelo produto do crédito médio mensal de cada propriedade pelo valor máximo de venda de $311 \mathrm{R} \$ / \mathrm{MWh}$. Esses mesmos valores da venda, após o investimento ser pago, é o lucro médio mensal de cada propriedade.

As figuras Figura 41, Figura 42 e Figura 43 representam o gráfico do fluxo de caixa anual de cada propriedade (propriedade 1, propriedade 2 e propriedade 3 , respectivamente) ao longo da vida útil de cada projeto de geração. O ponto onde o valor do fluxo de caixa se iguala a zero é o valor do Payback.

Figura 41 - Fluxo de caixa da Propriedade 1.

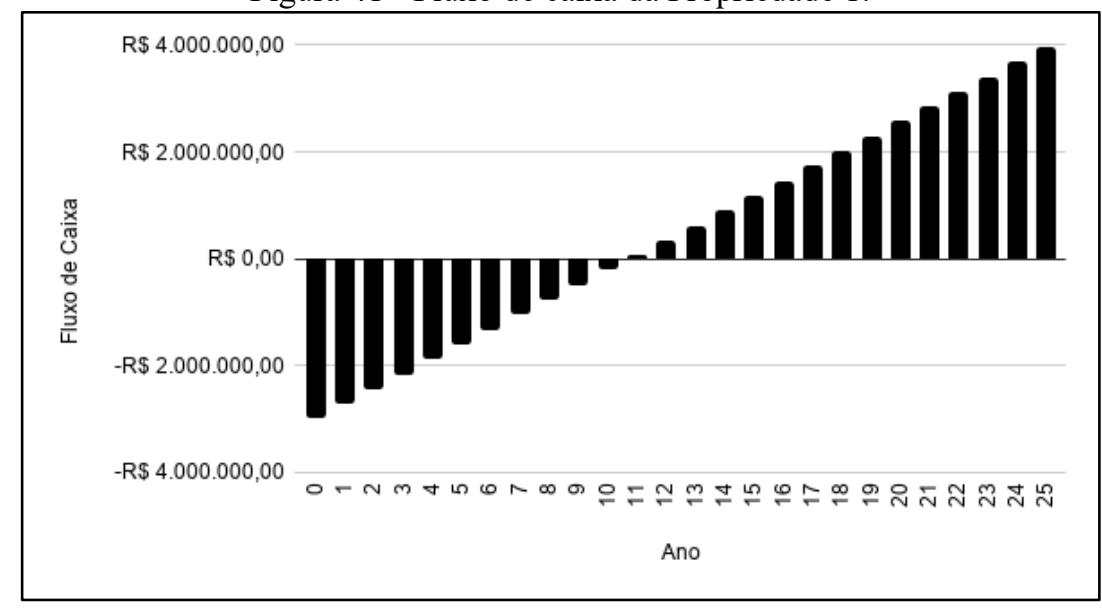

Fonte: Autoria Própria (2021). 
Figura 42 - Fluxo de caixa da Propriedade 2.

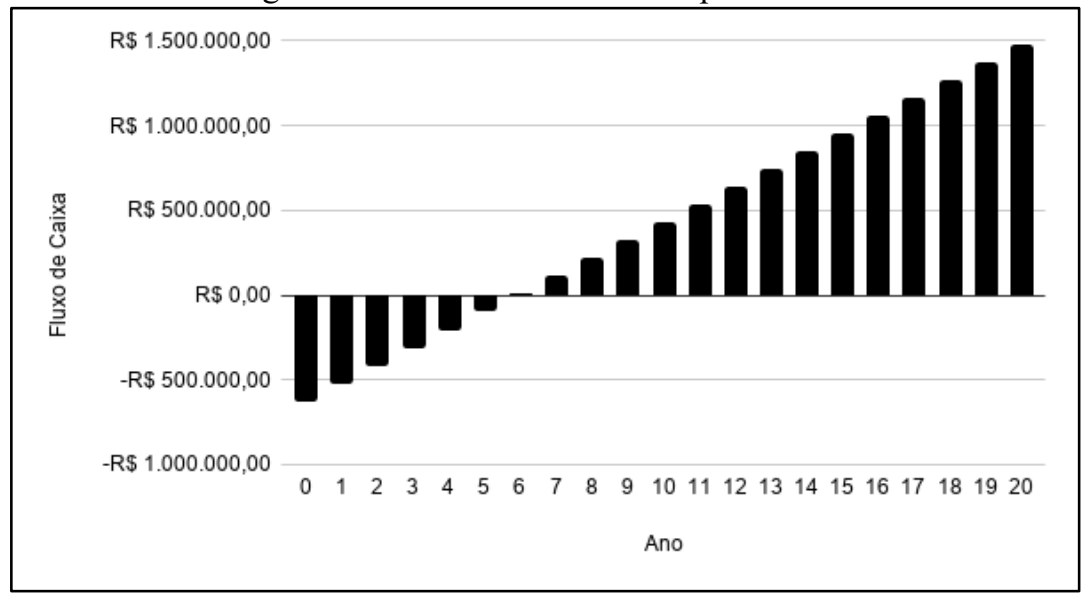

Fonte: Autoria Própria (2021).

Figura 43 - Fluxo de caixa da Propriedade 3.

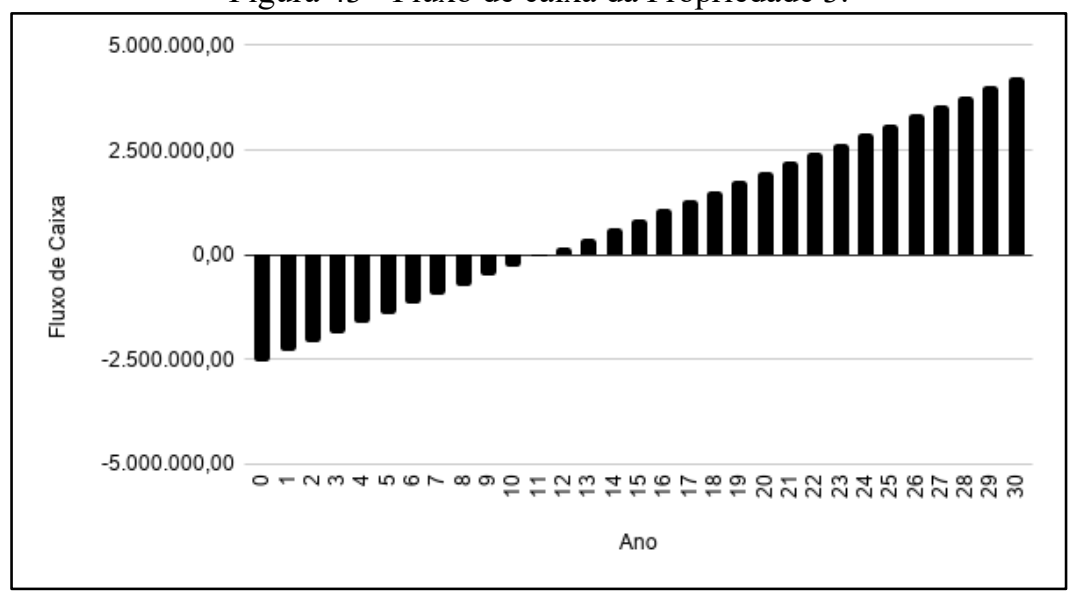

Fonte: Autoria Própria (2021).

Para o cálculo da TIR foi utilizada a Equação (18) em um período de 25 anos para a propriedade com geração fotovoltaica, 20 anos para a propriedade com geração a biogás e 30 anos para a propriedade com mini geração hidráulica, e os valores apresentados foram de $3 \%$ para a propriedade com geração Fotovoltaica, 13\% para a propriedade com geração a Biogás e $5 \%$ para a propriedade com Geração Hidrelétrica. Levando em conta a taxa SELIC em abril de 2021 de 2,75\% ao ano (Banco Central do Brasil, 2021) como valor que representa a taxa mínima de atratividade, esses valores nos apresentam que o investimento no projeto é algo viável por serem maiores que a taxa SELIC.

$$
\sum_{i=i}^{n} \frac{\mathrm{FC} * \mathrm{i}}{(1+\mathrm{TIR})^{\mathrm{i}}}-\text { Investimento Inicial }=0
$$


Onde 'FC' é o fluxo de caixa, 'i' o período de cada investimento e 'n' o período final do investimento.

Em um estudo de MS Aziz (2020) sobre eletrificação rural por meio de uma microrrede funcionando em modo ilha, foi também apresentado o desempenho e comparativo de uma rede simulada funcionando através de biogás, energia solar e energia hidrelétrica de uma área com recursos suficientes, constando também na rede uma bateria e conversores.

O local apresentado no estudo de MS Azis (2020) é uma zona sub-rural do Paquistão com potencial energético renovável, o que a aproxima do nosso caso de estudo. O estudo apresentado também utilizou o software HOMER Pro. Com a simulação dos sistemas, foi observado que o sistema híbrido com as três fontes é o mais estável e confiável, enquanto mantém o menor custo de energia e o menor valor presente líquido, como visto nos gráfícos. Outro dado importante é que o custo operacional dessa rede foi o que apresentou menores valores, como mostrado na Tabela 14.

Tabela 14 - Custo operacional de diferentes arquiuteturas

\begin{tabular}{cc} 
GERAÇÃO & $\begin{array}{c}\text { CUSTO OPERACIONAL } \\
\text { (US\$/ANO) }\end{array}$ \\
\hline FOTOVOLTAICA - BIOGÁS - & 953,3276 \\
HIDRELÉTRICA & 1523,692 \\
BIOGÁS - HIDRELÉTRICA & 2217,711 \\
FOTOVOLTAICA - BIOGÁS & 1258,296 \\
FOTOVOLTAICA - HIDRELÉTRICA & 3993,663 \\
BIOGÁS
\end{tabular}

Fonte: Adaptado de MS Azis (2020).

A título de comparação aos resultados econômicos obtidos, e confirmação da viabilidade apresentada, o projeto piloto da Energisa Minas Gerais (2015), que utiliza tecnologias semelhantes as demonstradas no estudo de caso apresentado neste trabalho, com 10 TripSaver® II Cutout-Mounted Recloser da S\&C conectados a média tensão em locais com serviços ruins de confiabilidade em zonas rurais, depois de um ano de serviço apresentou os resultados mostrados na Tabela 15 . 
Tabela 15 - Resultados estudo de caso S\&C.

\begin{tabular}{|c|c|c|c|c|}
\hline $\begin{array}{l}\text { INDICADOR DE } \\
\text { PERFORMANCE }\end{array}$ & $\begin{array}{l}\text { UM } \\
\text { ANO } \\
\text { ANTES }\end{array}$ & $\begin{array}{l}\text { UM ANO } \\
\text { DEPOIS }\end{array}$ & $\begin{array}{l}\text { MUDANÇA } \\
\text { RELATIVA }\end{array}$ & $\begin{array}{l}\text { PORCENTAGEM } \\
\text { DA MELHORIA }\end{array}$ \\
\hline ACESSO FÍSICO & 111 & 9 & -102 & $92 \%$ \\
\hline $\begin{array}{l}\text { DISTÂNCIA } \\
\text { PERCORRIDA ATÉ } \\
\text { O LOCAL (KM) }\end{array}$ & 1983 & 95 & -1888 & $95 \%$ \\
\hline $\begin{array}{l}\text { HOMEM-HORA DE } \\
\text { TRABALHO }\end{array}$ & 108,6 & 5,6 & $-103,2$ & $95 \%$ \\
\hline DEC & 0,0927 & 0,0067 & $-0,0860$ & $91 \%$ \\
\hline FEC & 0,0322 & 0,0030 & $-0,0292$ & $91 \%$ \\
\hline
\end{tabular}

A redução do custo financeiro relacionado às penalidades foi de mais de $98 \%$ e o Payback esperado é em torno de 6 anos.

Outro projeto para análise, executado pela COPEL (2020), a fim de melhorar os índices de desempenho DEC e FEC e atender especificação da ANEEL, conduziu um projeto piloto usando os religadores automáticos TripSaver® II da S\&C nas cidades de Cascavel e Maringá. Os dados da COPEL (2020) também mostram que, com a instalação de 1750 unidades ao longo de um período de 23 meses, os custos operacionais foram reduzidos em $20 \%$ do valor investido; Com a instalação de mais 1550 unidades, o DEC foi reduzido em $68,1 \%$, o que representa a redução das interrupções médias de 45 minutos. Dados complementares da COPEL (2020) sobre este projeto também mostraram a redução da necessidade de longos deslocamentos até as áreas rurais, reduzindo custos.

\subsection{CONCLUSÕES PARCIAIS DO CAPÍTULO}

Os dados energéticos disponíveis nas propriedades se mostram suficientes para geração de energia que suprem os gastos diários, além de fornecimento do potencial excedente para a rede local de distribuição, que podem ser convertidos em créditos para uso futuro ou venda para outros consumidores ligados a rede com utilização da energia fornecida pela mesma distribuidora. O payback e a taxa interna de retorno do projeto nos indica que a implementação do mesmo é viável e trará lucro aos consumidores.

Os dispositivos de interrupção de falta e integração das fontes a rede distribuição se mostram essenciais para a implementação de microrredes com restabelecimento otimizado. $\mathrm{O}$ isolamento da microrrede, ou o isolamento das propriedades, garantem energia de forma 
ininterrupta para as propriedades que possuem geração contínua (biomassa e microgeração hidrelétrica), e fornecimento durante um grande período para propriedades com nobreaks instalados (fotovoltaica).

A comunicação entre os dispositivos, e as centrais de controle redundantes em cada propriedade, traz uma maior segurança e facilidade na manutenção das fontes, sendo possível o seccionamento automático em detecções de falhas, ou o seccionamento forçado a partir do software de supervisão e controle. Com a utilização de sistemas SCADA fornecidos pelo próprio fabricante, é possível a visualização das fontes conectadas, e o consumo de cada propriedade. O monitoramento inteligente é o que possibilita a geração de créditos pela energia fornecida, sendo essencial para a geração distribuída e reduzindo consideravelmente os custos de operação e manutenção, como visto nos estudos de caso no Brasil.

Os equipamentos utilizados suportam ainda outras topologias de rede, como a topologia em anel, que traz maior confiabilidade e reconfiguração a microrrede. 


\section{CONCLUSÃO}

Em um mundo onde o uso de energia elétrica se tornou vital, novos caminhos para a gestão dessa demanda e suprimento crescentes se tornam primordiais. As ferramentas que são utilizadas para o gerenciamento de toda essa cadeia de fluxo não são novas, mas a possibilidade da integração e independência cada vez maior do usuário final ainda é algo de grande interesse para as companhias de energia elétrica, pela descentralização e principalmente pela redução da enorme carga que recai sobre as principais fontes atuais utilizadas na geração de energia, que apesar de renováveis, necessitam de um tempo útil para se restabelecer.

O Paraná e seu potencial em geração de energias renováveis, como o biogás, a fotovoltaica e as micro geradoras hidrelétricas, e por suas áreas cujo fornecimento de eletricidade pode ser facilmente prejudicado, principalmente por condições adversas de tempo e a demora na sua manutenção apresenta potencial para inovação e investimento em novas maneiras de gerar, distribuir, transportar e armazenar energias. O consumidor final, no caso deste estudo, o agronegócio também poderá se tornar o seu próprio fornecedor de energia elétrica e ainda contribuir com a sociedade ao seu redor e ser beneficiado compartilhando o excedente de geração seja através de sistema de Compensação de Energia Elétrica ou através da venda.

As fontes apresentadas no trabalho demonstram a capacidade de dar autonomia para cada propriedade no seu próprio fornecimento energético e com qualidade. A geração distribuída pode ser implementada em qualquer local que apresente um potencial de geração, pela quantidade de insumos disponíveis, junto a um estudo sobre o consumo da propriedade e o capital de investimento. Além disso, propriedades vizinhas podem se unir para compartilhar essa energia entre si em uma microrrede, e em caso da falta de alguma das unidades de geração e fornecimento, existe a possibilidade de alguma outra propriedade suprir essa demanda das cargas pelo restabelecimento otimizado da rede, o que aumenta a certeza de um fornecimento contínuo, e existem tecnologias habilitadoras para isso como apresentado ao longo deste trabalho.

\subsection{RECOMENDAÇÕES PARA TRABALHOS FUTUROS}

Uma indicação para trabalhos futuros neste tema é a implementação de um sistema de geração híbrida, com sistema de armazenamento de excedente e método de tomada de 
decisão para otimizar a escolha de fornecimento, consumo ou armazenamento da energia produzida, de acordo com critérios como tarifa, dados climáticos e previsão de geração futura.

Outra recomendação seria a análise da implementação dessas tecnologias de reestabelecimento otimizado e geração distribuída em áreas urbanas e com menos recursos abundantes para geração de energia renovável, estudando-se a possibilidade de integração das propriedades e suas respectivas capacidades de geração para potencializar o aproveitamento energético.

Tendo em mãos os principais pontos que relacionam redes inteligentes e a geração de energia renovável, as perspectivas futuras se dão na implementação destas tecnologias em propriedades existentes no estado e a criação de microrredes para estudos reais de funcionamento ao longo prazo. A ideia é cada vez mais expandir essa implementação e habilitar a autonomia da geração, a segurança e a qualidade do fornecimento, bem como a redução de custos e análise dos impactos sociais da integração de fontes alternativas renováveis de energia com restabelecimento otimizado para o agronegócio. 


\section{REFERÊNCIAS BIBLIOGRÁFICAS}

$\mathrm{ABE}$, Fernando. Caracterização do digestato de suínos para recomendação de adubação do milho na região oeste do Paraná, 2020. Disponível em: https://sucupira.capes.gov.br/sucupira/public/consultas/coleta/trabalhoConclusao/viewTrabalh oConclusao.jsf?popup=true\&id_trabalho=9288994. Acesso em: 30 de outubro de 2020.

ABOBOREIRA, Felipe; CRUZ, Antônia. A importância do smart grid na rede elétrica de distribuição do Brasil. XV SEPA - Seminário Estudantil de Produção Acadêmica, UNIFACS, 2016. Disponível em: http://www.revistas.unifacs.br/index.php/sepa. Acesso em: 15 de agosto de 2020.

AGÊNCIA NACIONAL DE ENERGIA ELETRICA. 2002. Atlas de energia elétrica do Brasil. Brasilia - DF : Agência Nacional de Energia Elétrica, 2002.

AGROLINK. PR: Geração de enegia solar cresce mais de 900\%, 2019. Disponível em: https://www.agrolink.com.br/noticias/pr--geracao-de-energia-solar-cresce-mais-de-900422636.html. Acesso em: 10 de outubro de 2019.

ALOU, Fadi. Segurança de Smart Grids, 2012. Disponível em: http://www.aloul.net/Papers/faloul_icsgce12.pdf. Acesso em: 05 de novembro de 2020.

ANEEL. Cadernos Temáticos ANEEL Micro e Minigeração Distribuída Sistema de Compensação de Energia Elétrica, 2016. Disponível em: https://www.aneel.gov.br/documents/656877/14913578/Caderno+tematico+Micro+e+Miniger a\%C3\%A7\%C3\%A3o+Distribuida+-+2+edicao/716e8bb2-83b8-48e9-b4c8-a66d7f655161. Acesso em: 25 de março de 2021.

ANNASWAMY, Anuradha. Smart Grid Research: Control Systems - IEEE Vision for Smart Grid Controls: 2030 and Beyond, 2013. Disponível em: https://ieeexplore.ieee.org/document/6577608. Acesso em: 02 de fevereiro de 2021. 
AZIZ, Muhammad Shahbaz. Rural Electrification through an Optimized Off-grid Microgrid based on Biogas, Solar, and Hydro Power. Disponível em:

https://ieeexplore.ieee.org/abstract/document/9048222. Acesso em: 13 de novembro de 2020.

BAKAR, Nur Najihah Abu. Esquema de microrrede e redução de carga durante o modo ilhado, 2017. Disponível em:

https://www.sciencedirect.com/science/article/pii/S1364032116311030?casa_token=2b9oJ7D 50JIAAAAA:0QqGaty2axVrcYWhTenPUPMR9HgPpN9iFmvLQxxwUBr6A2ft2hfQ_EBea1x9n5jvlMUqocaYdg. Acesso em: 05 de novembro de 2020.

BALFAR SOLAR. Datasheet Painel Nacional BS72M - 370W, 2019. Disponível em: http://balfarsolar.com.br/wp-content/uploads/2019/10/BALFAR-DATASHEET-MONO370W.pdf. Acesso em: 25 de Outubro de 2020.

BANCO CENTRAL DO BRASIL. [Site Institucional], 2021. Disponível em: https://www.bcb.gov.br/. Acesso em: 09 de abril de 2021.

BAYINDIR, R. Tecnologias e aplicações de Smart Grids, 2016. Disponível em: https://www.sciencedirect.com/science/article/pii/S1364032116304191?casa_token=JZNU05 kfKBMAAAAA:QKw0cBjeW1ZECeLMaLb1knlTbKifK11WYzoX_-

EM8D_QYEJqz_MtCJILggAZw862_qTOK9tL-i0. Acesso em: 05 de novembro de 2020.

BLASQUES, Luís Carlos Macedo. Estudo da viabilidade técnico-econômica de sistemas híbridos para geração de eletricidade. 2005.

CAMACHO, Eduardo F. et al. Control for renewable energy and smart grids. The Impact of Control Technology, Control Systems Society, p. 69-88, 2011.

CAMPOS, Bruna Andrade. Modelagem de sistemas de geração distribuída com motores de combustão interna invertidos a biogás, 2018. Disponível em: https://bdtd.ibict.br/vufind/Record/UNIOESTE-1_a787378c97129ce80afa1fe29f6eaf68. Acesso em: 29 de outubro de 2020 
CANAL ENERGIA. CCEE: PLD dispara 51\% no Sudeste, Sul e Norte e vai para 559,75/MWh, 2020. Disponível em:

https://www.canalenergia.com.br/noticias/53153361/ccee-pld-dispara-51-no-sudeste-sul-enorte-e-vai-para-55975mwh. Acesso em: 15 de novembro de 2020.

CITY OF ROCHELE. Universal Utility Supply Co., 2017. Disponível em: https://www.cityofrochelle.net/government-documents/city-council-agendas-andminutes/agendas/2017-city-council-meeting-documents/2017-09-11-agenda/5090-5-uuscoquote/file.html. Acesso em: 26 de abril de 2021.

CLIMATE. Dados climatológicos Paraná. [20-?]. Disponível em: https://pt.climatedata.org/america-do-sul/argentina/entre-rios/parana-1897/. Acesso em: 08 de fevereiro de 2021.

COOPER POWER SYSTEMS. SelfHealing, 201-?. Disponível em:

http://www.cooperindustries.com/content/public/en/power_systems/solutions/selfhealing.html. Acesso em: 19 de novembro de 2018

COPEL. [Site Institucional]: Biomassa, 2016. Disponível em:

http://www.copel.com/hpcopel/root/nivel2.jsp?endereco=\%2Fhpcopel $\% 2$ Froot $\% 2$ Fpagcopel2 .nsf\%2Fdocs\%2F24349F1A246428E1032574240049F201. Acesso em: 01 de novembro de 2018

COPEL. Normas técnicas Copel: NTC905200, 2018. Disponível em: https://www.copel.com/hpcopel/root/sitearquivos2.nsf/verdocatual/E59DF9E94B635F678325 831D0047F719/\$FILE/NTC905200_Rev04102018.pdf. Acesso em: 09 de abril de 2021.

COPEL. Geração Distribuída, 2019. Disponível em:

https://www.copel.com/hpcweb/fornecedores-e-parceiros/geracao-distribuida/. Acesso em: 20 de setembro de 2020 . 
COPEL. [Site Institucional]: Solar, 2016. Disponível em: https://www.copel.com/hpcopel/root/nivel2.jsp?endereco=\%2Fhpcopel\%2Froot\%2Fpagcopel 2.nsf\%2Fdocs\%2FBD1BFF96882FB88C032573FD0068962D. Acesso em: 10 de outubro de 2019.

COPEL (Paraná). 14 Semana de Engenharia do Instituto de engenharia do Paraná. PROJETO PARANÁ SMART GRID. Copel na 14 Semana de Engenharia, [S. 1.], p. 1, 1 dez. 2014. Disponível em: https://smartenergy.org.br/copel-desenvolve-sistema-de-controle-externo-degeracao-distribuida/. Acesso em: 20 set. 2020.

COPEL. Simulador de Consumo, 2020. Disponível em:

https://www.copel.com/scnweb/simulador/inicio.jsf. Acesso em: 08 de novembro de 2020.

COPEL. Taxas e Tarifas, 2020. Disponível em: https://www.copel.com/hpcweb/copeldistribuicao/taxas-tarifas/. Acesso em: 04 de fevereiro de 2021.

DILEEP, G. Uma pesquisa sobre tecnologias e aplicações de smart grid, 2019. Disponível em:

https://www.sciencedirect.com/science/article/pii/S0960148119312790?casa_token=t8FVJkkt 6gsAAAAA:3NFmVngZF1 teuqBFMvc8JIOr8fb2L-Nf5xilTyYZ88BwvuPfFwWsEU_GgrlH0P3nGxSX8ZRAnY. Acesso em: 05 de novembro de 2020.

DI SANTO, K G. Uma revisão sobre redes inteligentes e experiências no Brasil, 2015. Disponível em: https://www.sciencedirect.com/science/article/abs/pii/S1364032115008291?casa_token=xPT CuURSHQsAAAAA:qyRwdwU6RrIeti5NKjciJbjL0QJiS_L2NNv8OoEFBRCASyBBWq65 NzW3oF_vXZvgv02zG8s-3G8. Acesso em: 05 de novembro de 2020.

DUARTE, Daniel Perez et al. Brazilian smart grid roadmap-An innovative methodology for proposition and evaluation of smart grid functionalities for highly heterogeneous distribution networks. In: Innovative Smart Grid Technologies Latin America (ISGT LA), 2013 IEEE PES Conference On. IEEE, 2013. p. 1-8. 
EATON. Sensor Inteligente Grid Advisor Série II, 201-?. Disponível em:

http://www.eaton.com/us/en-us/catalog/utility-and-grid-solutions/gridadvisor-ii.html. Acesso em: 19 de novembro de 2018

EMPRESA DE PESQUISA ENERGÉTICA. Balanço Energético Nacional 2019: Ano base 2018. Rio de Janeiro, 2019. Disponível em: https://www.epe.gov.br/sites-pt/publicacoesdados-abertos/publicacoes/PublicacoesArquivos/publicacao-377/topico-

494/BEN\%202019\%20Completo\%20WEB.pdf. Acesso em: 10 de outubro de 2019.

ERBR. Grupo Geradores, 2020. Disponível em: https:/www.erbr.com.br/produtos/1/grupogeradores. Acesso em: 01 de novembro de 2020.

ETAP. Electrical Transient Analyzer Program, 2021. Disponível em: https://etap.com/. Acesso em: 13 de março de 2021.

FANG, X. S; MISRA, G; XUE, E D; YANG. 2012. "Smart Grid - The New and Improved Power Grid: A Survey". IEEE Communications Surveys Tutorials 14 (4): 94480. https://doi.org/10.1109/SURV.2011.101911.00087.

FARHANGI, Hassan. The path of the smart grid. IEEE power and energy magazine, v. 8, n. $1,2010$.

FRAZÃO, Rodrigo. Proteção do Sistema Elétrico de Potência. Londrina - PR: Editora e Distribuidora Educacional S.A., 2019.

G1 PRESIDENTE PRUDENTE E TV FRONTEIRA. Sem energia elétrica e sistema de ventilação, cerca de 6 mil aves morrem por causa do forte calor em granja em Adamantina, 2020. Disponível em: https:/g1.globo.com/sp/presidente-prudenteregiao/noticia/2020/10/01/sem-energia-eletrica-e-sistema-de-ventilacao-cerca-de-6-mil-avesmorrem-por-causa-do-forte-calor-em-granja-em-adamantina.ghtml. Acesso em: 28 de outubro de 2020 . 
GENERAL CABLE. Cabos de baixa tensão, 2020. Disponível em: https://www.generalcable.com/eu/assets/CatalogLibrary/Power-and-Low-Voltage/0200C0050-0P-Low-Voltage-eBook-2020_07.pdf. Acesso em: 29 de abril de 2021.

GENERAL CABLE. Cabos de média tensão, 2021. Disponível em: https://www.generalcable.com/assets/documents/LATAM\%20Documents/Brazil\%20Site/Cat alogo-Cabos-de-Media-Tensao.pdf?ext=.pdf. Acesso em: 09 de abril de 2021.

GOVERNO DO PARANÁ (Paraná). IPARDES. INDICADORES SELECIONADOS PARANÁ. [S.1.], 10 out. 2019. Disponível em:

http://www.aen.pr.gov.br/modules/noticias/article.php?storyid=108706\&tit=Parana-investeR-820-milhoes-para-modernizar-distribuicao-de-energia. Acesso em: 02 ago. 2020.

GOVERNO DO PARANÁ. Paraná investe R\$ 820 milhões para modernizar distribuição de energia, 2020. Disponível em:

http://www.aen.pr.gov.br/modules/noticias/article.php?storyid=108160\&tit=Ipiranga-agoraconta-com-controle-eficiente-do-consumo-de-energia. Acesso em: 02 de fevereiro 2021.

GOVERNO DO PARANÁ. Ipiranga agora conta com controle eficiente do consumo de energia, 2020. Disponível em:

http://www.aen.pr.gov.br/modules/noticias/article.php?storyid=108706\&tit=Parana-investeR-820-milhoes-para-modernizar-distribuicao-de-energia. Acesso em: 02 de fevereiro de 2021.

GROTH, Júlio Augusto. Usina de geração fotovoltaica. 2013.

GUNGOR, V. C., D. SAHIN, T. KOCAK, S. ERGUT, C. BUCCELlA, C. CECATI, E G. P. HANCKE. "Smart Grid Technologies: Communication Technologies and Standards", 2011. IEEE Transactions on Industrial Informatics 7 (4): 529-39. https://doi.org/10.1109/TII.2011.2166794.

HUAYLlAS, T. Micro-redes elétricas: Estado da Arte e contribuição para o dimensionamento, aplicação e comercialização da energia produzida. 2015. 
IPEADATA. [Site Institucional]. Disponível em: http://www.ipeadata.gov.br/Default.aspx. Acesso em: 25 de março de 2021.

IRENA. Renewable Power Generation Costs in 2019, 2020. International Renewable Energy Agency, Abu Dhabi. Disponível em: https://www.irena.org//media/Files/IRENA/Agency/Publication/2020/Jun/IRENA_Power_Generation_Costs_2019.p df. Acesso em: 25 de março de 2021.

ISLANDS GOING GREEN. Eigg Eletric. Disponível em: https://islandsgoinggreen.org/about/eigg-electric. Acesso em: 17 de novembro de 2018

KASIM, Naseer, HUSSAIN, Hazim. Performance Improvement of CIGS PV Solar Grid Tied System Using Planer Concentrators, Case Study : Baghdad. 2020. Disponível em: https://www.researchgate.net/publication/342736081_Performance_Improvement_of_CIGS_ PV_Solar_Grid_Tied_System_Using_Planer_Concentrators_Case_Study_Baghdad. Acesso em: 05 de novembro de 2020.

LISERRE, Marco; SAUTER, Thilo; HUNG, John Y. Future energy systems: Integrating renewable energy sources into the smart power grid through industrial electronics. IEEE industrial electronics magazine, v. 4, n. 1, p. 18-37, 2010.

LIU, Fangrui; DUAN, Shanxu; LIU, Fei; LIU, Bangyin; KANG, Yong. A Variable Step Size INC MPPT Method for PV Systems. IEEE Transactions on industrial eletronics, vol. 55, no 7. 2008. Disponível em:

https://citeseerx.ist.psu.edu/viewdoc/download?doi=10.1.1.472.5768\&rep=rep1\&type=pdf. Acesso em: 09 de fevereiro de 2021.

MARQUES, Cleber Aimoni et al. Microgeração de energia elétrica em uma propriedade rural utilizando biogás como fonte primária de energia elétrica. 2012.

MARTINS, Fernando Ramos; PEREIRA, Enio Bueno; ECHER, MP de S. Levantamento dos recursos de energia solar no Brasil com o emprego de satélite geoestacionário-o Projeto Swera. Revista Brasileira de Ensino de Física, v. 26, n. 2, p. 145-159, 2004. 
MATALLANAS, E.. Controlador de rede neural para gerenciamento ativo do lado da demanda com energia fotovoltaica no setor residencial, 2012. Disponível em:

https://www.sciencedirect.com/science/article/abs/pii/S0306261911005630?casa_token=PUof fPkCMgkAAAAA:mw06kNzDhDq-

VWLiJuS10TQFn_6hoayL7NT04yqCF9ac1S2c6qIFa_efMUW4nKxntGgUTcblDhU. Acesso em: 05 de novembro de 2020 .

MCCARTHY, C. Tecnologia PulseClosing, 2017. Disponível em:

https://www.engerati.com/transmission-and-distribution/article/network-management/pulseclosing-technology-distribution-line. Acesso em: 19 de novembro de 2018

MINISTÉRIO DO MEIO AMBIENTE. Caderno setorial de recursos hídricos: geração de energia hidrelétrica. Brasilia : Projects Brasil Multimídia, 2006.

MOREIRA, Guilherme. Dimensionamento e análise de viabilidade econômica de usina fotovoltaica em Nova Iguaçu - RJ, 2015. Disponível em: http://monografias.poli.ufrj.br/monografias/monopoli10015187.pdf. Acesso em: 28 de outubro de 2020 .

MORETTI, Jorge. Manual de Eletrificação Rural, 1997. Disponível em: http://www.moretti.agrarias.ufpr.br/publicacoes/man_1997_eletrificacao_rural.pdf. Acesso em: 28 de outubro de 2020 .

MOURAD, Anna L.; AMBROGI, Vinicius S.; GUERRA, Sinclair MG. Potencial de utilização energética de biomassa residual de grãos. Procedings of the 5th Encontro de Energia no Meio Rural, 2004.

NEO SOLAR. Bateria Estacionária Moura Solar 12MS234 (220Ah). Disponível em: https://www.neosolar.com.br/loja/bateria-estacionaria-moura-solar-12ms234-220ah.html. Acesso em: 17 de fevereiro de 2021. 
NOGUEIRA, Carlos. Dimensionamento de sistemas integrados de energia em ambientes rurais, 2004. Disponível em:

https://repositorio.ufsc.br/xmlui/bitstream/handle/123456789/88061/208617.pdf?sequence=1 \&isAllowed=y. Acesso em: 09 de fevereiro de 2021.

NOJA POWER SYSTEMS. Guia do Produto: Religador Automático OMS, 20-?. Disponível em: $\quad$ https://www.nojapower.com.br/images/NOJA-58006\%20NOJA\%20Power\%20OSM15-27-38\%20Guia\%20do\%20Produto\%20-\%20po_0.pdf. Acesso em: 19 de novembro de 2018

NUNES, Angelo. Análise de viabilidade econômica de geração de energia elétrica a partir de biogás de suinocultura, 2017. Disponível em: https://repositorio.ufsc.br/handle/123456789/178021. Acesso em: 30 de outubro de 2020.

OGAWA, Vitor. PAraná é responsável por $10 \%$ da energia hidrelétrica do País. Folha de Londrina, [S.l.],p.1-1, 9 out. 2018. Disponível em: https://www.folhadelondrina.com.br/geral/parana-e-responsavel-por-10-da-energiahidreletrica-do-pais-1017514.html. Acesso em: 27 ago. 2020.

PARANOÁ ENERGIA. GE traz solução de microgeração hidrelétrica, 2019. Disponível em: https://www.paranoaenergia.com.br/noticias/2019/10/07/ge-traz-solucao-demicrogeracao-hidreletrica/. Acesso em: 01 de novembro de 2020.

PAZZINI, Luiz Henrique Alves et al. Luz para todos no campo: a universalização do atendimento de energia elétrica na zona rural brasileira. Procedings of the 4th Encontro de Energia no Meio Rural, 2002.

PIFTSCHER, L. Reconfiguração Automática das redes de distribuição de energia elétrica com monitoramento em tempo real. 2013.

PINHO, Joao Tavares; GALDINO, Marco Antônio. Manual de engenharia para sistemas fotovoltaicos. 2014. 
REDES INTELIGENTES BRASIL. Projetos pilotos no Brasil. Disponível em: http://redesinteligentesbrasil.org.br/projetos-piloto-brasil.html. Acesso em: 27 de agosto de 2020.

REIS, L. B. Geração de energa elétrica, 2011. Barueri, SP: Manole.

REIS, Pedro. Quais são os painéis solares fotovoltaicos mais eficientes no mercado?. Portal Energia, 2018. Disponível em: https://www.portal-energia.com/paineis-solaresfotovoltaicos-mais-eficientes-mercado/. Acesso em: 10 de outubro de 2019.

SANTOS, Emily. Brasileiros criam micro hidrelétrica capaz de abastecer 5 casas, 2018. Disponível em: https:/ciclovivo.com.br/inovacao/tecnologia/brasileiros-criam-microhidreletrica-capaz-de-abastecer-5-casas/. Acesso em: 01 de novembro de 2020.

S\&C. Boletim Informativo: IntelliRupter, 2017. Disponível em: https://www.sandc.com/globalassets/sac-electric/content-callouts/intellirupter/ir-circuit.pdf. Acesso em: 19 de novembro de 2018.

S\&C. IntelliRupter interruptor de falhas, 201-?. Disponível em: https://www.sandc.com/en/products--services/products/intellirupter-pulsecloser-faultinterrupter/. Acesso em: 19 de novembro de 2018.

S\&C. Interruptor de falhas IntelliRupter: Especificações, 2020. Disponível em: https://www.sandc.com/globalassets/sac-electric/documents/sharepoint/documents---alldocuments/boletim-de-especificacoes-766-31p.pdf?dt=637405572053933480. Acesso em: 30 de outubro de 2020.

S\&C. Religadores da S\&C nas Laterais Ajudam Concessionária a Atender Requisitos Regulatórios no Brasil, 2020. Disponível em:

https://www.scelectric.org/globalassets/sac-electric/documents/sharepoint/documents---alldocuments/estudo-de-caso-461-1005p.pdf?dt=637409576357717603. Acesso em: 13 de novembro de 2020 . 
S\&C. Religadores Monofásicos em Linhas de Distribuição Rural Melhoram Confiabilidade em Concessionária, 2017. Disponível em:

https://www.sandc.hk/globalassets/sac-electric/documents/sharepoint/documents---alldocuments/estudo-de-caso-461-1000p.pdf?dt=637410770558108887. Acesso em: 13 de novembro de 2020 .

S\&C. Rethinking Your Lateral Protection Strategy, 2019. Disponível em: https://www.sandc.com/globalassets/sac-electric/documents/sharepoint/documents---alldocuments/educational-material-461-4500.pdf?dt=637423025391886889. Acesso em: 03 de fevereiro de 2021.

S\&C. Sistema de Recomposição Automática IntelliTeam SG, [20-?]. Disponível em: https://www.sandc.com/pt/produtos-e-servicos/produtos/sistema-de-recomposicaoautomatica-intelliteam-sg/\#e16b828f-d290-4478-89b3-6323aea8b296. Acesso em: 28 de fevereiro de 2021.

S\&C. S\&C's TripSaver ${ }^{\circledR}$ II Cutout-Mounted Reclosers Help Rural Utility Break Its Annual Maintenance Cycle, 2020. Disponível em:

https://electricenergyonline.com/energy/news/product-highlights/864792/s-c-s-tripsaver-iicutout-mounted-reclosers-help-rural-utility-break-its-annual-maintenance-cycle.htm. Acesso em: 28 de fevereiro de 2021.

S\&C Eletric Company. Soluções para Microrredes, 2018. Disponível em:

https://www.sandc.com/pt/solucoes/solucoes-para-microrredes/. Acesso em: 17 de novembro de 2018.

SECRETÁRIA DA AGRICULTURA E DO ABASTECIMENTO. [Site Institucional]. Disponível em:

http://www.agricultura.pr.gov.br/modules/conteudo/conteudo.php?conteudo=137. Acesso em: 11 de novembro de 2018.

SMART ENERGY GB. [Site Institucional], 2017. Disponível em:

https://www.smartenergygb.org/en/resources/press-centre/press-releases-folder/future-ruralenergy. Acesso em: 17 de novembro de 2018. 
SOUZA, Samuel NM de; SORDI, Alexandre; OLIVA, Carlos A. Potencial de energia primária de resíduos vegetais no Paraná: $4^{0}$ Encontro de Energia no Meio Rural. Procedings of the 4th Encontro de Energia no Meio Rural, 2002.

TELE, Walter. Preço de energia da Copel aumenta mais de 15\% a partir de domingo. Autorização foi aprovada pela Aneel nesta terça-feira. Maringá Post, [S. l.] p. 1-1, 19 jun. 2018. Disponível em: https://maringapost.com.br/poder/2018/06/19/preco-de-energia-dacopel-aumenta-mais-de-15-a-partir-de-domingo-autorizacao-foi-aprovada-pela-aneel-nestaterca-feira. Acessado em: 27 ago. 2020.

TIEPOLO, G.; JUNIOR, Osiris Canciglieri; JUNIOR, Jair Urbanetz. Estudo do potencial de participação das fontes renováveis de energia na matriz elétrica do Estado do Paraná. In: CONGRESSO BRASILEIRO DE PLANEJAMENTO ENERGÉTICO. 2014.

TIEPOLO, G.M.; PEREIRA, E. B.;URBANETZ JR, J.; PEREIRA, S. V.; GONÇALVES, A. R.; LIMA, F. J. L.; COSTA, R. S.; ALVES, A. R. Atlas de Energia Solar do Estado do Paraná. 1 $1^{\text {a }}$ Edição. Curitiba: UTFPR, 2017.

TIMOSSI , MARCELO SANTIAGO. Avaliação dos benefícios na utilização dos conceitos de Smart Grid para reconfiguração automática de cargas na rede de distribuição de energia. Orientador: Dr. Antônio Carlos de Francisco. 2013. 46 p. Monografia (Especialista) - UNIVERSIDADE TECNOLÓGICA FEDERAL DO PARANÁ CAMPUS PONTA GROSSA, [S. 1.], 2013.

TUBALLA, Maria Lorena. Uma revisão do desenvolvimento de tecnologias de Smart Grids, 2016. Dsiponível em:

https://www.sciencedirect.com/science/article/pii/S1364032116000393?casa_token=_TWVPa0CaYAAAAA:hwSE0s0a9X7-

UGgFtTsQTg1iN5rup6AjMYvEeKDTIayQ8HkeeEJjzBeYC-2XBQd9netDmky2gnc. Acesso em: 05 de novembro de 2020.

WEG. DWB e DWA - Disjuntores em Caixa Moldada, 2021. Disponível em: https://static.weg.net/medias/downloadcenter/h83/hd0/WEG-disjuntores-em-caixa-moldadadw-50009825-catalogo-pt.pdf. Acesso em: 28 de abril de 2021. 
WEG. Energia Hidrogeradores, 2015. Disponível em:

https://static.weg.net/medias/downloadcenter/h28/hf8/WEG-hidrogeradores-50005371catalogo-portugues-br.pdf. Acesso em: 09 de fevereiro de 2021.

WEG. Nobreak enterprise: tecnologia avançada para proteção de sistemas críticos, 20-?. Disponível em: https://static.weg.net/medias/downloadcenter/h7e/hb0/WEG-nobreakenterprise-50102821-pt.pdf. Acesso em: 29 de outubro de 2020.

WEG. SIW - Inversores String, 201-?. Disponível em:

https://static.weg.net/medias/downloadcenter/ha4/h35/WEG-inversores-string-SIW500HSIW300H-50076575-pt.pdf. Acesso em 28 de outubro de 2020.

WEG. Transformador Óleo 500kVA, 2020. Disponível em: https://www.weg.net/catalog/weg/BR/pt/Gera\%C3\%A7\%C3\%A3o\%2CTransmiss $\% \mathrm{C} 3 \% \mathrm{~A} 3 \mathrm{o}-\mathrm{e}-\mathrm{Distribui} \% \mathrm{C} 3 \% \mathrm{~A} 7 \% \mathrm{C} 3 \% \mathrm{~A} 3 \mathrm{o} /$ Transformadores-e-Reatores-a$\%$ C3\%931eo/Transformadores-de-Distribui $\% \mathrm{C3} \% \mathrm{~A} 7 \% \mathrm{C} 3 \% \mathrm{~A} 3 \mathrm{o}-\mathrm{a}-\% \mathrm{C} 3 \% 931$ eo/301-a-3-000kVA/Transformador-\%C3\%93leo-500-0kVA-13-8-0-38kV-CST-ONAN/p/14367708. Acesso em: 28 de outubro de 2020 .

ZAGO, Ricardo Mazza. Sistema de baixo custo para monitoramento da geração de energia solar com conexão para Internet das Coisas. 2018. 
ANEXO I - SIMULAÇÃO CONSUMO PROPRIEDADE 1

\begin{tabular}{|c|c|c|c|c|c|c|c|c|c|c|}
\hline \multicolumn{11}{|c|}{ Simulador de consumo } \\
\hline \multirow{2}{*}{ Aparelho } & \multicolumn{4}{|c|}{ Consumo } & \multicolumn{3}{|c|}{ Tarlfa Convenclonal } & \multicolumn{3}{|c|}{ Tarlfa Branca } \\
\hline & FP & $\pi$ & PT & Total & FP & IT & PT & FP & IT & PT \\
\hline \multicolumn{11}{|l|}{ Banheiro } \\
\hline Chuveiro & $159.63 \mathrm{kWh}$ & $0,00 \mathrm{kWh}$ & $88,68 \mathrm{kWh}$ & $248,32 \mathrm{kWh}$ & R\$ 98.57 & $\mathrm{R} \$ 0.00$ & R\$ 54,76 & R\$ 84,00 & R\$ 0,00 & R\$ 100,43 \\
\hline $\begin{array}{l}\text { Lampada } \\
\text { fluorescente }\end{array}$ & $0,51 \mathrm{kWh}$ & $0.00 \mathrm{kWh}$ & $1,29 \mathrm{kWh}$ & $1,80 \mathrm{kWh}$ & $R \$ 0,32$ & $R \$ 0.00$ & $R \$ 0,80$ & $R \$ 0.27$ & R\$ 0.00 & R $\$ 1,46$ \\
\hline $\begin{array}{l}\text { Secador de } \\
\text { cabelo }\end{array}$ & $0,00 \mathrm{kWh}$ & $0.00 \mathrm{kWh}$ & $32,25 \mathrm{kWh}$ & $32,25 \mathrm{kWh}$ & R\$ 0.00 & $R \$ 0,00$ & $R \$ 19.91$ & RS 0,00 & RS 0,00 & $R \$ 36,52$ \\
\hline \multicolumn{4}{|c|}{ Total do consumo: } & $282,38 \mathrm{kWh}$ & \multicolumn{2}{|c|}{ Total da convenclonal: } & R\$ 174,36 & \multicolumn{2}{|c|}{ Total da branca: } & $R \$ 222,68$ \\
\hline \multicolumn{11}{|l|}{ Cozinha } \\
\hline Geladeira & $307,45 \mathrm{kWh}$ & $21,50 \mathrm{kWh}$ & $32,25 \mathrm{kWh}$ & $361,20 \mathrm{kWh}$ & $R \$ 189.83$ & $\mathrm{R} \$ 13,27$ & $R \$ 19,91$ & $R \$ 161,78$ & $R \$ 15,79$ & $R \$ 36,52$ \\
\hline Freezer & $184,47 \mathrm{kWh}$ & $12,90 \mathrm{kWh}$ & $19.35 \mathrm{kWh}$ & $216,72 \mathrm{kWh}$ & RS 113.90 & R\$ 7.96 & R\$ 11,95 & $R \$ 97,07$ & $R \$ 9.48$ & $R \$ 21,91$ \\
\hline Freezer & $307,45 \mathrm{kWh}$ & $21.50 \mathrm{kWh}$ & $32,25 \mathrm{kWh}$ & $361,20 \mathrm{kWh}$ & $R \$ 189,83$ & $R \$ 13,27$ & R\$ 19.91 & $R \$ 161,78$ & $R \$ 15,79$ & $R \$ 36,52$ \\
\hline $\begin{array}{l}\text { Fogāo } \\
\text { elétrico }\end{array}$ & $180,60 \mathrm{kWh}$ & $0,00 \mathrm{kWh}$ & $0,00 \mathrm{kWh}$ & $180,60 \mathrm{kWh}$ & R\$ 111,51 & $R \$ 0,00$ & $R \$ 0,00$ & RS 95,03 & RS 0,00 & R\$ 0.00 \\
\hline $\begin{array}{l}\text { Lampada } \\
\text { fluorescente }\end{array}$ & $0,51 \mathrm{kWh}$ & $0.00 \mathrm{kWh}$ & $1,29 \mathrm{kWh}$ & $1,80 \mathrm{kWh}$ & $R \$ 0,32$ & $\mathrm{R} \$ 0.00$ & $R \$ 0,80$ & $R \$ 0.27$ & RS 0.00 & R\$ 1,46 \\
\hline Exaustor & $4,51 \mathrm{kWh}$ & $0.00 \mathrm{kWh}$ & $0.00 \mathrm{kWh}$ & $4.51 \mathrm{kWh}$ & $R \$ 2.79$ & $\mathrm{R} \$ 0.00$ & $R \$ 0.00$ & $R \$ 2,38$ & RS 0.00 & R\$ 0.00 \\
\hline Liquidificador & $1,07 \mathrm{kWh}$ & $0.00 \mathrm{kWh}$ & $0,00 \mathrm{kWh}$ & $1.07 \mathrm{kWh}$ & R\$ 0.66 & $R \$ 0.00$ & $R \$ 0,00$ & RS 0.57 & RS 0.00 & R\$ 0.00 \\
\hline Microondas & $5,01 \mathrm{kWh}$ & $0.00 \mathrm{kWh}$ & $0,00 \mathrm{kWh}$ & $5,01 \mathrm{kWh}$ & $\mathrm{R} \$ 3,10$ & $R \$ 0.00$ & $R \$ 0,00$ & $R \$ 2,64$ & RS 0.00 & R\$ 0.00 \\
\hline \multicolumn{4}{|c|}{ Total do consumo: } & $1.132,13 \mathrm{kWh}$ & \multicolumn{2}{|c|}{ Total da convenclonal: } & R\$ 699,01 & \multicolumn{2}{|c|}{ Total da branca: } & R\$ 658,99 \\
\hline \multicolumn{11}{|l|}{ Quarto } \\
\hline Televisor & $13,35 \mathrm{kWh}$ & $5.80 \mathrm{kWh}$ & $17,41 \mathrm{kWh}$ & $36.57 \mathrm{kWh}$ & $R \$ 8.24$ & $R \$ 3,58$ & R\$ 10,75 & $R \$ 7.03$ & R\$ 4.26 & R\$ 19,72 \\
\hline $\begin{array}{l}\text { Ar } \\
\text { condicionado }\end{array}$ & $1.137,78 \mathrm{kWh}$ & $0.00 \mathrm{kWh}$ & $0.00 \mathrm{kWh}$ & $1.137,78 \mathrm{kWh}$ & RS 702,51 & $\mathrm{R} \$ 0.00$ & $R \$ 0,00$ & $R \$ 598,70$ & RS 0.00 & R\$ 0.00 \\
\hline $\begin{array}{l}\text { Lampada } \\
\text { fluorescente }\end{array}$ & $3,09 \mathrm{kWh}$ & $0.00 \mathrm{kWh}$ & $7.74 \mathrm{kWh}$ & $10,83 \mathrm{kWh}$ & R\$ 1,91 & $R \$ 0,00$ & R\$ 4,78 & $R \$ 1,63$ & RS 0.00 & RS 8,77 \\
\hline \multicolumn{4}{|c|}{ Total do consumo: } & $1.185,18 \mathrm{kWh}$ & \multicolumn{2}{|c|}{ Total da convenclonal: } & RS 731, 77 & \multicolumn{2}{|c|}{ Total da branca: } & RS 640,11 \\
\hline \multicolumn{11}{|l|}{ Sala } \\
\hline Televisor & $0,77 \mathrm{kWh}$ & $0.00 \mathrm{kWh}$ & $1,93 \mathrm{kWh}$ & $2,70 \mathrm{kWh}$ & $R \$ 0.48$ & $R \$ 0.00$ & RS 1.19 & RS 0.41 & RS 0.00 & $\mathrm{R} \$ 2,19$ \\
\hline $\begin{array}{l}\text { Làmpada } \\
\text { fluorescente }\end{array}$ & $2,06 \mathrm{kWh}$ & $0.00 \mathrm{kWh}$ & $5.16 \mathrm{kWh}$ & $7,22 \mathrm{kWh}$ & RS 1,27 & $R \$ 0.00$ & $\mathrm{R} \$ 3,19$ & $R \$ 1,09$ & RS 0,00 & $R \$ 5,84$ \\
\hline & & Total & do consumo: & 9,93 kWh & Total da & ivencional: & $R \$ 6,13$ & & da branca: & R\$ 9,53 \\
\hline Lavanderla & & & & & & & & & & \\
\hline $\begin{array}{l}\text { Làmpada } \\
\text { fluorescente }\end{array}$ & $0,51 \mathrm{kWh}$ & $0,00 \mathrm{kWh}$ & $2,58 \mathrm{kWh}$ & $3,09 \mathrm{kWh}$ & $R \$ 0,32$ & $R \$ 0.00$ & $R \$ 1,59$ & $R \$ 0.27$ & RS 0,00 & R\& 2,92 \\
\hline $\begin{array}{l}\text { Ferro } \\
\text { elétrico }\end{array}$ & $8,60 \mathrm{kWh}$ & $0.00 \mathrm{kWh}$ & $0.00 \mathrm{kWh}$ & $8,60 \mathrm{kWh}$ & $R \$ 5,31$ & $\mathrm{R} \$ 0.00$ & $R \$ 0,00$ & $R \$ 4.53$ & RS 0.00 & R\$ 0.00 \\
\hline $\begin{array}{l}\text { Máquina de } \\
\text { lavar }\end{array}$ & 4,30 kWh & $0.00 \mathrm{kWh}$ & $8,60 \mathrm{kWh}$ & $12,89 \mathrm{kWh}$ & $R \$ 2,65$ & $\mathrm{R} \$ 0.00$ & $\mathrm{R} \$ 5,31$ & $R \$ 2,26$ & RS 0.00 & RS 9.74 \\
\hline & & Total & do consumo: & $24,59 \mathrm{kWh}$ & Total da & ivenclonal: & R\$ 15,18 & & da branca: & RS 19,72 \\
\hline Garagem / Jar & rdim & & & & & & & & & \\
\hline $\begin{array}{l}\text { Cortador de } \\
\text { grama }\end{array}$ & $5,59 \mathrm{kWh}$ & $0.00 \mathrm{kWh}$ & $0,00 \mathrm{kWh}$ & $5,59 \mathrm{kWh}$ & $R \$ 3,45$ & $R \$ 0.00$ & $R \$ 0.00$ & $R \$ 2,94$ & RS 0.00 & R\$ 0.00 \\
\hline & & Total & do consumo: & $5,59 \mathrm{kWh}$ & Total da & ivenclonal: & RS 3,45 & & da branca: & R\$ 2,94 \\
\hline Galpōes & & & & & & & & & & \\
\hline Comedouro & $28,44 \mathrm{kWh}$ & $0.00 \mathrm{kWh}$ & $15,80 \mathrm{kWh}$ & $44,24 \mathrm{kWh}$ & R\$ 17.56 & $R \$ 0.00$ & $R \$ 9,76$ & R\$ 14,97 & RS 0.00 & R\$ 17.90 \\
\hline Ventilador & $\begin{array}{r}3.689,40 \\
\mathrm{kWh}\end{array}$ & $258,00 \mathrm{kWh}$ & $387,00 \mathrm{kWh}$ & $\begin{array}{r}4.334,40 \\
\mathrm{kWh}\end{array}$ & R\$2.277.98 & R\$ 159.30 & RS 238,95 & $R \$ 1.941,36$ & R\$ 189,50 & RS 438,25 \\
\hline $\begin{array}{l}\text { Motor } \\
\text { Nebulizador }\end{array}$ & $238.65 \mathrm{kWh}$ & $39.77 \mathrm{kWh}$ & $0.00 \mathrm{kWh}$ & $278,42 \mathrm{kWh}$ & R\$ 147,35 & $R \$ 24,56$ & R\$ 0.00 & R\$ 125,58 & $R \$ 29,22$ & $R \$ 0,00$ \\
\hline $\begin{array}{l}\text { Làmpada } \\
\text { fluorescente }\end{array}$ & $2,58 \mathrm{kWh}$ & $0.00 \mathrm{kWh}$ & $6,45 \mathrm{kWh}$ & $9.03 \mathrm{kWh}$ & $R \$ 1,59$ & R\$ 0.00 & R\$ 3,98 & $R \$ 1,36$ & RS 0.00 & RS 7.30 \\
\hline $\begin{array}{l}\text { Conjunto } \\
\text { Motobomba }\end{array}$ & $\begin{array}{r}5297.60 \\
\mathrm{kWh}\end{array}$ & $0,00 \mathrm{kWh}$ & $0,00 \mathrm{kWh}$ & $\begin{array}{r}5.297,60 \\
\mathrm{kWh}\end{array}$ & RS 3.270 .95 & R\$ 0.00 & R\$ 0.00 & RS $2.787,60$ & RS 0,00 & $R \$ 0,00$ \\
\hline $\begin{array}{l}\text { Bomba Alta } \\
\text { Pressāo }\end{array}$ & $\begin{array}{r}2.731,57 \\
\mathrm{kWh}\end{array}$ & $0.00 \mathrm{kWh}$ & $0.00 \mathrm{kWh}$ & $\begin{array}{r}2.731,57 \\
\mathrm{kWh}\end{array}$ & R\$ $1.686,58$ & R\$ 0.00 & R\$ 0.00 & $R \$ 1.437,35$ & R\$ 0.00 & $R \$ 0,00$ \\
\hline & & Total & I do consumo: & $\begin{array}{r}12.695,27 \\
\mathrm{kWh}\end{array}$ & Total da & ivenclonal: & RS $7.838,56$ & & da branca: & RS $6.990,39$ \\
\hline & Consumo - $\mathrm{T}$ & Total & & Tarlfa & Convenclonal - & & & Tarlfa E & Ica - Total & \\
\hline & $15.335,09 \mathrm{kV}$ & & & & RS 9.468,46 & & & & 44,36 & \\
\hline $\begin{array}{c}\text { Fora-Ponta } \\
14.315,56 \mathrm{kWh}\end{array}$ & \begin{tabular}{|l} 
Intermediár \\
$359,47 \mathrm{~kW}$
\end{tabular} & $\begin{array}{r}\text { Pont } \\
660,051\end{array}$ & $\mathrm{kWh}$ & $\begin{array}{l}\text { Fora-Ponta } \\
\text { RS } 8.838,98\end{array}$ & $\begin{array}{c}\text { Intermediário } \\
\text { R\$ 221,94 }\end{array}$ & $\begin{array}{c}\text { Ponta } \\
\text { R\$ } 407,54\end{array}$ & $\begin{array}{l}\text { Fora- } \\
\text { R\$ } 7.5\end{array}$ & $\begin{array}{l}\text { Ponta } \\
32,87\end{array}$ & $\begin{array}{l}\text { ediário } \\
44,04\end{array}$ & 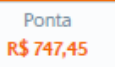 \\
\hline
\end{tabular}


ANEXO II - SIMULAÇÃO CONSUMO PROPRIEDADE 2

\begin{tabular}{|c|c|c|c|c|c|c|c|c|c|c|}
\hline \multicolumn{11}{|c|}{ Simulador de consumo } \\
\hline \multirow{2}{*}{ Aparelho } & \multicolumn{4}{|c|}{ Consumo } & \multicolumn{3}{|c|}{ Tarifa Convencional } & \multicolumn{3}{|c|}{ Tarlfa Branca } \\
\hline & FP & IT & PT & Total & FP & IT & PT & FP & IT & PT \\
\hline \multicolumn{11}{|l|}{ Banheiro } \\
\hline $\begin{array}{l}\text { Làmpada } \\
\text { fluorescente }\end{array}$ & $0.51 \mathrm{kWh}$ & $0.00 \mathrm{kWh}$ & $1.29 \mathrm{kWh}$ & $1,80 \mathrm{kWh}$ & $R \$ 0.32$ & $R \$ 0.00$ & $\mathrm{R} \$ 0.80$ & $R \$ 0.27$ & $R \$ 0.00$ & $R \$ 1.46$ \\
\hline Chuveiro & $159.63 \mathrm{kWh}$ & $0.00 \mathrm{kWh}$ & $88.68 \mathrm{kWh}$ & $248.32 \mathrm{kWh}$ & $R \$ 98.57$ & R\$ 0.00 & $R \$ 54.76$ & $R \$ 84.00$ & $\mathrm{R} \$ 0.00$ & $\mathrm{R} \$ 100.43$ \\
\hline $\begin{array}{l}\text { Secador de } \\
\text { cabelo }\end{array}$ & $0.00 \mathrm{kWh}$ & $0.00 \mathrm{kWh}$ & $21,50 \mathrm{kWh}$ & $21,50 \mathrm{kWh}$ & $\mathrm{R} \$ 0.00$ & $R \$ 0.00$ & $\mathrm{R} \$ 13.27$ & $\mathrm{R} \$ 0.00$ & $R \$ 0.00$ & $R \$ 24,35$ \\
\hline \multicolumn{4}{|c|}{ Total do consumo: } & $271,63 \mathrm{kWh}$ & \multicolumn{2}{|c|}{ Total da convenclonal: } & $R \$ 167,72$ & \multicolumn{2}{|c|}{ Total da branca: } & RS 210,51 \\
\hline \multicolumn{11}{|l|}{ Cozinha } \\
\hline Freezer & $184.47 \mathrm{kWh}$ & $12,90 \mathrm{kWh}$ & $19.35 \mathrm{kWh}$ & $216,72 \mathrm{kWh}$ & $R \$ 113.90$ & $R \$ 7.96$ & R\$ 11.95 & $\mathrm{R} \$ 97.07$ & $R \$ 9.48$ & $\mathrm{R} \$ 21.91$ \\
\hline $\begin{array}{l}\text { Fogão } \\
\text { elétrico }\end{array}$ & $180,60 \mathrm{kWh}$ & $0.00 \mathrm{kWh}$ & $0.00 \mathrm{kWh}$ & $180.60 \mathrm{kWh}$ & R\$ 111,51 & R\$ 0.00 & $R \$ 0.00$ & $R \$ 95.03$ & $R \$ 0.00$ & $R \$ 0.00$ \\
\hline $\begin{array}{l}\text { Làmpada } \\
\text { fluorescente }\end{array}$ & $0.51 \mathrm{kWh}$ & $0.00 \mathrm{kWh}$ & $1,29 \mathrm{kWh}$ & $1.80 \mathrm{kWh}$ & $R \$ 0.32$ & $R \$ 0.00$ & $R \$ 0.80$ & $R \$ 0,27$ & $R \$ 0.00$ & $R \$ 1,46$ \\
\hline Liquidificador & $1,07 \mathrm{kWh}$ & $0.00 \mathrm{kWh}$ & $0.00 \mathrm{kWh}$ & $1.07 \mathrm{kWh}$ & $R \$ 0.66$ & R\$ 0.00 & $R \$ 0.00$ & $R \$ 0.57$ & $R \$ 0.00$ & $R \$ 0.00$ \\
\hline Microondas & $5.01 \mathrm{kWh}$ & $0.00 \mathrm{kWh}$ & $0.00 \mathrm{kWh}$ & $5.01 \mathrm{kWh}$ & $R \$ 3.10$ & R\$ 0.00 & $R \$ 0.00$ & $R \$ 2,64$ & $R \$ 0.00$ & $R \$ 0.00$ \\
\hline Celadeira & $307.45 \mathrm{kWh}$ & $21,50 \mathrm{kWh}$ & $32,25 \mathrm{kWh}$ & $361.20 \mathrm{kWh}$ & $R \$ 189,83$ & $\mathrm{R} \$ 13.27$ & R\$ 19.91 & $R \$ 161.78$ & $\mathrm{R} \$ 15.79$ & $R \$ 36.52$ \\
\hline \multicolumn{4}{|c|}{ Total do consumo: } & $766,41 \mathrm{kWh}$ & \multicolumn{2}{|c|}{ Total da convenclonal: } & R\$ 473,21 & \multicolumn{2}{|c|}{ Total da branca: } & R\$ 442,52 \\
\hline Quarto & & & & & & & & & & \\
\hline $\begin{array}{l}\text { Làmpada } \\
\text { fluorescente }\end{array}$ & $3.09 \mathrm{kWh}$ & $0.00 \mathrm{kWh}$ & $7.74 \mathrm{kWh}$ & $10,83 \mathrm{kWh}$ & $R \$ 1,91$ & R\$ 0.00 & $R \$ 4.78$ & $R \$ 1,63$ & $R \$ 0.00$ & $\mathrm{R} \$ 8.77$ \\
\hline Televisor & 22,25 kWh & $9.67 \mathrm{kWh}$ & $29.02 \mathrm{kWh}$ & $60.95 \mathrm{kWh}$ & $\mathrm{R} \$ 13,74$ & $\mathrm{R} \$ 5.97$ & $\mathrm{R} \$ 17,92$ & $\mathrm{R} \$ 11,71$ & $\mathrm{R} \$ 7.11$ & $\mathrm{R} \$ 32,87$ \\
\hline $\begin{array}{l}\text { Ar } \\
\text { condicionado }\end{array}$ & 1.517 .04 kWh & $0.00 \mathrm{kWh}$ & $0.00 \mathrm{kWh}$ & $1.517,04 \mathrm{kWh}$ & $R \$ 936,68$ & R\$ 0.00 & $\mathrm{R} \$ 0.00$ & $R \$ 798.27$ & $R \$ 0.00$ & $R \$ 0.00$ \\
\hline Aquecedor & $0.00 \mathrm{kWh}$ & $0.00 \mathrm{kWh}$ & $206,40 \mathrm{kWh}$ & $206.40 \mathrm{kWh}$ & $R \$ 0,00$ & R\$ 0.00 & $R \$ 127,44$ & $R \$ 0.00$ & $R \$ 0.00$ & R\$233.74 \\
\hline & & Total & I do consumo: & $\begin{array}{r}1.795,22 \\
\mathrm{kWh}\end{array}$ & Total da c & ivenclonal: & R\$ $1.108,44$ & & la branca: & R\$ $1.094,10$ \\
\hline Sala & & & & & & & & & & \\
\hline Televisor & $0.77 \mathrm{kWh}$ & $0.00 \mathrm{kWh}$ & $1.93 \mathrm{kWh}$ & $2.70 \mathrm{kWh}$ & $R \$ 0.48$ & R\$ 0.00 & $R \$ 1.19$ & $\mathrm{R} \$ 0.41$ & $R \$ 0.00$ & $\mathrm{R} \$ 2.19$ \\
\hline $\begin{array}{l}\text { Lâmpada } \\
\text { fluorescente }\end{array}$ & $2,06 \mathrm{kWh}$ & $0.00 \mathrm{kWh}$ & $5.16 \mathrm{kWh}$ & $7.22 \mathrm{kWh}$ & $R \$ 1.27$ & R\$ 0.00 & $\mathrm{R} \$ 3.19$ & $R \$ 1.09$ & $R \$ 0.00$ & $R \$ 5.84$ \\
\hline $\begin{array}{l}\text { Ar } \\
\text { condicionado }\end{array}$ & $36,12 \mathrm{kWh}$ & $0.00 \mathrm{kWh}$ & $36,12 \mathrm{kWh}$ & $72,24 \mathrm{kWh}$ & $\mathrm{R} \$ 22,30$ & R\$ 0.00 & $\mathrm{R} \$ 22,30$ & $R \$ 19,01$ & $R \$ 0.00$ & $\mathrm{R} \$ 40,90$ \\
\hline & & Total & I do consumo: & $82,17 \mathrm{kWh}$ & Total da c & ivenclonal: & $R \$ 50,73$ & & la branca: & R\$ 69,44 \\
\hline Lavanderia & & & & & & & & & & \\
\hline $\begin{array}{l}\text { Làmpada } \\
\text { fluorescente }\end{array}$ & $0.51 \mathrm{kWh}$ & $0.00 \mathrm{kWh}$ & $2,58 \mathrm{kWh}$ & $3.09 \mathrm{kWh}$ & $\mathrm{R} \$ 0.32$ & R\$ 0.00 & $\mathrm{R} \$ 1,59$ & $R \$ 0,27$ & $R \$ 0.00$ & $R \$ 2,92$ \\
\hline $\begin{array}{l}\text { Ferro } \\
\text { elétrico }\end{array}$ & $8,60 \mathrm{kWh}$ & $0,00 \mathrm{kWh}$ & $0,00 \mathrm{kWh}$ & $8,60 \mathrm{kWh}$ & $\mathrm{R} \$ 5,31$ & R\$ 0.00 & $R \$ 0.00$ & $R \$ 4,53$ & $R \$ 0.00$ & $R \$ 0.00$ \\
\hline $\begin{array}{l}\text { Máquina de } \\
\text { lavar }\end{array}$ & $4,30 \mathrm{kWh}$ & $0.00 \mathrm{kWh}$ & $8.60 \mathrm{kWh}$ & $12,89 \mathrm{kWh}$ & $\mathrm{R} \$ 2,65$ & R\$ 0.00 & $\mathrm{R} \$ 5,31$ & $R \$ 2.26$ & $R \$ 0.00$ & $\mathrm{R} \$ 9.74$ \\
\hline & & Total & I do consumo: & $24,59 \mathrm{kWh}$ & Total da c & ivencional: & R\$ 15,18 & & la branca: & $R \$ 19,72$ \\
\hline Garagem / Jar & rdim & & & & & & & & & \\
\hline $\begin{array}{l}\text { Cortador de } \\
\text { grama }\end{array}$ & $5,59 \mathrm{kWh}$ & $0.00 \mathrm{kWh}$ & $0,00 \mathrm{kWh}$ & $5,59 \mathrm{kWh}$ & $\mathrm{R} \$ 3,45$ & R\$ 0.00 & $R \$ 0.00$ & $\mathrm{R} \$ 2,94$ & $\mathrm{R} \$ 0.00$ & $R \$ 0.00$ \\
\hline & & Total & I do consumo: & 5,59 kWh & Total da c & venclonal: & R\$ 3,45 & & la branca: & $R \$ 2,94$ \\
\hline Criaçāo Porco & & & & & & & & & & \\
\hline $\begin{array}{l}\text { Lampada } \\
\text { fluorescente }\end{array}$ & $0.51 \mathrm{kWh}$ & $0.00 \mathrm{kWh}$ & $1,29 \mathrm{kWh}$ & $1,80 \mathrm{kWh}$ & $\mathrm{R} \$ 0.32$ & $R \$ 0.00$ & $R \$ 0.80$ & $R \$ 0,27$ & $R \$ 0.00$ & $R \$ 1.46$ \\
\hline $\begin{array}{l}\text { Misturador } \\
\text { de Raçāo }\end{array}$ & $116.10 \mathrm{kWh}$ & $0.00 \mathrm{kWh}$ & $0.00 \mathrm{kWh}$ & $116.10 \mathrm{kWh}$ & R\$ 71.68 & $R \$ 0.00$ & $R \$ 0.00$ & $R \$ 61,09$ & $R \$ 0.00$ & $R \$ 0.00$ \\
\hline $\begin{array}{l}\text { Conjunto } \\
\text { Motobomba }\end{array}$ & $\begin{array}{r}2.648 .80 \\
k W h\end{array}$ & $0,00 \mathrm{kWh}$ & $0.00 \mathrm{kWh}$ & $\begin{array}{r}2.648 .80 \\
\mathrm{kWh}\end{array}$ & R\$ $1.635,48$ & R\$ 0.00 & $R \$ 0.00$ & $\mathrm{R} \$ 1.393,80$ & $R \$ 0.00$ & $R \$ 0,00$ \\
\hline $\begin{array}{l}\text { Bomba Alta } \\
\text { Pressão }\end{array}$ & $\begin{array}{r}1.324 .40 \\
k W h\end{array}$ & $0.00 \mathrm{kWh}$ & $0.00 \mathrm{kWh}$ & $\begin{array}{r}1.324 .40 \\
k W h\end{array}$ & $\mathrm{R} \$ 817.74$ & $R \$ 0.00$ & $R \$ 0.00$ & $R \$ 696.90$ & $R \$ 0.00$ & $\mathrm{R} \$ 0.00$ \\
\hline & & Total & I do consumo: & $\begin{array}{r}4.091,10 \\
\text { kWh }\end{array}$ & Total da c & venclonal: & R\$ $2.526,02$ & & la branca: & RS $2.153,52$ \\
\hline & Consumo - To & & & Tarifa C & Convenclonal - & & & Tarifa B & ca - Total & \\
\hline & $7.036,74 \mathrm{~kW}$ & & & & $R \$ 4.344,75$ & & & & 2,75 & \\
\hline $\begin{array}{l}\text { Fora-Ponta } \\
6.529,44 \mathrm{kWh}\end{array}$ & $\begin{array}{l}\text { Intermediár } \\
44,07 \text { kWh }\end{array}$ & $\begin{array}{r}\text { Pont: } \\
463,21 \mathrm{k}\end{array}$ & & $\begin{array}{l}\text { ora-Ponta } \\
\$ 4.031,54\end{array}$ & $\begin{array}{l}\text { Intermediário } \\
R \$ 27,20\end{array}$ & $\begin{array}{c}\text { Ponta } \\
\text { R\$ 286,01 }\end{array}$ & $\begin{array}{l}\text { Fora-f } \\
R \$ 3.4\end{array}$ & $\begin{array}{l}\text { onta } \\
35,81\end{array}$ & $\begin{array}{l}\text { diârio } \\
, 38\end{array}$ & $\begin{array}{c}\text { Ponta } \\
\text { R\$ } 524,56\end{array}$ \\
\hline
\end{tabular}


ANEXO III - SIMULAÇÃO CONSUMO PROPRIEDADE 3

\begin{tabular}{|c|c|c|c|c|c|c|c|c|c|c|}
\hline \multicolumn{11}{|c|}{ Simulador de consumo } \\
\hline \multirow{2}{*}{ Aparelho } & \multicolumn{4}{|c|}{ Consumo } & \multicolumn{3}{|c|}{ Tarifa Convenclonal } & \multicolumn{3}{|c|}{ Tarlfa Branca } \\
\hline & FP & IT & PT & Total & FP & IT & PT & FP & IT & PT \\
\hline \multicolumn{11}{|l|}{ Banhelro } \\
\hline $\begin{array}{l}\text { Lâmpada } \\
\text { fluorescente }\end{array}$ & $0.51 \mathrm{kWh}$ & $0.00 \mathrm{kWh}$ & $1.29 \mathrm{kWh}$ & $1,80 \mathrm{kWh}$ & R\$ 0.32 & R\$ 0.00 & R\$ 0.80 & $R \$ 0.27$ & RS 0.00 & R\$ 1,46 \\
\hline Chuveiro & $106.42 \mathrm{kWh}$ & $0.00 \mathrm{kWh}$ & $59.12 \mathrm{kWh}$ & $165,55 \mathrm{kWh}$ & $R \$ 65,71$ & R\$ 0.00 & $R \$ 36,51$ & $R \$ 56.00$ & RS 0.00 & RS 66.96 \\
\hline $\begin{array}{l}\text { Secador de } \\
\text { cabelo }\end{array}$ & $0,00 \mathrm{kWh}$ & $0,00 \mathrm{kWh}$ & $10,75 \mathrm{kWh}$ & $10,75 \mathrm{kWh}$ & RS 0.00 & R\$ 0,00 & RS 6,64 & RS 0.00 & RS 0.00 & RS 12,17 \\
\hline \multicolumn{4}{|c|}{ Total do consumo: } & $178,10 \mathrm{kWh}$ & \multicolumn{2}{|c|}{ Total da convenclonal: } & R\$ 109,98 & \multicolumn{2}{|c|}{ Total da branca: } & R\$ 136,86 \\
\hline \multicolumn{11}{|l|}{ Cozlnha } \\
\hline Freezer & $184,47 \mathrm{kWh}$ & $12,90 \mathrm{kWh}$ & $19.35 \mathrm{kWh}$ & $216.72 \mathrm{kWh}$ & RS 113.90 & $R \$ 7,96$ & R\$ 11.95 & R\$ 97,07 & $R \$ 9.48$ & $R \$ 21,91$ \\
\hline $\begin{array}{l}\text { Fogāo } \\
\text { elêtrico }\end{array}$ & $180,60 \mathrm{kWh}$ & $0,00 \mathrm{kWh}$ & $0,00 \mathrm{kWh}$ & $180.60 \mathrm{kWh}$ & $R \$ 111,51$ & R\$ 0,00 & R\$ 0.00 & R\$ 95,03 & RS 0.00 & $R \$ 0,00$ \\
\hline $\begin{array}{l}\text { Lâmpada } \\
\text { fluorescente }\end{array}$ & $0,51 \mathrm{kWh}$ & $0,00 \mathrm{kWh}$ & $1,29 \mathrm{kWh}$ & $1,80 \mathrm{kWh}$ & $R \$ 0,32$ & R\$ 0.00 & R\$ 0,80 & $R \$ 0,27$ & RS 0.00 & R\$ 1.46 \\
\hline Liquidificador & $1,07 \mathrm{kWh}$ & 0.00 kWh & $0,00 \mathrm{kWh}$ & $1,07 \mathrm{kWh}$ & R\$ 0,66 & R\$ 0.00 & R\$ 0.00 & RS 0.57 & RS 0.00 & $R \$ 0,00$ \\
\hline Microondas & $5,01 \mathrm{kWh}$ & $0.00 \mathrm{kWh}$ & $0,00 \mathrm{kWh}$ & $5,01 \mathrm{kWh}$ & RS 3.10 & R\$ 0,00 & R\$ 0,00 & $R \$ 2,64$ & RS 0.00 & $R \$ 0,00$ \\
\hline Geladeira & $153,72 \mathrm{kWh}$ & $10.75 \mathrm{kWh}$ & $16.12 \mathrm{kWh}$ & $180.60 \mathrm{kWh}$ & R\$ 94.92 & R\$ 6.64 & R\$ 9.96 & R\$ 80.89 & $\operatorname{R} \$ 7.90$ & R\$ 18,26 \\
\hline Torradeira & 4,01 kWh & 0,00 kWh & $0,00 \mathrm{kWh}$ & 4,01 kWh & $R \$ 2,48$ & $\mathrm{R} \$ 0,00$ & R\$ 0.00 & $\mathrm{R} \$ 2,11$ & R\$ 0.00 & $R \$ 0,00$ \\
\hline \multicolumn{4}{|c|}{ Total do consumo: } & $589,83 \mathrm{kWh}$ & Total da c & venclonal: & RS 364,20 & & la branca: & R\$ 337,59 \\
\hline Quarto & & & & & & & & & & \\
\hline Televisor & $13,35 \mathrm{kWh}$ & $5.80 \mathrm{kWh}$ & $17.41 \mathrm{kWh}$ & $36,57 \mathrm{kWh}$ & $R \$ 8,24$ & $R \$ 3,58$ & $R \$ 10,75$ & R\$7,03 & $R \$ 4,26$ & $R \$ 19.72$ \\
\hline $\begin{array}{l}\text { Ar } \\
\text { condicionado }\end{array}$ & $1.137,78 \mathrm{kWh}$ & $0,00 \mathrm{kWh}$ & $0.00 \mathrm{kWh}$ & $1.137,78 \mathrm{kWh}$ & RS 702,51 & $\mathrm{R} \$ 0,00$ & $R \$ 0,00$ & $\mathrm{R} \$ 598,70$ & RS 0.00 & $R \$ 0.00$ \\
\hline $\begin{array}{l}\text { Lâmpada } \\
\text { fluorescente }\end{array}$ & $3.09 \mathrm{kWh}$ & $0.00 \mathrm{kWh}$ & $7.74 \mathrm{kWh}$ & $10,83 \mathrm{kWh}$ & R\$ 1.91 & R\$ 0.00 & R\$ 4,78 & $R \$ 1,63$ & RS 0.00 & RS 8,77 \\
\hline Aquecedor & $0,00 \mathrm{kWh}$ & $0.00 \mathrm{kWh}$ & $103.20 \mathrm{kWh}$ & $103,20 \mathrm{kWh}$ & RS 0.00 & R\$ 0.00 & RS 63,72 & R\$ 0.00 & RS 0.00 & RS 116,87 \\
\hline & & Total & do consumo: & $\begin{array}{r}1.288,38 \\
\mathrm{kWh}\end{array}$ & Total da c & venclonal: & RS 795,49 & & la branca: & R\$ 756,98 \\
\hline Sala & & & & & & & & & & \\
\hline Televisor & $0,77 \mathrm{kWh}$ & $0.00 \mathrm{kWh}$ & $1,93 \mathrm{kWh}$ & $2,70 \mathrm{kWh}$ & $\operatorname{R} \$ 0,48$ & R\$ 0,00 & $R \$ 1,19$ & RS 0,41 & R\$ 0.00 & $\mathrm{R} \$ 2,19$ \\
\hline $\begin{array}{l}\text { Làmpada } \\
\text { fluorescente }\end{array}$ & $2,06 \mathrm{kWh}$ & $0.00 \mathrm{kWh}$ & $5.16 \mathrm{kWh}$ & $7.22 \mathrm{kWh}$ & RS 1.27 & R\$ 0,00 & R\$ 3.19 & $R \$ 1,09$ & RS 0.00 & $R \$ 5,84$ \\
\hline & & Total & do consumo: & 9,93 kWh & Total da c & venclonal: & R\$ 6,13 & & da branca: & $R \$ 9,53$ \\
\hline Lavanderla & & & & & & & & & & \\
\hline $\begin{array}{l}\text { Lâmpada } \\
\text { fluorescente }\end{array}$ & $0.51 \mathrm{kWh}$ & $0.00 \mathrm{kWh}$ & $2.58 \mathrm{kWh}$ & $3.09 \mathrm{kWh}$ & R\$ 0.32 & R\$ 0.00 & $R \$ 1.59$ & $R \$ 0,27$ & RS 0.00 & RS 2,92 \\
\hline $\begin{array}{l}\text { Ferro } \\
\text { elétrico }\end{array}$ & $8,60 \mathrm{kWh}$ & $0.00 \mathrm{kWh}$ & $0.00 \mathrm{kWh}$ & $8.60 \mathrm{kWh}$ & RS 5.31 & $R \$ 0,00$ & $R \$ 0,00$ & R\$ 4,53 & RS 0.00 & $R \$ 0.00$ \\
\hline $\begin{array}{l}\text { Máquina de } \\
\text { lavar }\end{array}$ & $4,30 \mathrm{kWh}$ & $0.00 \mathrm{kWh}$ & $8.60 \mathrm{kWh}$ & $12,89 \mathrm{kWh}$ & $R \$ 2,65$ & R\$ 0.00 & $R \$ 5.31$ & $R \$ 2,26$ & RS 0.00 & RS 9,74 \\
\hline & & Total & do consumo: & $24,59 \mathrm{kWh}$ & Total da c & venclonal: & RS 15,18 & & da branca: & RS 19,72 \\
\hline Garagem / Jar & rdim & & & & & & & & & \\
\hline $\begin{array}{l}\text { Cortador de } \\
\text { grama }\end{array}$ & $5,59 \mathrm{kWh}$ & $0,00 \mathrm{kWh}$ & $0,00 \mathrm{kWh}$ & $5,59 \mathrm{kWh}$ & $R \$ 3,45$ & R\$ 0.00 & R\$ 0,00 & R\$2,94 & RS 0,00 & $R \$ 0.00$ \\
\hline & & Total & do consumo: & $5,59 \mathrm{kWh}$ & Total da c & venclonal: & RS 3,45 & & la branca: & RS 2,94 \\
\hline Lavroura & & & & & & & & & & \\
\hline $\begin{array}{l}\text { Lâmpada } \\
\text { fluorescente }\end{array}$ & $2,58 \mathrm{kWh}$ & $0.00 \mathrm{kWh}$ & $6.45 \mathrm{kWh}$ & $9,03 \mathrm{kWh}$ & $R \$ 1,59$ & $R \$ 0.00$ & $R \$ 3,98$ & $R \$ 1,36$ & RS 0.00 & R\$7,30 \\
\hline $\begin{array}{l}\text { Conjunto } \\
\text { Motobomba }\end{array}$ & $\begin{array}{r}5.297 .60 \\
\mathrm{kWh}\end{array}$ & $0.00 \mathrm{kWh}$ & $0.00 \mathrm{kWh}$ & $\begin{array}{r}5.297 .60 \\
\mathrm{kWh}\end{array}$ & R\$ $3.270,95$ & R\$ 0.00 & R\$ 0.00 & R\$ $2.787,60$ & RS 0.00 & $R \$ 0.00$ \\
\hline $\begin{array}{l}\text { Bomba Alta } \\
\text { Pressāo }\end{array}$ & $\begin{array}{r}2.731,57 \\
\mathrm{kWh}\end{array}$ & $0.00 \mathrm{kWh}$ & $0.00 \mathrm{kWh}$ & $\begin{array}{r}2.731,57 \\
\mathrm{kWh}\end{array}$ & $R \$ 1.686 .58$ & R\$ 0.00 & R\$ 0.00 & $R \$ 1.437 .35$ & RS 0.00 & $R \$ 0.00$ \\
\hline $\begin{array}{l}\text { Classificador } \\
\text { de Café }\end{array}$ & $1.451,25 \mathrm{kWh}$ & $161,25 \mathrm{kWh}$ & $0,00 \mathrm{kWh}$ & $\begin{array}{r}1.612,50 \\
\mathrm{kWh}\end{array}$ & R\$ 896.06 & R\$ 99.56 & R\$ 0.00 & RS 763,65 & R\$ 118,44 & $R \$ 0.00$ \\
\hline $\begin{array}{l}\text { Catador } \\
\text { para } \\
\text { Limpeza } \\
\text { Café }\end{array}$ & $\begin{array}{r}1.032,00 \\
\mathrm{kWh}\end{array}$ & $0,00 \mathrm{kWh}$ & $0,00 \mathrm{kWh}$ & $\begin{array}{r}1.032,00 \\
\mathrm{kWh}\end{array}$ & $R \$ 637,20$ & R\$ 0,00 & R\$ 0,00 & R\$ 543,04 & RS 0.00 & $R \$ 0.00$ \\
\hline $\begin{array}{l}\text { Bomba para } \\
\text { Irrigaçäo }\end{array}$ & $564,37 \mathrm{kWh}$ & $0.00 \mathrm{kWh}$ & $0,00 \mathrm{kWh}$ & $564,37 \mathrm{kWh}$ & RS 348,47 & R\$ 0.00 & R\$ 0.00 & R\$ 296,97 & RS 0.00 & $R \$ 0,00$ \\
\hline & & Total & do consumo: & $\begin{array}{r}11.247,08 \\
\mathrm{kWh}\end{array}$ & Total da c & vencional: & RS 6.944,39 & & da branca: & RS $5.955,71$ \\
\hline & Consumo - 1 & & & Tarlfa & Convencional - & & & Tarifa B & ca - Total & \\
\hline & $13.343,52 \mathrm{kl}$ & & & & R\$ 8.238,82 & & & & 9,33 & \\
\hline $\begin{array}{l}\text { Fora-Ponta } \\
12.891,80 \mathrm{kWh}\end{array}$ & $\begin{array}{c}\text { Intermedia } \\
190,70 \mathrm{~kW}\end{array}$ & $\begin{array}{r}\text { Pont } \\
261,01 k\end{array}$ & a & $\begin{array}{l}\text { Fora-Ponta } \\
\text { R\$7.959,91 }\end{array}$ & $\begin{array}{l}\text { Intermediário } \\
\text { R\$ } 117,74\end{array}$ & $\begin{array}{c}\text { Ponta } \\
\text { R\$ 161,17 }\end{array}$ & $\begin{array}{l}\text { Fora-t } \\
\text { R\$ } 6.7\end{array}$ & onta & diário & $\begin{array}{c}\text { Ponta } \\
\text { R\$ } 295,57\end{array}$ \\
\hline
\end{tabular}


ANEXO IV - CONFIGURAÇÃO EQUIPAMENTOS NO SOFTWARE ETAP
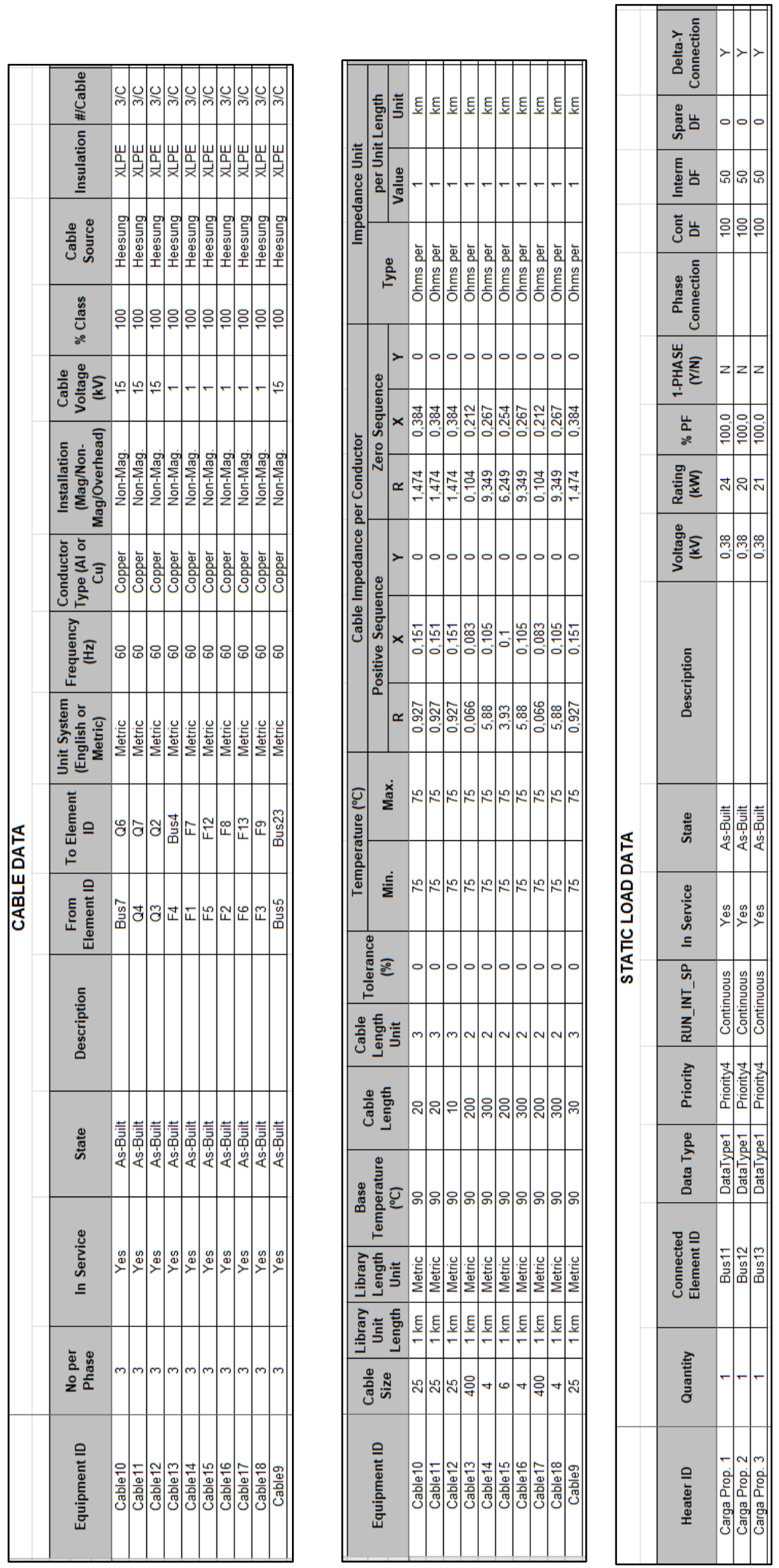


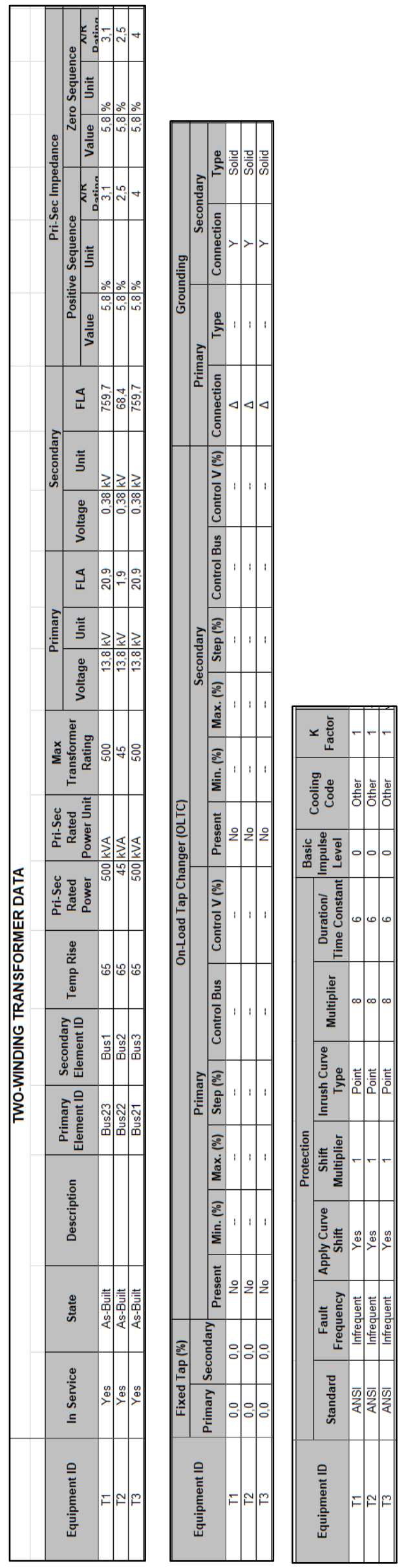



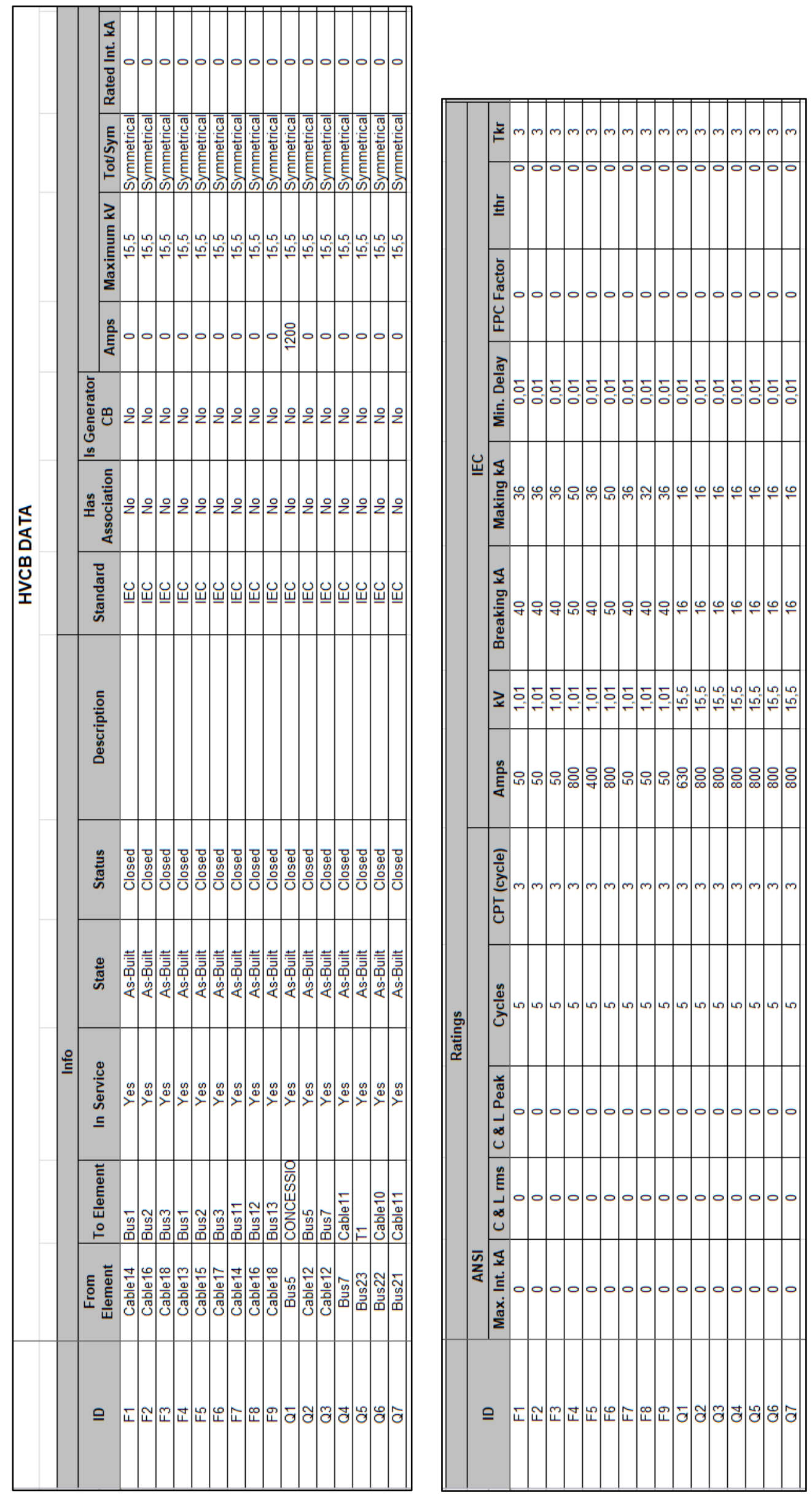